\title{
Policy Shocks and Market-Based Regulations: Evidence from the Renewable Fuel Standard
}

\author{
Gabriel E. Lade, C.-Y. Cynthia Lin Lawell, and Aaron Smith
}

Working Paper 16-WP 565

May 2016

\author{
Center for Agricultural and Rural Development \\ lowa State University \\ Ames, lowa 50011-1070 \\ www.card.iastate.edu
}

\begin{abstract}
Gabriel E. Lade is an assistant professor in the Department of Economics and the Center for Agricultural and Rural Development at lowa State University. E-mail: glade@iastate.edu.

C.-Y. Cynthia Lin Lawell is an associate professor and Aaron Smith is a professor in the Department of Agricultural and Resource Economics at the University of California, Davis.
\end{abstract}

Aaron Smith is a professor in the Department of Agricultural and Resource Economics at the University of California, Davis.

Lin Lawell and Smith are members of the Giannini Foundation of Agricultural Economics.

This publication is available online on the CARD website: www.card.iastate.edu. Permission is granted to reproduce this information with appropriate attribution to the author and the Center for Agricultural and Rural Development, lowa State University, Ames, lowa 50011-1070.

We gratefully acknowledge financial support for this research from Resources for the Future's Regulatory Policy Initiative; and from the National Center for Sustainable Transportation, which is supported by the U.S. Department of Transportation through the University Transportation Centers program. We thank Jim Bushnell, Kevin Novan, Stephen Holland, Scott Irwin, Rob Johansson, and Richard Morgenstern for valuable comments. We also received helpful comments from participants at the University of Michigan Transportation, Energy, Economics and the Environment Conference; Camp Resources XXI; the 8th Annual Berkeley Bioeconomy Conference; and at seminars at the University of California at Davis, lowa State University, and the University of Illinois. All errors are our own.

For questions or comments about the contents of this paper, please contact Gabriel Lade, glade@iastate.edu.

lowa State University does not discriminate on the basis of race, color, age, ethnicity, religion, national origin, pregnancy, sexual orientation, gender identity, genetic information, sex, marital status, disability, or status as a U.S. veteran. Inquiries can be directed to the Interim Assistant Director of Equal Opportunity and Compliance, 3280 Beardshear Hall, (515) 294-7612. 


\title{
Policy Shocks and Market-Based Regulations: Evidence from the Renewable Fuel Standard
}

\author{
Gabriel E. Lade, C.-Y. Cynthia Lin Lawell, and Aaron Smith ${ }^{\dagger}$
}

May 2016

\begin{abstract}
The Renewable Fuel Standard (RFS2) mandates large increases in U.S. biofuel consumption and is implemented using a market for tradable compliance credits, known as RINs. In early 2013, RIN prices soared, causing the regulator to propose reducing future mandates. We develop a dynamic model of RFS2 compliance to demonstrate how changes in expectations about future policy affect current compliance costs, and we use a market efficiency test to demonstrate that RIN markets have behaved in accordance with our model. We then estimate empirically the effect of three 'policy shocks' that reduced the expected mandates in 2013. The largest of these shocks decreased the total cost of compliance by nearly $\$ 8$ billion. The burden of the mandate reductions fell primarily on advanced biofuel firms and on commodity markets of the marginal compliance biofuel. We argue that the policy shocks reduced the incentive to invest in the technologies required to meet the future objectives of the RFS2.
\end{abstract}

JEL Codes: Q42, Q50, H23

Keywords: tradable credits, policy design, quantity mechanisms, renewable fuel standard

\footnotetext{
*Corresponding author: gelade@iastate.edu

${ }^{\dagger}$ Gabriel E. Lade is an assistant professor in the Department of Economics and the Center for Agricultural and Rural Development at Iowa State University. C.-Y. Cynthia Lin Lawell is an associate professor and Aaron Smith is a professor in the Department of Agricultural and Resource Economics at the University of California, Davis. Lin Lawell and Smith are members of the Giannini Foundation of Agricultural Economics. We gratefully acknowledge financial support for this research from Resources for the Future's Regulatory Policy Initiative; and from the National Center for Sustainable Transportation, which is supported by the U.S. Department of Transportation through the University Transportation Centers program. We thank Jim Bushnell, Kevin Novan, Stephen Holland, Scott Irwin, Rob Johansson, and Richard Morgenstern for valuable comments. We also received helpful comments from participants at the University of Michigan Transportation, Energy, Economics and the Environment Conference; Camp Resources XXI; the 8th Annual Berkeley Bioeconomy Conference; and at seminars at the University of California at Davis, Iowa State University, and the University of Illinois. All errors are our own.
} 


\section{Introduction}

Regulations that allow firms to trade compliance credits are less costly than corresponding command and control policies (Coase, 1960; Crocker, 1966; Dales, 1968). Instead of instituting firm-level controls or giving firms exclusive rights to an economic activity, a regulator can minimize compliance costs by limiting the level of the activity and allowing parties to trade the right to it. In competitive markets with no barriers to trade, economic theory predicts that trading credits will lead to an efficient market outcome in which marginal compliance costs are equalized across parties (Montgomery, 1972). Moreover, allowing parties to bank and borrow credits can smooth marginal compliance costs over time, further improving regulatory efficiency (Kling and Rubin, 1997).

Tradable credits have been used more recently in policies that mandate large investments in the development of new technologies. In particular, the federal government and several states have passed or considered regulations in the energy sector that require large expansions in the production and distributional capacity of low-carbon, renewable energy (National Low Carbon Fuel Standard Project, 2012; Department of Energy, 2015). These policies set mandates that can be met with existing technology and infrastructure in the first few years, but require increasing amounts of new technology and infrastructure investments for future years. The willingness of firms to invest in developing such new technologies, and therefore the future success of the policy, depends crucially on the market's expectations about whether the regulation will be fully enforced.

In this paper, we show that allowing firms to bank and borrow compliance credits creates a channel through which expectations about the future policy stringency can affect the viability of a policy. Under a system that allows banking and borrowing, firms consider both current and expected future compliance costs when making production and investment decisions. Expectations of high future compliance costs raise demand for compliance credits in the present, and therefore increase current compliance costs. If high compliance costs generate political pressure and cause a regulator to reduce the stringency of a policy, we show that the firms most harmed are those using and investing in marginal compliance technologies.

This paper studies the U.S. Renewable Fuel Standard (RFS2), the most ambitious and longest standing U.S. renewable energy policy to date. Under the RFS2, biofuels are scheduled to increase from $3 \%$ of U.S. transportation fuel consumption when the legislation was passed in 2007 to approximately $25 \%$ of consumption by 2022. Tens of billions of RFS2 credits are generated and traded each year, making the RFS2 tradable credit market among the largest in the world.

We make three contributions to the literature. First, we develop a dynamic model of RFS2 compliance to show how expectations about future policy stringency affect current compliance costs. The model incorporates salient features of the RFS2 that are applicable to many other intensity standards, including multiple compliance periods, banking and borrowing across compliance periods, and the nesting of mandates. We show that changes in expectations can have large effects on current compliance costs, especially if the 
marginal compliance cost curve is steep around the initial mandate level. Second, we show empirically that the market for RFS2 credits, known as Renewable Identification Numbers (RINs), has operated efficiently and is therefore concordant with the predictions of our conceptual model.

Our third contribution is an event study of three policy shocks to the expected future stringency of the RFS2 in 2013. We show that the events led to large decreases in RIN prices, and that the incidence of these shocks fell disproportionately on firms investing in marginal compliance technologies. The first event was the release of the EPA's 2013 Final Rule in which the Agency indicated for the first time that it would likely reduce the 2014 mandate. Shortly thereafter a Reuters news article leaked a draft of the proposed cuts, our second event. The final event was the release of the 2014 Proposed Rule itself in which the EPA officially proposed cuts to the biofuel mandates. We estimate that the release of the 2013 Final Rule decreased the value of the RFS2 subsidy (tax) to the biofuel (fossil fuel) industry in 2013 alone by nearly $\$ 8$ billion and $\$ 6$ billion over two- and five-day horizons, respectively. Smaller losses are observed following the subsequent two events, with estimated five-day losses of $\$ 800$ million and $\$ 400$ million following the release of the Reuters article and 2014 Proposed Rule, respectively.

Prior to 2013, RFS2 compliance could be achieved almost entirely by blending up to $10 \%$ ethanol, produced predominantly from corn, with gasoline. Since 2013 the policy has required an increasing proportion of biofuel to be derived from 'advanced' feedstocks, as well as for fuels with high biofuels blends to penetrate U.S. fuels markets. Advanced biofuels generate large estimated greenhouse gas reductions relative to gasoline, but are more costly to produce than ethanol from corn. To the extent that advanced biofuels are expected to serve as marginal compliance technologies for 2013 and beyond, we would expect the burden of mandate reductions to fall disproportionately on firms producing these fuels. Consistent with this logic, we find that stock prices of corn ethanol producers were largely unaffected by the events, but that companies that produced or had investments in advanced biofuels experienced significant abnormal losses following the three events. In addition, we find that futures contracts for crude oil, ethanol, corn, and sugar futures markets did not experience significant abnormal returns following any of the three events. The market for soybean oil (the predominant input to biodiesel), however, experienced a significant abnormal loss of approximately $2 \%$ across all traded contracts following the publication of the Reuters article. The finding is consistent with our finding that biodiesel, an advanced biofuel that is costly produce, served as the marginal biofuel for RFS2 compliance in 2013 .

In addition to reducing the expected future stringency of the policy, the EPA's announcements created significant policy uncertainty regarding firms' compliance schedules for 2014 and beyond. Policy uncertainty in turn creates an option value to delaying investments in advanced fuel production capacity (Dixit and Pindyck, 1994). Although we are unable to separately identify the effects of the decrease in expected future stringency of the mandate and the increase in policy uncertainty, the increase in uncertainty likely further undermined the RFS2 objectives. 
Our results highlight the role of bankable compliance credits in translating changes in expectations about future compliance costs into changes in current compliance costs. We discuss two implications of the findings for the design of environmental policies more broadly. First, a well-known drawback to quantity-based regulations is that they do not provide cost certainty (Weitzman, 1974; Roberts and Spence, 1976). Increasing compliance costs can therefore undermine a regulation if they increase political pressure on a regulator to reduce the stringency of the policy. We propose alternative policy designs to address this shortcoming by imposing a price ceiling on compliance credits. Second, the level of compliance cost uncertainty can depend on whether the regulation is specified in terms of total volume (e.g., a required number of gallons of biofuel) or a rate (e.g., a required proportion of blended biofuel in gasoline and diesel). Designing the RFS2 as a rate standard would likely have been more efficient than the chosen volume standard because short-run marginal compliance cost curve becomes steep at an ethanol-gasoline blend rate of $10 \%$. Specifying a volume standard for biofuels generates high compliance cost uncertainty because variation in gasoline and diesel consumption causes the implicit blend mandate to vary. This finding illustrates the importance for regulators to understand key barriers to achieving policy goals, and to set policies in ways that can create greater certainty regarding future compliance costs.

The paper proceeds as follows. Section 2 provides a background on the Renewable Fuel Standard and RIN markets. Section 3 presents a dynamic model of an industry facing a fuel mandate in the presence of uncertainty about fuel prices and policy stringency. Three special cases of the model are considered to understand the impacts of alternative design features of the RFS2 on RIN prices. Section 4 discusses historical RIN prices and other relevant data used in our subsequent analysis, and presents a test of market efficiency for RIN markets. Section 5 estimates the effects of the three policy shocks on RIN prices, commodity markets, and biofuel company stock prices. Section 6 discusses the results and concludes.

\section{The RFS2 and the Market for RINs}

\subsection{Background}

The Renewable Fuel Standard was created by the Energy Policy Act of 2005 and expanded under the Energy Independence and Security Act (EISA) of 2007, creating the RFS2. The program sets ambitious standards for biofuel consumption, with the goal of expanding consumption to 36 billion gallons (bgal) per year by 2022. The Environmental Protection Agency (EPA) administers the program, and while the EISA provides specific biofuel consumption targets, the EPA is allowed discretion in setting each year's mandates.

\footnotetext{
${ }^{1}$ Biomass-based diesel (BBD) includes biodiesel and renewable diesel. Little renewable diesel was blended into the U.S. fuel supply over our sample period. As such, we use the terms 'biodiesel' and 'biomass-based diesel' interchangeably when referring to the BBD portion of the RFS2 requirements.
} 
Figure 1: The Renewable Fuel Standard

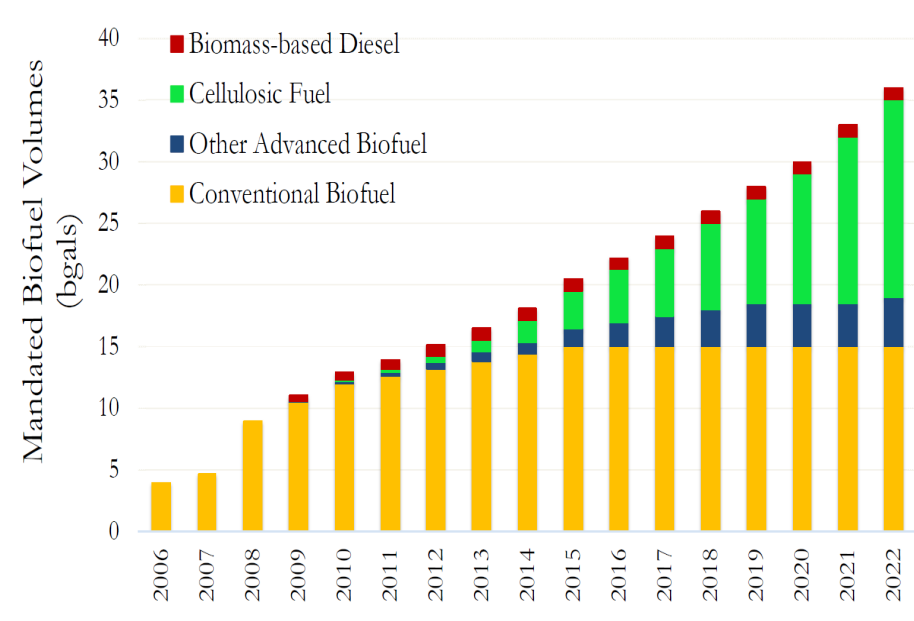

(a) RFS2 Mandates

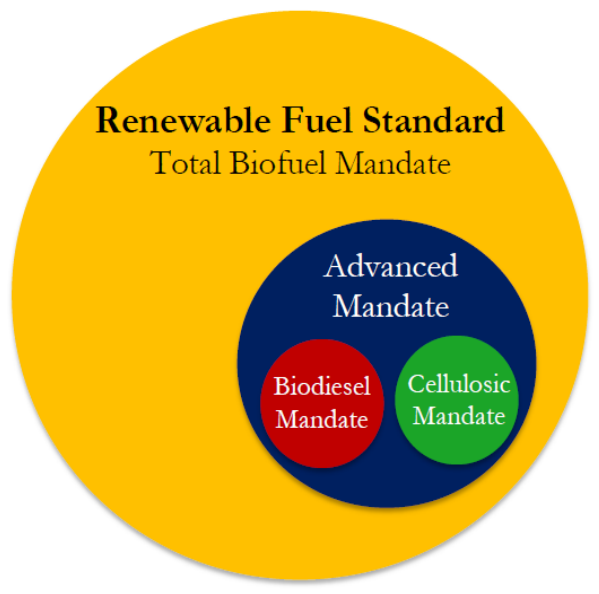

(b) Nested Mandate Structure

Note: The left figure graphs the EISA statutory RFS2 mandates from 2006-2022, and the right figure graphs the nested structure of the mandate.

The RFS2 distinguishes between categories, or types, of biofuel and sets separate mandates for each. The biofuel categories are: (i) cellulosic biofuel, which can be produced from wood, grasses, or the inedible parts of plants; (ii) biomass-based diesel, predominantly produced from soybeans or canola in the U.S.; ${ }^{1}$ (iii) advanced biofuel, or fuels with life-cycle greenhouse gas emissions at least 50 percent below a threshold set by the law; and (iv) renewable fuel, including all previous categories as well as ethanol derived from corn. The mandates are nested so that cellulosic biofuel and biodiesel count toward the advanced biofuel mandate, and all biofuels count toward the overall renewable fuel mandate.

Figure 1a graphs the EISA mandates for 2006-2022, and Figure 1b illustrates the nested structure of the RFS2. The program is designed so that compliance in early years can be met mostly with corn ethanol, with increasing requirements for categories (i) - (iii) later in the program. For example, the total renewable fuel mandate in 2013 was set at 16.5 bgal, of which 13.8 bgal could be met with corn ethanol. In contrast, in 2022 the total renewable fuel mandate is 36 bgal, of which corn ethanol is limited to 15 bgal (Environmental Protection Agency, 2013b). Thus, the program relies on the speedy development of a large advanced biofuel industry, especially after 2015.

To enforce the RFS2, every gallon of approved renewable fuel produced in or imported into the United States is associated with a RIN. Whenever a gallon of renewable fuel is blended into the U.S. fuel supply,

\footnotetext{
${ }^{2}$ McPhail et al. (2011) and Verleger (2013) provide more thorough primers on the institutional features of RIN markets and discussions of factors driving RIN prices. In addition, several authors regularly publish commentaries and working papers on the RFS2 and RIN markets (see e.g., Thompson et al. (2010, 2012); Babcock (2012); Babcock and Pouliot (2013); Irwin $(2014 b))$.
} 
the RIN is 'detached' and able to be sold to other parties. Obligated parties, predominantly oil refiners and importers, comply with the RFS2 by turning in a quantity of RINs equal to their prorated portion of the RFS2 mandate. Thus, parties maintain compliance with the program either by blending renewable fuel or by purchasing RINs generated by other firms. ${ }^{2}$ The EPA allows limited banking and borrowing of RINs across compliance years. Firms may use RINs generated in the previous compliance year to meet up to $20 \%$ of their compliance obligation in any year. In addition, firms may carry a deficit between compliance years, but may only do so once (Environmental Protection Agency, 2007). As a result, the industry as a whole is able to carry a net deficit or net surplus from one compliance year to the next, but is limited in the extent to which it may do so.

RINs are differentiated by both fuel type and vintage year in order to enforce the nested mandates and the banking/borrowing restrictions, respectively. RIN 'types' correspond to the biofuel categories described above with conventional RINs applying towards the total renewable fuel mandate; advanced RINs applying towards the advanced and renewable fuel mandates; and biodiesel RINs applying towards the biodiesel, advanced, and renewable fuel mandate. We do not consider cellulosic ethanol RINs in this paper because little cellulosic biofuel has been produced to date and a viable market for cellulosic RINs has not emerged.

The success of the RFS2 in expanding U.S. biofuel consumption faces two major challenges: (i) the blend wall, and (ii) the lack of development of a commercial-scale advanced biofuel industry. The blend wall is the notion that it is expensive to comply with the RFS2 beyond a $10 \%$ ethanol-gasoline blend. Ethanol has historically been blended with gasoline at two levels: 10\% ethanol, referred to as E10; and 85\% ethanol, referred to as E85. E10 has been approved by the EPA for decades and makes up most of ethanol-blended gasoline sales in the U.S. ${ }^{3}$ To maintain compliance with the RFS2 past a 10\% ethanol-gasoline blend, refiners must either sell greater volumes of E85 or increase sales of biodiesel, for which blending constraints do not bind. Both compliance options are costly and require high RIN prices. In addition to the blend wall, the levels of advanced biofuel production envisioned in 2007 have yet to materialize. This is especially true of cellulosic biofuels. As of May 2014, six cellulosic biofuel plants were expected to produce fuel in 2014 (Adler et al., 2014), and little commercial-scale production has occurred as of spring 2016 despite large initial mandates for its production.

Due in large part to these issues, the EPA has failed to release a Final Rule in a timely manner since 2013. In addition, the Agency has vastly scaled back the total biofuel mandates for 2014 to 2016 (Environmental Protection Agency, 2015b). Delays first arose during the 2013 rulemaking process. The Agency did not release the 2013 Proposed Rule until the end of January 2013, and the Final Rule was not released until August of that year, eight months into the compliance year. In the rule, the EPA stated that it may reduce the overall biofuel mandate for 2014 (Environmental Protection Agency, 2013a). In its subsequent 2014

\footnotetext{
${ }^{3}$ In 2010, the EPA granted a partial waiver for E15 blends, or gasoline containing up to $15 \%$ ethanol; however, little E15 has been sold in the U.S. to date.
} 
Table 1: Statutory vs. Proposed Mandates: 2013-2014

\begin{tabular}{c|cc|cc} 
& \multicolumn{2}{|c|}{ Statutory Volumes (bgals) } & \multicolumn{2}{r}{ EPA Rule (bgals) } \\
& 2013 & 2014 & 2013 & $2014(\mathrm{a})$ \\
\hline Cellulosic Biofuel & 1 & 1.75 & 0.006 & 0.017 \\
Biomass-Based Diesel & $>1$ & $>1$ & 1.28 & 1.28 \\
Advanced Biofuel & 2.75 & 3.75 & 2.75 & 2.20 \\
Total Biofuel & 16.55 & 18.15 & 16.55 & 15.21 \\
\hline
\end{tabular}

Note: 2013 refers to the Final Rule, and 2014(a) refers to the 2014 Proposed Rule volumes from November 2013. (Source: EPA)

Proposed Rule, released in November 2013, the Agency called for a significant cut to the overall biofuel mandate. Table 1 compares the EISA statutory mandates for 2013 and 2014 with the EPA proposed standards. As can be seen, the proposed mandates for 2014 represent a large decrease relative to the EISA statutory mandates, and the proposed total biofuel mandate is lower than its level in the 2013 mandate. ${ }^{4}$

\subsection{Previous Literature}

Our work contributes to a growing literature studying the economics of biofuel mandates. Early work by de Gorter and Just (2009), Lapan and Moschini (2012), and Holland et al. (2009) study the market effects and efficiency of fuel mandates such as the RFS2 and California's Low Carbon Fuel Standard. More recent work compares welfare and markets outcomes under fuel mandates to those under taxes and cap and trade programs in alternative market settings and with different policy designs (Rajagopal et al., 2011; Rajagopal and Plevin, 2013; Lemoine, 2016; Bento et al., 2014; Lade and Lin Lawell, 2015a), explores unintended consequences of fuel mandates (Khanna et al., 2008; Holland et al., 2014, 2015), and studies the impact of economic and policy uncertainty on the incentive for investments in advanced fuel technologies (Miao et al., 2012; Clancy and Moschini, 2015). ${ }^{5}$

Corts (2010) and Anderson (2012) are among the first empirical papers to study issues related to the biofuel mandates. Anderson (2012) estimates demand for E85, a high ethanol blend fuel, in Minnesota and finds that demand for the fuel is elastic, with a constituent of consumers willing to pay a premium for E85. Corts (2010) finds that mandated government fleet investments in flex fuel vehicles spurred investments in

\footnotetext{
${ }^{4} \mathrm{~A}$ subsequent rule was not released until 2015. In its June 2015 proposed rulemaking, the EPA largely upheld the proposed cuts from 2014, and proposed similar large reductions to the 2015 and 2016 mandates. In November 2015, the EPA finalized the mandates for 2014-2016, slightly increasing mandates for all biofuel volumes over the levels from the June rulemaking; however, the final mandates remain well below statutory levels (Environmental Protection Agency, 2015b). Given the importance of the initial proposed cuts, our analysis focuses on rulemaking in 2013 and 2014.

${ }^{5}$ Lade and Lin Lawell (2015b) provide a more thorough review of the economics literature on low carbon fuel standards.
} 
E85 fueling infrastructure. Subsequent papers study the demand for high-blend ethanol and alternative fuel vehicles in the United States and Brazil and find mixed evidence regarding consumers' preferences for biofuels (Du and Carriquiry, 2013; Salvo and Huse, 2013; Babcock and Pouliot, 2013; Pouliot and Babcock, 2014c). Knittel et al. (2015) study the pass-through of RIN prices to wholesale and retail fuel prices. The authors find that wholesale fuel markets adjust quickly and exhibit near full pass through of RINs; however, the authors find little evidence that RIN prices are passed through to average U.S. E85 prices. In addition, several papers study the impacts of the RFS2 on fuel prices (Du and Hayes, 2009; Pouliot and Babcock, 2014a,b; Knittel and Smith, 2015; Whistance et al., 2016) and food prices (Hausman et al., 2012; Roberts and Schlenker, 2013; Wright, 2014; Carter et al., 2016).

\section{A Dynamic Model of Compliance}

In a model with no uncertainty, a single compliance period, and a single biofuel mandate, compliance credit prices reflect the cost difference between the marginal renewable fuel used for compliance and the marginal fossil fuel (Lade and Lin Lawell, 2015a). Static models of the RFS2 omit three important features relevant to our study of RIN markets. First, regulated parties are uncertain about future fuel supply and prices, as well as future mandates. Second, the RFS2 is applied over many years and firms are allowed to bank and borrow credits from one compliance year to the next. Third, the mandate has a nested structure, with certain biofuels counting towards compliance for sub-mandates and the total mandate. To capture these three features, we develop a dynamic model of compliance with the RFS2 under uncertainty. ${ }^{6}$

Consider a competitive industry that must comply with a biofuel mandate. Suppose each firm uses two types of inputs in the production of fuel $Q$ : (i) a cheap and abundant conventional input $q^{c}$ and (ii) costly renewable inputs $\mathbf{q}^{r}$. Total fuel production in a period is given by:

$$
Q_{t}=\sum_{i}\left(q_{i, t}^{c}+\sum_{j} q_{i, j, t}^{r}\right),
$$

where $t$ denotes the time period in production days, $i$ denotes the firm, and $j$ denotes the renewable fuel. Under a fuel mandate, renewable fuels generate a vector of a compliance credits denoted by $\mathbf{w}$ that can be purchased or sold at market clearing prices $\mathbf{r}$.

Uncertainty enters the model through several avenues. Each day, firms may experience a common price (demand) shock $\theta_{t}^{p}$; a cost (supply) shock $\theta_{t}^{c}$ for conventional fuel; cost (supply) shocks $\theta_{t}^{r}$ for renewable fuels; and a policy shock $\theta_{t}^{\alpha}$. The tuple of shocks is denoted by $\Theta_{t}=\left(\theta_{t}^{p}, \theta_{t}^{c}, \theta_{t}^{r}, \theta_{t}^{\alpha}\right)$. All shocks are realized before firms make their period $t$ production decisions. Thus, firms make production decisions knowing the

\footnotetext{
${ }^{6}$ The model is similar to that of Schennach (2000), who studies $\mathrm{SO}_{2}$ permits under the Clean Air Act Amendments of 1990, and those of Rubin (1996) and Holland and Moore (2012, 2013), who study permit markets under cap and trade programs.
} 
current value and history of all shocks, but not the value of future shocks. We assume every firm knows the distribution of possible future shocks conditional on current and past shocks, and is able to form consistent, rational expectations given a realized history of shocks.

Let $T_{l}$ denote each compliance period $l$, which spans many production days $t .^{7}$ We define the state variable(s) $\mathbf{B}_{i, t}$ as the amount of banked credits, where $\mathbf{B}_{i, t}$ may be a vector or single valued. All policy constraints are written as limits on the amount of banked credits that firms may carry beyond each compliance period. The most general formulation of a firm $i$ 's dynamic compliance problem on any day $t$ can represented by the Bellman equation:

$$
\begin{aligned}
V_{i, t}\left(\mathbf{B}_{i, t} ; \Theta_{t}\right)=\max _{\substack{q_{i, t}^{c}, \mathbf{q}_{i, t}^{r} \geq 0, \mathbf{w}_{i, t}^{r}}} \Pi_{i, t}\left(q_{i, t}^{c}, \mathbf{q}_{i, t}^{r}, \mathbf{w}_{i, t} ; \mathbf{B}_{i, t} ; \Theta_{t}\right)+\beta \mathbb{E}_{t}\left[V_{i, t+1}\left(\mathbf{B}_{i, t+1} ; \Theta_{t+1}\right)\right] \\
\text { subject to } \quad \begin{array}{l}
\mathbf{B}_{i, t+1}=\mathbf{G}_{i, t}\left(q_{i, t}^{c}, \mathbf{q}_{i, t}^{r}, \mathbf{w}_{i, t}, \mathbf{B}_{i, t} ; \Theta_{t}\right) \\
\mathbf{H}_{i, t}\left(\mathbf{B}_{i t} ; \Theta_{t}\right) \geq 0 \quad t=1, \cdots, T \\
\mathbf{B}_{i, 1}=0,
\end{array}
\end{aligned}
$$

where $V_{i, t}(\cdot)$ is firm $i$ 's Bellman equation, $\Pi_{i, t}(\cdot)$ denotes firm $i$ 's profit function at time $t, \beta$ is the discount factor, $\mathbf{G}(\cdot)$ is the equation of motion for the state variable(s) $\mathbf{B}_{i, t}$, and $\mathbf{H}(\cdot)$ are the policy constraints on the state variable(s) $\mathbf{B}_{i t}$. We do not impose a non-negativity constraint on $\mathbf{w}_{i t}$, allowing firms to either purchase or sell compliance credits in each period.

We consider three special cases of the model above. We first study a market with a single renewable fuel and a single compliance period as a baseline model to show clearly how expectations affect compliance costs. Second, we examine a market with a single renewable fuel and two compliance periods to analyze the impacts of banking and borrowing restrictions on the relationship between RIN prices across vintage years for the same RIN type. Last, we consider a market with two renewable fuels, a single compliance period, and a nested mandate to derive the relationship between RIN prices for different biofuel types due to the nested structure of the RFS mandate.

In all cases, consumers are assumed to have have quasilinear preferences for fuel with aggregate inverse demand $P\left(Q ; \Theta_{t}\right)$. Renewable and conventional fuels are specified in units so that they are perfect substitutes in production and consumption. ${ }^{8}$ All cost functions are assumed to be separable, increasing, and strictly

\footnotetext{
${ }^{7}$ We model multiple time periods $t$ within each compliance period $T_{l}$ because our observed credit price data are daily while compliance is determined on an annual basis by the EPA. Thus, a theoretical model of the trajectory of prices within a compliance period better explains the data as production decisions are made daily or weekly, while firms meet their compliance obligations at the end of each year $T_{l}$. In addition, our model produces important testable implications for the trajectory of prices within each compliance year.

${ }^{8}$ Energy content differences across fuels are accommodated by assuming the fuels units are specified in equivalent units such as gasoline gallon equivalents (GGE).
} 
convex such that:

$$
C_{i, t}\left(q_{i, t}^{c}, \mathbf{q}_{i, t}^{r} ; \Theta_{t}\right)=C_{i, t}^{c}\left(q_{i, t}^{c} ; \Theta_{t}\right)+\sum_{j} C_{i, j, t}^{r}\left(q_{i, j, t}^{r} ; \Theta_{t}\right)
$$

where $C_{i, t}^{c}\left(\cdot ; \Theta_{t}\right)$ is the cost function for conventional fuel and $C_{i, j, t}^{r}\left(\cdot ; \Theta_{t}\right)$ is the cost function for renewable fuel $j$, with $C_{i, t}^{c^{\prime}}\left(\cdot ; \Theta_{t}\right)>0$ and $C_{i, t}^{c^{\prime \prime}}\left(\cdot ; \Theta_{t}\right)>0$ for all $i$ and $t$. Similar conditions hold for $C_{i, j, t}^{r}\left(\cdot ; \Theta_{t}\right)$.

\subsection{Single Compliance Period and One Renewable Fuel}

Consider a market with a single renewable fuel and a single compliance period. Suppose firms make production decisions on days $t=1,2, \ldots, T$ and have to establish compliance on day $T$. A biofuel mandate requires each firm's combined production of renewable fuel and purchase of compliance credits over all $t$ to be greater than or equal to a blend mandate $\alpha$ times the total production of conventional fuel. The constraint is similar to the total biofuel mandate faced by refiners under the RFS2, and is written as:

$$
\sum_{t=1}^{T}\left(q_{i, t}^{r}+w_{i, t}\right) \geq \alpha \sum_{t=1}^{T} q_{i, t}^{c} .
$$

The right-hand side of the inequality is often referred to as the firm's renewable volume obligation (RVO). Summing equation (1) over all firms yields the industry's RVO, equal to the total volume of renewable fuel mandated by the program. The constraint can be rewritten in a compact form by defining the state variable $B_{i, t}$ as the number of 'banked' credits held by firm $i$ on day $t$. The variable evolves over time according to:

$$
B_{i, t+1}=B_{i, t}+q_{i, t}^{r}+w_{i, t}-\alpha q_{i, t}^{c}
$$

for $t=1, \cdots, T$. Assume the bank is empty on the first day so that $B_{i, 1}=0$. In this scenario, the policy constraint (1) can be rewritten as: ${ }^{9}$

$$
B_{i, T+1} \geq 0 \text {. }
$$

Assume there is no scrap value to having a positive bank of credits on the final day $T$, therefore the value function for $T+1$ is zero. Firm $i$ 's Bellman equation in each day is given by:

$$
\begin{gathered}
V_{i, t}\left(B_{i, t} ; \Theta_{t}\right)=\max _{\substack{q_{i, t}^{c} ; q_{i, t}^{r} \geq 0, w_{i, t}}} P_{t}\left(Q_{t} ; \Theta_{t}\right) Q_{i, t}-C_{i, t}^{c}\left(q_{i, t}^{c} ; \Theta_{t}\right)-C_{i, t}^{r}\left(q_{i, t}^{r} ; \Theta_{t}\right)-r_{t} w_{i, t}+\beta \mathbb{E}_{t}\left[V_{i, t+1}\left(B_{i, t+1} ; \Theta_{t+1}\right)\right] \\
\text { subject to } B_{i, t+1}=B_{i, t}+q_{i, t}^{r}+w_{i, t}-\alpha q_{i, t}^{c} \\
B_{i, T+1} \geq 0 \\
B_{i, 1}=0,
\end{gathered}
$$

where $Q_{i, t}=q_{i, t}^{c}+q_{i, t}^{r}$ and $Q_{t}=\sum_{i} Q_{i, t}$.

Result 1 presents the market clearing compliance credit prices under a competitive equilibrium for this case. Detailed derivations of all results are presented in Appendix A.

\footnotetext{
${ }^{9}$ To see this, note that $B_{i, T+1}=B_{i, T}+q_{i, T}^{r}+w_{i, T}-\alpha q_{i, T}^{c}=\sum_{t=1}^{T}\left(q_{i, t}^{r}+w_{i, t}-\alpha q_{i, t}^{c}\right)$.
} 
Result 1. When firms face maximization problem (3), market clearing RIN prices are given by:

$$
r_{t}=\beta^{(T-t)} \mathbb{E}_{t}\left[r_{T}\right],
$$

with

$$
r_{T}=\max \left[C_{T}^{r^{\prime}}\left(q_{T}^{r} ; \Theta_{t}\right)-P_{T}, 0\right]=\max \left[\frac{C_{T}^{r^{\prime}}\left(q_{T}^{r}\right)-C_{T}^{c^{\prime}}\left(q_{T}^{c}\right)}{1+\alpha}, 0\right],
$$

where $C_{T}^{r^{\prime}}\left(q_{T}^{r} ; \Theta_{t}\right)$ is the aggregate renewable marginal cost, $C_{T}^{c^{\prime}}\left(q_{T}^{c} ; \Theta_{t}\right)$ is the aggregate conventional marginal cost, and $P_{T}$ is the equilibrium price of fuel at time $T$. The aggregate marginal cost for fuel $f=r, c$ equals the horizontal sum of $C_{i, T}^{f^{\prime}}\left(q_{i, T}^{f} ; \Theta_{t}\right)$ over all firms $i$.

Result 1 states that compliance credit prices follow Hotelling's rule and grow at the rate of interest in expectation. The finding provides a baseline with which we evaluate the efficiency of RIN markets in Section 4.5. In addition, Result 1 states that the RIN price on the last day bridges the gap, if positive, between the renewable fuel marginal cost and the equilibrium fuel price. Expressed another way, the RIN price equals the difference in marginal costs between the two fuels divided by $1+\alpha$. The $1+\alpha$ term arises because, when a firm blends a gallon of renewable fuel in place of conventional fuel, it reduces its mandated obligation by $\alpha$ thereby offsetting some of the cost of the renewable fuel.

Prior to the final day, RIN prices reflect expected future compliance costs. Thus, high expected future compliance costs lead to high compliance costs in earlier periods, even if physical costs of blending at the mandated rate are low. This differs from a model with no dynamics in which compliance costs reflect only the current period cost difference between the marginal renewable fuel used for compliance and the marginal fossil fuel (Lade and Lin Lawell, 2015a).

Result 2 provides further intuition as to the market effects of compliance credits.

Result 2. A binding fuel mandate has an equivalent price-based mechanism, namely instituting a revenueneutral tax on conventional fuel that funds a subsidy for renewable fuel. The per-unit implicit tax on conventional fuel on each day is $\alpha r_{t}=\alpha \beta^{(T-t)} \mathbb{E}_{t}\left[r_{T}\right]$, and the per-unit implicit subsidy for renewable fuel is $r_{t}=\beta^{(T-t)} \mathbb{E}_{t}\left[r_{T}\right]$.

Result 2 confirms previous findings in the literature on market effects of fuel mandates (Lapan and Moschini, 2012; Holland et al., 2009). The result is analogous to the equivalence between cap and trade programs and an emissions tax. In Section 5 we use this insight to quantify changes in the value of the RFS2 to the U.S. fuel industry around the three policy shocks. Importantly, in a dynamic setting the implicit tax and subsidy are determined by expected future compliance costs, and are therefore influenced by beliefs regarding both future fuel costs and the future stringency of the policy.

A negative policy shock, or decrease in the expected future stringency of the mandate, affects the market equilibrium through several channels. Reductions in the expected future mandate relax the policy constraint 
$B_{i, T+1} \geq 0$, as each firm's RVO $\alpha q_{i, t}^{c}$ decreases in all future production periods. In addition, to the extent that expected marginal compliance costs increase in the industry RVO, a negative policy shock will decrease $E_{t}\left[r_{T}\right]$ and therefore $r_{t}$ in all days. From Result 2, both effects decrease the implicit tax on conventional fuel and the subsidy for renewable fuel, potentially well in advance of when compliance is due.

\subsection{Two Compliance Periods and One Renewable Fuel}

Next consider a market with one conventional and one renewable fuel, and suppose there are two compliance periods. The first compliance period occurs for days $t \in\left[1, T_{1}\right]$ with mandate $\alpha_{1}$, and the second compliance period occurs for $t \in\left[T_{1}+1, T_{2}\right]$ with mandate $\alpha_{2}$, which does not necessarily equal $\alpha_{1}$. Denote a compliance credit generated from period $j$ renewable fuel production and purchased by firm $i$ on day $t$ as $w_{i, j, t}$. The stock of period 1 and 2 compliance credits evolves as follows:

$$
\begin{aligned}
& B_{i, 1, t+1}=B_{i, 1, t}+\left(q_{i, t}^{r}-\alpha_{1} q_{i, t}^{c}\right) \mathbf{1}\left(t \leq T_{1}\right)+w_{i, 1, t} \\
& B_{i, 2, t+1}=B_{i, 2, t}+\left(q_{i, t}^{r}-\alpha_{2} q_{i, t}^{c}\right) \mathbf{1}\left(t>T_{1}\right)+w_{i, 2, t},
\end{aligned}
$$

where $B_{i, 1, t}$ is the stock of period 1 compliance credits held by firm $i$ on day $t, B_{i, 2, t}$ is the stock of period 2 compliance credits held by firm $i$ on day $t, \mathbf{1}(\cdot)$ denotes the indicator function, and $B_{i, 1,0}=B_{i, 2,0}=0$. We allow a forward market for period 2 compliance credits, which means that firms can trade them in period 1 even though none get generated until period 2. The policy constraint over both compliance periods is:

$$
B_{i, 1, T_{2}+1}+B_{i, 2, T_{2}+1} \geq 0
$$

i.e., the aggregate stock of credits must be non-negative at the end of the second compliance period.

Firms may over- or under-comply with their renewable volume obligations in each compliance period, but are limited in the extent to which they may do so. These limits restrict the extent of intertemporal substitution of compliance obligations, which we show mitigates the pass-through of shocks to future compliance costs to current RIN prices. A firm cannot meet more than a proportion $\gamma_{1}$ of its period 1 obligation with credits generated in period 2, a borrowing restriction. In addition, it cannot meet more than a proportion $\gamma_{2}$ of its period 2 obligation with credits generated in period 1, a banking restriction. We write the borrowing

\footnotetext{
${ }^{10}$ To see this, consider a binding banking constraint, which implies $B_{i, 2, T_{2}+1}=-\gamma_{2} \sum_{t=T_{1}+1}^{T_{2}} \alpha_{2} q_{i, t}^{c}$. Substituting this into the total mandate constraint implies $B_{i, 1, T_{2}+1}-\gamma_{2} \sum_{t=T_{1}+1}^{T_{2}} \alpha_{2} q_{i, t}^{c} \geq 0$, or

$$
\sum_{t=1}^{T_{1}}\left(q_{i, t}^{r}+w_{i, 1, t}-\alpha q_{i, t}^{c}\right) \geq \gamma_{2} \sum_{t=T_{1}+1}^{T_{2}} \alpha_{2} q_{i, t}^{c},
$$

i.e., the firm must obtain enough RINs in period 1 to cover the period 1 obligation plus a proportion $\gamma_{2}$ of the period 2 obligation. An analogous argument applies for the borrowing restriction.
} 
and banking restrictions, respectively, as:

$$
\begin{aligned}
& B_{i, 1, T_{2}+1} \geq-\gamma_{1} \sum_{t=1}^{T_{1}} \alpha_{1} q_{i, t}^{c} \\
& B_{i, 2, T_{2}+1} \geq-\gamma_{2} \sum_{t=T_{1}+1}^{T_{2}} \alpha_{2} q_{i, t}^{c} .
\end{aligned}
$$

The constraints state that the bank of credits in either period may be negative, but not too negative. Any deficit in the bank of credits in one period must be made up by credits generated in the other period. ${ }^{10}$ Result 3 presents market clearing RIN prices when firms are able to bank and borrow credits over compliance periods.

Result 3. When firms face compliance over two periods with one renewable fuel, market clearing RIN prices $r_{1, t}$ and $r_{2, t}$ for first period and second period compliance credits, respectively, are:

$$
\begin{aligned}
& r_{1, t}= \begin{cases}\beta^{\left(T_{2}-t\right)} \mathbb{E}_{t}\left[r_{2, T}-\Phi_{2}+\beta^{\left(T_{1}-T_{2}\right)} \Phi_{1}\right] & \text { if } t \leq T_{1} \\
\beta^{\left(T_{2}-t\right)} \mathbb{E}_{t}\left[r_{2, T}-\Phi_{2}\right] & \text { if } t>T_{1}\end{cases} \\
& r_{2, t}=\beta^{\left(T_{2}-t\right)} \mathbb{E}_{t}\left[r_{2, T}\right],
\end{aligned}
$$

with

$$
r_{2, T_{2}}=\max \left[C_{T_{2}}^{r^{\prime}}\left(q_{T_{2}}^{r} ; \Theta_{t}\right)-P_{T_{2}}, 0\right]
$$

where $\Phi_{1}$ and $\Phi_{2}$ denote the Lagrange multipliers on the borrowing and banking restrictions, respectively, and are positive when the respective restrictions bind. $C_{T_{2}}^{r^{\prime}}\left(q_{T_{2}}^{r} ; \Theta_{t}\right)$ is the aggregate marginal cost for renewable fuel.

If the probability equals zero that any of the three policy constraints will bind, then both RIN prices equal zero on that day. If it is expected that the total mandate may bind $\left(E_{t}[\lambda]>0\right)$, but the probability is zero that either the banking or borrowing constraint will bind, then RIN prices for the two periods are equal to each other and given by $r_{1, t}=r_{2, t}=E_{t}\left[\max \left[C_{T_{2}}^{r^{\prime}}\left(q_{T_{2}}^{r}\right)-P_{T_{2}}, 0\right]\right]>0$.

Any difference between period 1 and period 2 RIN prices depends on whether the banking or borrowing constraints are expected to bind. Only one of these constraints can bind, and market participants learn which, if any, will bind as time progresses. Decisions made in the first compliance period determine whether the borrowing constraint binds. If at the end of the first compliance period the number of generated RINs is at its lower bound, then the borrowing constraint binds. In period 2, then, the industry will need to generate enough RINs to meet both the period 1 deficit and the period 2 volume obligation. A binding borrowing restriction arises when the cost of generating RINs is expected to decrease in the second period. Firms defer to period 2 as much renewable fuel use as they are allowed. Thus, a binding borrowing constraint implies at the end of period 1 that $r_{1, T_{1}}>r_{2, T_{1}}$. 
In contrast, if there is a RIN surplus at the end of period 1, then the borrowing restriction cannot bind. The industry is banking rather than borrowing RINs in this case. Up to a proportion $\gamma_{2}$ of the period 2 obligation can be met with period 1 RINs, so whether the banking restriction binds depends on renewable fuel use during period 2. If the industry generates the minimum number of RINs during period 2, then the banking restriction binds. A binding banking restriction arises if two conditions are satisfied. First, firms produce extra renewable fuel in period 1 in expectation that the cost of generating RINs will increase in period 2. Second, the expected increase in compliance costs eventuates, which makes it cheaper to use banked RINs than to use renewable fuel in period 2.

Result 4 summarizes the implications of binding banking or borrowing constraints for RIN prices.

Result 4. On the last day $T_{1}$ of the first compliance period, if the borrowing constraint binds $\left(\Phi_{1}>0\right)$, then the banking constraint does not bind $\left(\Phi_{2}=0\right)$ and RIN prices are given by:

$$
\begin{aligned}
r_{1, T_{1}} & =C_{T_{1}}^{r^{\prime}}\left(q_{T_{1}}^{r}\right)-P_{T_{1}} \\
& =\frac{C_{T_{1}}^{r^{\prime}}\left(q_{T_{1}}^{r}\right)-C_{T_{1}}^{c^{\prime}}\left(q_{T_{1}}^{c}\right)}{1+\alpha_{1}\left(1-\gamma_{1}\right)}-\frac{\alpha_{1} \gamma_{1}}{1+\alpha_{1}\left(1-\gamma_{1}\right)} r_{2, T_{1}}>0 \\
r_{2, T_{1}} & =\beta^{\left(T_{2}-T_{1}\right)} E_{T_{1}}\left[\max \left[C_{T_{2}}^{r^{\prime}}\left(q_{T_{2}}^{r}\right)-P_{T_{2}}, 0\right]\right] \\
& =\beta^{\left(T_{2}-T_{1}\right)} E_{T_{1}}\left[\max \left[\frac{C_{T_{2}}^{r^{\prime}}\left(q_{T_{2}}^{r}\right)-C_{T_{2}}^{c^{\prime}}\left(q_{T_{2}}^{c}\right)}{1+\alpha_{2}}, 0\right]\right]<r_{1, T_{1}} .
\end{aligned}
$$

On the last day $T_{2}$ of the second compliance period, if the banking constraint binds $\left(\Phi_{2}>0\right)$, then the borrowing constraint does not bind $\left(\Phi_{1}=0\right)$ and RIN prices are given by:

$$
\begin{aligned}
& r_{1, T_{2}}=0 \\
& r_{2, T_{2}}=C_{T_{2}}^{r^{\prime}}\left(q_{T_{2}}^{r}\right)-P_{T_{2}}=\frac{C_{T_{2}}^{r^{\prime}}\left(q_{T_{2}}^{r}\right)-C_{T_{2}}^{c^{\prime}}\left(q_{T_{2}}^{c}\right)}{1+\alpha_{2}\left(1-\gamma_{2}\right)}>0 .
\end{aligned}
$$

Result 4 shows that when the borrowing constraint binds on the last day $T_{1}$ of the first compliance period, the period 1 RIN price equals the weighted difference in marginal costs between the two fuels minus an extra term. As before, the denominator $\left(1+\alpha_{1}\left(1-\gamma_{1}\right)\right)$ reflects that when a firm blends a gallon of renewable fuel in place of conventional fuel, it reduces its mandated period 1 obligation by $\alpha_{1}$. Compared to Result 1 , the denominator here has an extra term $1-\gamma_{1}$. This term arises because, when a firm blends a gallon of renewable fuel in place of conventional fuel, it reduces its mandated period 1 obligation by $\alpha_{1}\left(1-\gamma_{1}\right)$ thereby offsetting some of the cost of the renewable fuel. The borrowing constraint allows the firm the option to cover only a proportion of $1-\gamma_{1}$ of its period 1 obligation with period 1 RINs, so the net reduction in the obligation under a binding borrowing constraint is $\alpha_{1}\left(1-\gamma_{1}\right)$ rather than $\alpha_{1}$. However, the smaller net reduction in the period 1 obligation also reduces the need to produce period 2 RINs that will be borrowed for period 1 compliance. This latter effect is the source of the extra term $\frac{\alpha_{1} \gamma_{1}}{1+\alpha_{1}\left(1-\gamma_{1}\right)} r_{2, T_{1}}$. 
A binding borrowing constraint means there are no period 1 RINs available for trade in period 2. All period 1 RINs that were generated have been allocated for period 1 compliance, so there is nothing to trade in period 2. Thus, the second line in equation 4 of Result 3 is only relevant when the borrowing constraint is not binding. During period 1, a nonzero probability of a binding borrowing constraint puts upward pressure on $r_{1, t}$. During period 2, either there is no market for period 1 RINs or the borrowing constraint was non-binding.

A binding banking constraint implies that there are surplus period 1 credits that the firm would like to use towards its period 2 compliance obligation, but the banking restriction prevents it from fully doing so. As shown in Result 4, these surplus period 1 credits therefore have no value on the margin, i.e., $r_{1, T_{2}}=0$. The price of period 2 RINs is positive because using renewable fuel in period 2 is costly - if it were not, then the firm would not be wanting to use more period 1 RINs for compliance and the banking constraint would not bind. Analogous to the borrowing constraint, the price of period 2 RINs contains a $1-\gamma_{2}$ term in the denominator.

One difference between the effects of the borrowing and banking restrictions arises because the path of time cannot be reversed. When the bindingness of the banking restriction is resolved at the end of period 2 , the production of period 1 RINs has already occurred. It is not possible to go back in time and generate fewer period 1 RINs. The cost of generating those excess RINs is sunk and so their value is zero. However, the bindingness of the borrowing restriction is determined before any period 2 RINs are generated. The costs of generating period 2 RINs have yet to be realized, so they are reflected in RIN prices. All that is known on day $T_{1}$ under a binding borrowing restriction is that generating period 2 RINs is expected to be cheaper than generating period 1 RINs was.

Results 3 and 4 explain the price differences that arise between RINs of the same type that are generated in different compliance years. These differences stem from borrowing and banking restrictions, which limit the pass-through of shocks to future expected mandates to current RIN prices. For example, it is often the case that future-year ethanol RINs trade at a premium to prior year RINs. Our results imply that this phenomena arises due to firms' anticipation that the EPA's banking constraint will bind, which prevents firms from equalizing marginal compliance costs over time.

\subsection{Single Compliance Period and Two Renewable Fuels}

Last, consider a market with two renewable fuels $q_{i, j, t}^{r}$, where $j \in 1,2$ denotes the type of renewable fuel. Each gallon of renewable fuel $j$ generates a credit $w_{i, j, t}$ that can be sold at price $r_{j, t}$. Assume that there is only one compliance period for $t \in[1, T]$. Suppose firms face two policy constraints: (i) a mandate on total renewable fuel production with blend requirement $\alpha_{1}$; and (ii) a sub-mandate for $q_{i, 2, t}^{r}$ with blend mandate 
$\alpha_{2}$. The policy constraints are given by:

$$
\begin{gathered}
\sum_{t=1}^{T}\left(q_{i, 1, t}^{r}+w_{i, 1, t}+q_{i, 2, t}^{r}+w_{i, 2, t}\right) \geq \alpha_{1} \sum_{t=1}^{T} q_{i, t}^{c} \\
\sum_{t=1}^{T}\left(q_{i, 2, t}^{r}+w_{i, 2, t}\right) \geq \alpha_{2} \sum_{t=1}^{T} q_{i, t}^{c} .
\end{gathered}
$$

The constraints are written in compact form by defining the amount of banked credits $B_{i, 1, t}^{r}$ and $B_{i, 2, t}^{r}$ as:

$$
\begin{aligned}
& B_{i, 1, t+1}^{r}=B_{i, 1, t}^{r}+q_{i, 1, t}^{r}+w_{i, 1, t}+q_{i, 2, t}^{r}+w_{i, 2, t}-\alpha_{1}^{r} q_{i, t}^{c} \\
& B_{i, 2, t+1}^{r}=B_{i, 2, t}^{r}+q_{i, 2, t}^{r}+w_{i, 2, t}-\alpha_{2}^{r} q_{i, t}^{c} .
\end{aligned}
$$

Given the definitions above, the policy constraints for the two mandates can be written as:

$$
\begin{aligned}
& B_{i, 1, T+1}^{r} \geq 0 \\
& B_{i, 2, T+1}^{r} \geq 0 .
\end{aligned}
$$

Result 5 presents the market clearing compliance credit prices for this scenario.

Result 5. When firms face a nested mandate structure for renewable fuels $q_{i, 1, t}^{r}$ and $q_{i, 2, t}^{r}$, their respective market clearing RIN prices are given by:

$$
\begin{aligned}
r_{1, t} & =\beta^{(T-t)} \mathbb{E}_{t}\left[r_{1, T}\right] \\
r_{2, t} & =\beta^{(T-t)}\left(\mathbb{E}_{t}\left[r_{1, T}\right]+\mathbb{E}_{t}\left[\lambda_{2}\right]\right),
\end{aligned}
$$

with

$$
\begin{aligned}
r_{1, T} & =\max \left[C_{1, T}^{r^{\prime}}\left(q_{1, T}^{r} ; \Theta_{t}\right)-P_{T}, 0\right] \\
r_{2, T} & =\max \left[C_{2, T}^{r^{\prime}}\left(q_{2, T}^{r} ; \Theta_{t}\right)-P_{T}, 0\right] \\
\lambda_{2} & =\max \left[C_{2, T}^{r^{\prime}}\left(q_{2, T}^{r}\right)-\max \left[C_{1, T}^{r^{\prime}}\left(q_{1, T}^{r}\right), P_{T}\right], 0\right],
\end{aligned}
$$

where $\lambda_{2}$ denotes the Lagrange multiplier on the sub-mandate, and is positive when the respective restrictions bind. $C_{j, T}^{r^{\prime}}\left(q_{j, T}^{r} ; \Theta_{t}\right)$ are aggregate marginal cost functions for renewable fuels $j=1,2$.

Result 5 states that RIN prices for the nested biofuel sub-mandate $r_{2, t}$ can never be less valuable than RIN prices for the overall biofuel mandate $r_{1, t}$. This arises because $q_{i, 2, t}^{r}$ is used for compliance towards both mandates. Furthermore, the price of credits for a binding sub-mandate reflect the difference in marginal cost between the marginal fuel used to meet the sub-mandate and the marginal cost of the renewable fuel used to meet the overall mandate. Thus, if RIN prices converge across RIN types such that $r_{1, t}=r_{2, t}>0$, we can infer the industry is over-complying with the nested sub-mandate in order to meet the requirements of the overall renewable fuel mandate, and therefore that the nested sub-mandate is not binding. 


\section{Data and RIN Market Efficiency}

\subsection{Historical RIN Prices}

The Oil Price Information Service (OPIS) is the main industry source of RIN price data. ${ }^{11}$ Prices for conventional RINs have been recorded by OPIS since April 2008, advanced RINs have been reported since January 2011, and biodiesel RINs have been reported since June 2009. Figure 2 plots the average price for each RIN type from 2008-2014. Conventional RINs traded at low prices from 2008 through 2012, with the highest observed price before 2013 occurring in January 2009 when conventional RINs traded for \$0.18/gal. This occurred as oil prices fell from their July 2008 high of over $\$ 140 /$ barrel to around $\$ 40 /$ barrel while other commodity market prices such as ethanol and corn remained relatively stable. In contrast, prices of advanced and biodiesel RINs have been relatively high over their entire recorded history, reflecting high compliance costs for both sub-mandates. Both advanced and biodiesel RIN prices increased in mid-2011 following increasing commodities prices during that period, after which prices fell steadily.

In January 2013 prices of all RINs rose sharply, rising above \$1.40/gal in July 2013. The increase corresponded with the delayed release of the 2013 Proposed Rule in which the Agency upheld the statutory mandates for 2013 (Energy Information Agency, 2013b). The 2013 mandates pushed the industry towards the blend wall, and RIN prices rose sharply thereafter reflecting the industry anticipating higher marginal compliance costs for 2013 and beyond. ${ }^{12}$

\subsection{Banking Constraints and Nested Mandates}

Figure 3a graphs the advanced-conventional RIN and biodiesel-conventional RIN price spreads to illustrate the historical importance of the nested mandates. Before 2013, advanced and biodiesel RINs traded at a $\$ 0.60$ and $\$ 1.00$ premium over conventional RINs, respectively. Following the increase in RIN prices in January 2013, the spreads decreased sharply, and conventional RINs traded at nearly the same price as advanced and biodiesel RINs in 2013 and 2014. The convergence corresponds to $\mathbb{E}_{t}\left[\lambda_{2}\right]=0$ in Result 5 of the theory model, implying that the industry expected to over-comply with the biodiesel mandate in order

\footnotetext{
${ }^{11}$ OPIS determines prices through daily surveys of market participants and reports a low, high and average price for each RIN type and vintage. Conversations with an executive at a major oil refinery as well as employees at a large U.S. biodiesel producer confirm that OPIS is regularly used to determine market RIN values when making sales and purchases. For information on the methods used by OPIS to collect its data, see Oil Price Information Service (2015).

${ }^{12}$ The run-up RIN in prices in early 2013 came later than some industry analysts had expected. In 2012, more than $80 \%$ of U.S. farmland experienced drought conditions (USDA Economic Research Service, 2013). In addition, the statutory 2013 EISA mandates were expected to exceed the blend wall for the first time (Energy Information Agency, 2013a). Both factors should have put upward pressure on conventional RIN prices. In December 2012, Thompson et al. (2012) suggested that the fuel industry may have expected the EPA to waive a portion of the 2013 mandate.
} 
Figure 2: Historical RIN Prices

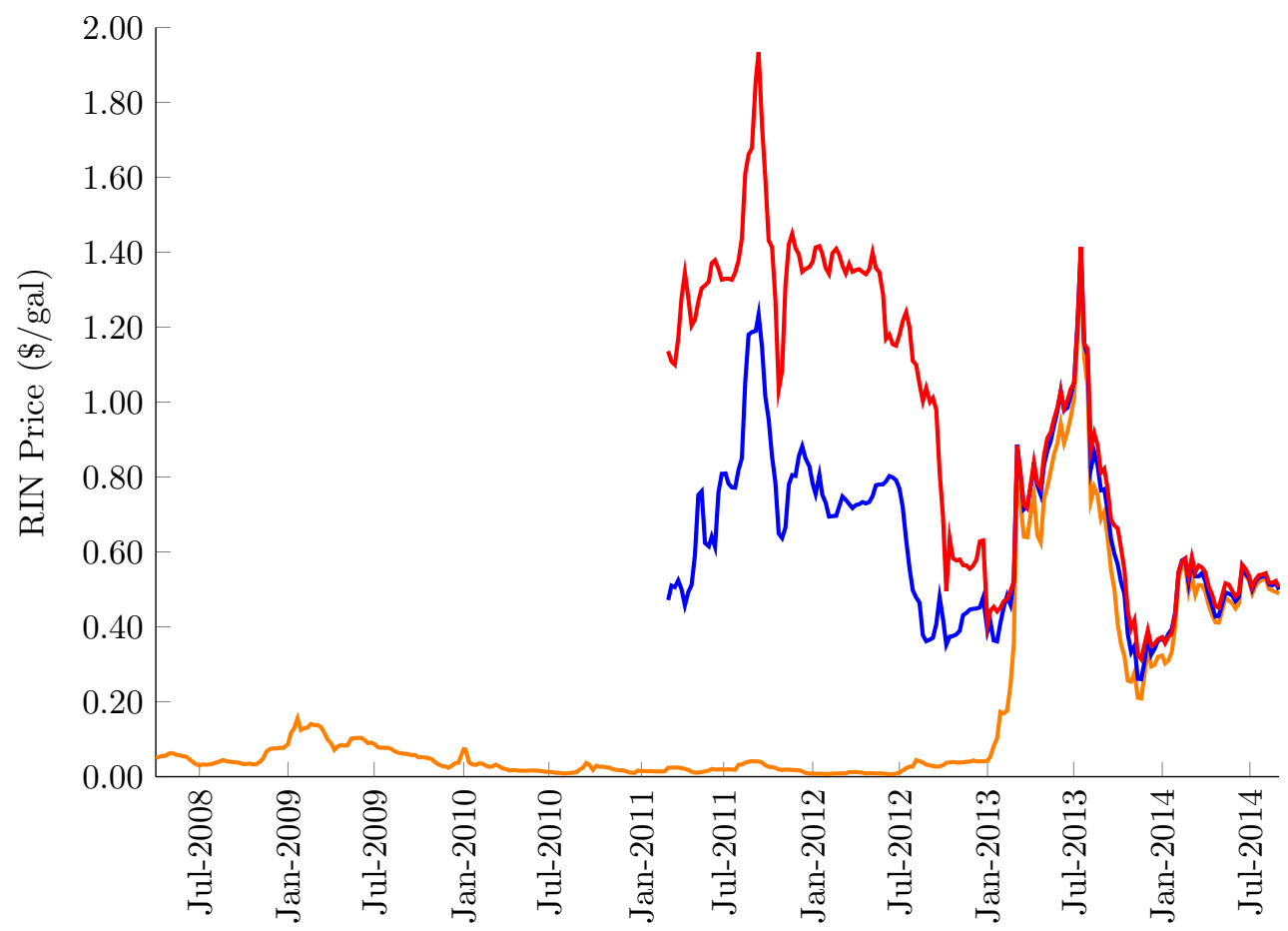

Note: The figure graphs average conventional (orange), advanced (blue), and biodiesel (red) RIN prices across all RIN vintages trading at the time. (Source: OPIS).

to comply with the overall and advanced biofuel mandates. Thus, we can infer from Figure 3a that the market expected biodiesel to be the industry marginal compliance fuel in 2013 and 2014. We make use of this insight when studying commodity market effects of the policy shocks in Section 5.3.

Figure 3b graphs the spread between front-year and prior-year prices for conventional RINs. For example, in 2009 the figure graphs the price difference between 2009 and 2008 conventional RINs. From 2008 through mid-2013, the spread was typically positive. In 2009, current vintage conventional RINs traded for more than a $\$ 0.14 /$ RIN premium over 2008 RINs for a brief period. As explained in Results 3 and 4 of the theoretical model, a positive spread between front- and prior-year RIN vintages reflects a positive option value to current year RINS due to an expectation that the banking constraint may bind (i.e., $\mathbb{E}_{t}\left[\Phi_{2}\right]>0$ ). The spread in 2013 was high initially, but fell sharply early in the year, suggesting that the industry learned that the banking restriction would not bind. Overall, the graph suggests that banking restrictions played an important role in determining historical RIN prices, but became less important late by 2014 after the EPA revised the volume obligations downward. 
Figure 3: Relationship Across Biofuel Types and Vintages

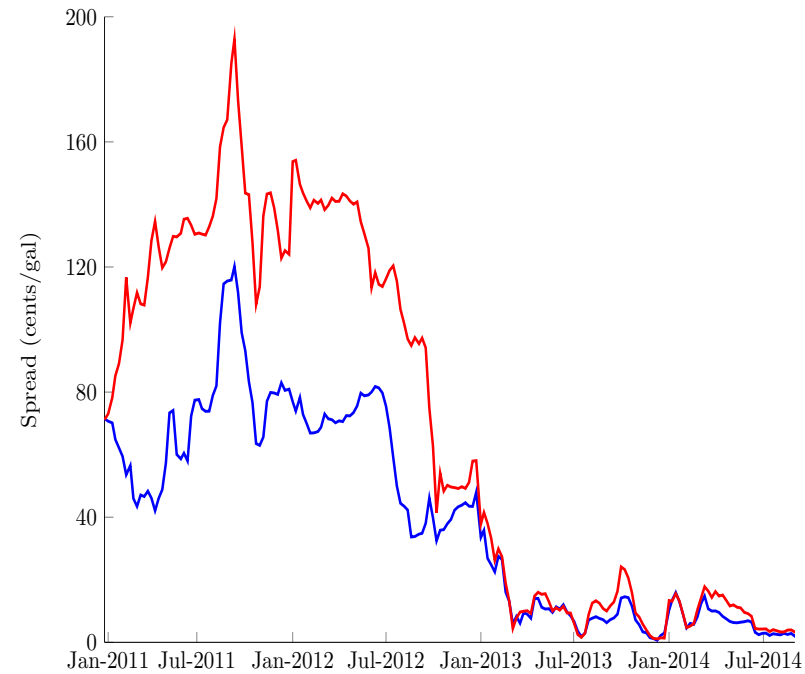

(a) Advanced and Biodiesel to Conventional Spread

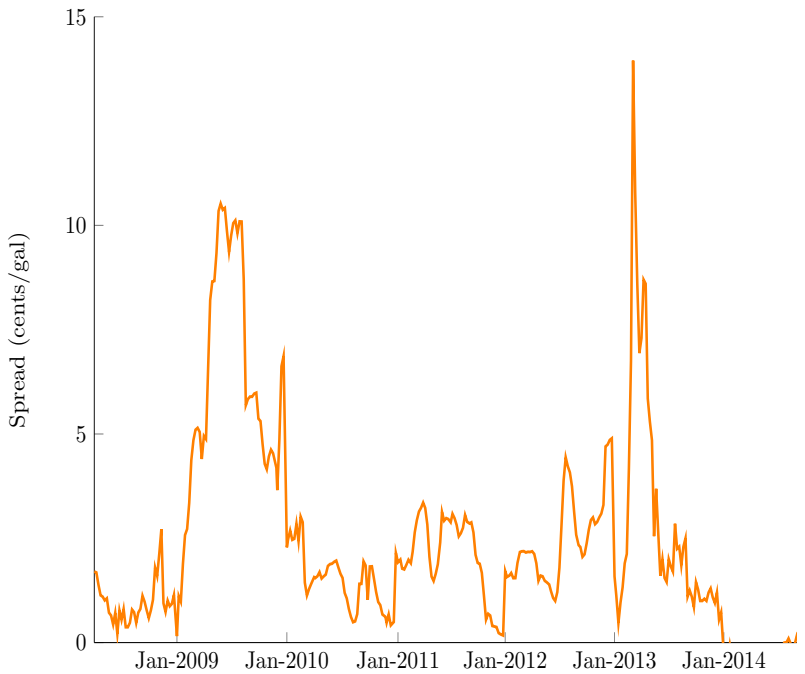

(b) Front-Prior Conventional Spread

Note: The left figure graphs the spread between front year biodiesel and conventional RIN prices (red) and advanced and conventional RIN prices (blue). The right graphs the spread between front and prior year RIN prices for conventional RINs.

\subsection{Energy Price Data}

In Section 5, we study 2013 conventional, advanced, and biodiesel RIN prices. From our model, RIN prices should reflect expected future compliance costs, which are a function of both expected future fuel costs and expectations regarding the future stringency of the policy. To control for expected future fuel costs, we collect CME futures prices for July 2014 ethanol, soybean oil, and WTI crude oil contracts from Quandl. ${ }^{13}$ We choose July 2014 contracts because the series traded over the entire observation period, and July contracts are typically among the most heavily traded commodities contracts. Table 2 presents summary statistics of the price series used in our analysis. All price series are converted to a cents per gallon basis for comparison. ${ }^{14}$ Oil futures prices fluctuated between $\$ 2.02 /$ gal and $\$ 2.43 /$ gal over the period, and ethanol futures prices traded $\$ 0.25$ lower than oil futures prices on average. ${ }^{15}$ Soybean oil futures prices fluctuated more widely over the period, ranging between $\$ 2.90$ and $\$ 4.28 /$ gal. Given the high production costs of soybean oil, our proxy for biodiesel prices is much higher than both oil and ethanol costs on average.

\footnotetext{
${ }^{13}$ Ideally, we would observe a futures price series for biodiesel; however, such a series is not currently trading on a major exchange. As a result, we use soybean oil, the dominant feedstock for biodiesel in the United States, to control for biodiesel prices.

${ }^{14} \mathrm{~A}$ conversion ratio of 1 pound of soybean oil to 7.7 gallons of biodiesel is assumed in converting soybean oil prices to $\$ /$ gal (Sadaka, 2012).

${ }^{15}$ The ethanol prices do not account for the lower energy content of the fuel.
} 
Table 2: Summary Statistics for Price Data (cents/gal)

\begin{tabular}{lccccc}
\hline \hline & Mean & Std. Dev. & Min & Max & N \\
\hline 2013 Conventional (D6) RINs & 44.92 & 33.37 & 4.75 & 145.5 & 423 \\
2013 Advanced (D5) RINs & 59.89 & 26.52 & 22 & 146.5 & 423 \\
2013 Biodiesel (D4) RINs & 71.74 & 26.86 & 23.5 & 146.5 & 423 \\
July 2014 WTI Oil Futures & 222.38 & 7.65 & 202.33 & 242.93 & 423 \\
July 2014 Ethanol Futures & 196.25 & 20.39 & 159 & 240.8 & 423 \\
July 2014 Soybean Oil Futures & 360.69 & 37.36 & 290.29 & 427.74 & 423 \\
\hline \hline
\end{tabular}

\subsection{Policy Announcements}

In addition to anticipated future fuel costs, the expected future stringency of the mandate should affect RIN prices. We estimate the effect of three 'policy shocks' on RIN prices that unexpectedly reduced the 2014 RFS2 mandates. The first event is the release of the 2013 Final Rule in August 2013. In the Rule, the EPA upheld the standards from the 2013 Proposed Rule; however, the Agency acknowledged for the first time publicly the challenges with meeting the standards for 2014 and beyond, including the following language in the Rule:

[W]e recognize that...for 2014 the ability of the market to consume ethanol as E15 [and] E85 is constrained in a number of ways. We believe that it will be challenging for the market to consume sufficient quantities of ethanol...and to produce sufficient volumes of non-ethanol biofuels...to reach the mandated 18.15 bill gal for 2014. Given these challenges, EPA anticipates that adjustments to the 2014 volume requirements are likely to be necessary based on the projected circumstances for 2014...[emphasis added $]^{16}$

Before the large run-up in RIN prices, some parties argued that firms anticipated the EPA would relax the standards in its 2013 Proposed Rule (Thompson et al., 2012). When this did not occur, RIN prices climbed quickly, reflecting the high marginal costs of crossing the blend wall. In response to the sudden increase in RIN prices, a number of congressional hearings were held, and there was much discussion that the EPA may step in to relieve compliance costs (Irwin, 2013b). The August ruling, however, was the first time that the EPA suggested it may consider change statutory mandate levels, and was the strongest signal that the mandates would be reduced later that year.

The second event is the publication of a news article in Reuters in October 2013 leaking an early version of EPA's 2014 Proposed Rule. To the authors' knowledge, and consistent with a discussion by Irwin (2013a), the news release was the first time that the EPA's draft rules were released to the general public. The article included the following discussion:

\footnotetext{
${ }^{16}$ The 18.15 billion gallon number corresponds to the overall biofuel mandate specified under EISA for 2014.
} 
In a leaked proposal that would significantly scale back biofuel blending requirements next year, the U.S. Environmental Protection Agency (EPA) says the blend wall...is an "important reality"....according to an August 26 draft proposal seen by Reuters, the waiver has enabled the EPA to cut the amount of corn-based ethanol that would be required in 2014 to 13 billion gallons. That is about 6 percent less than this year and well short of the 14.4 billion gallons required under the 2007 law... (Podkul, 2013) [emphasis added]

The article was the first insight into the EPA's coming cuts to the 2014 standard, and revealed that the EPA was considering reducing the overall standard not only below statutory levels, but below the 2013 mandate levels.

The final event is the release of the 2014 Proposed Rule in early November 2013 in which the EPA officially proposed reducing the 2014 biofuel mandates. ${ }^{17}$ In the Rule, the EPA proposed deep cuts to the overall biofuel standard, reducing the overall biofuel mandate 2.94 bgals below the EISA mandates and 1.34 bgals below the 2013 level. The proposed cuts are presented in Table 1.

A number of other events could be included in our analysis. For example, Morgenson and Gebeloff (2013) present a time series of RIN prices in 2013 along with the dates of industry events, congressional hearings, and news articles to highlight the volatility in RIN prices around the events. In this paper, we seek to study policy induced movements in RIN prices. As such, we have chosen a careful set of events that introduced new information from the EPA regarding the future mandates levels.

\subsection{A Test of the Efficiency of RIN Markets}

The presence of incomplete price discovery due to an inefficient or illiquid RIN market would encumber our efforts to estimate RIN price drivers using daily transactions data. Proper reporting of RIN prices may be a concern given that RINs do not trade on a formal exchange and OPIS collects data through daily surveys. In addition, several industry participants have called into question the efficiency of RIN markets (Morgenson and Gebeloff, 2013). To ascertain whether historical RIN prices have acted in a manner consistent with our model, we provide a test of the market's efficiency. A key prediction from Result 1 of our theory model is that for each RIN type and vintage, prices from $t$ to $t+1$ should satisfy:

$$
r_{t}=\beta \mathbb{E}_{t}\left[r_{t+1}\right]
$$

Because we observe daily prices and there is presumably no cost to storing RINs, it is reasonable to assume $\beta \approx 1$. Thus, equation (6) implies the following testable hypothesis:

$$
H_{0}: \mathbb{E}_{t}\left[\mathbf{x}_{t}\left(r_{t+1}-r_{t}\right)\right]=0 .
$$

\footnotetext{
${ }^{17}$ The 2013 RFS2 Final Rule was released on 08/06/2013, the Reuters article was published on 10/11/2013, and the 2014 RFS2 Proposed Rule was released on 11/15/2013. Dates for the Final and Proposed rules were determined by the date the EPA's news releases, which are often published a week or two in advance of the Rules' publication in the Federal Register.
} 
Equation (7) states that in a rational expectations equilibrium, changes in RIN prices from $t$ to $t+1$ should be uncorrelated with variables $\mathbf{x}_{t}$. A key implication, therefore, is that RIN price movements should be unpredictable. Testing equation (7) amounts to a test of market efficiency in the sense of Fama (1965) and the related literature testing various forms of efficient market hypotheses (Lo and MacKinlay, 1988, 1999; Malkiel, 2005). We test equation (7) using an out-of-sample forecasting exercise. For each date $t+1$, we generate a large number of forecasts, each from a model estimated using data up to $t$. Then, we construct a Model Confidence Set (MCS) comparing the forecast models of RIN prices to a random walk forecast using methods developed by Hansen et al. (2011). Here, we discuss the intuition behind the procedure and our findings. Appendix B provides a detailed description of the methods and results.

Given a set of predictors $\mathbf{x}_{t}$ including energy prices, macroeconomic variables, lagged RIN prices, and lagged RIN price changes we construct and evaluate a large number of competing forecasts of RIN prices using various combinations of $\mathbf{x}_{t}$. The MCS procedure identifies the best performing forecast model and estimates the set of models whose performance are statistically indistinguishable from it. Our objective is to evaluate the relative performance of the random walk model to that of all other models. In particular, if the random walk model does not lie in the MCS, there would be cause for concern that RIN price movements have been predictable and that the market is inefficient.

We construct the MCS for each RIN type and vintage, as well as for a number of combined RIN price series. In all cases, the random walk forecast is among the top performing forecasts, and is never excluded from the MCS at conventional confidence levels. For advanced and biodiesel RINs, top competing models in several instances contain lagged differenced RIN prices, suggesting the series may exhibit price drift. The gains from using lagged RIN prices, however, dissipate when evaluating RIN price forecasts from week to week. This suggests there may be timing issues with daily reported RIN prices for advanced and biodiesel, with some reported prices reflecting previous day transaction prices. Alternatively, some of the early markets for advanced and biodiesel RINs may have been relatively illiquid from day to day.

Unpredictability represents a necessary but not sufficient condition for market efficiency. Thus, the test does not address all concerns, particularly those regarding potential manipulation in RIN markets. However, the exercise supports modeling RINs as a random walk, and suggests that the market exhibits proper price discovery. This implies that the event study techniques used in the next section are suitable for our analysis.

\section{$5 \quad$ Event Study Analysis}

In this section, we estimate the effects of the three policy shocks on conventional, advanced, and biodiesel RIN prices. Because the EPA's banking restrictions were binding for early conventional RIN vintages, aggregating RINs across vintage years may induce non-linearities in the series (Smith, 2005). Thus, we study only 2013 
Figure 4: 2013 Vintage RINs

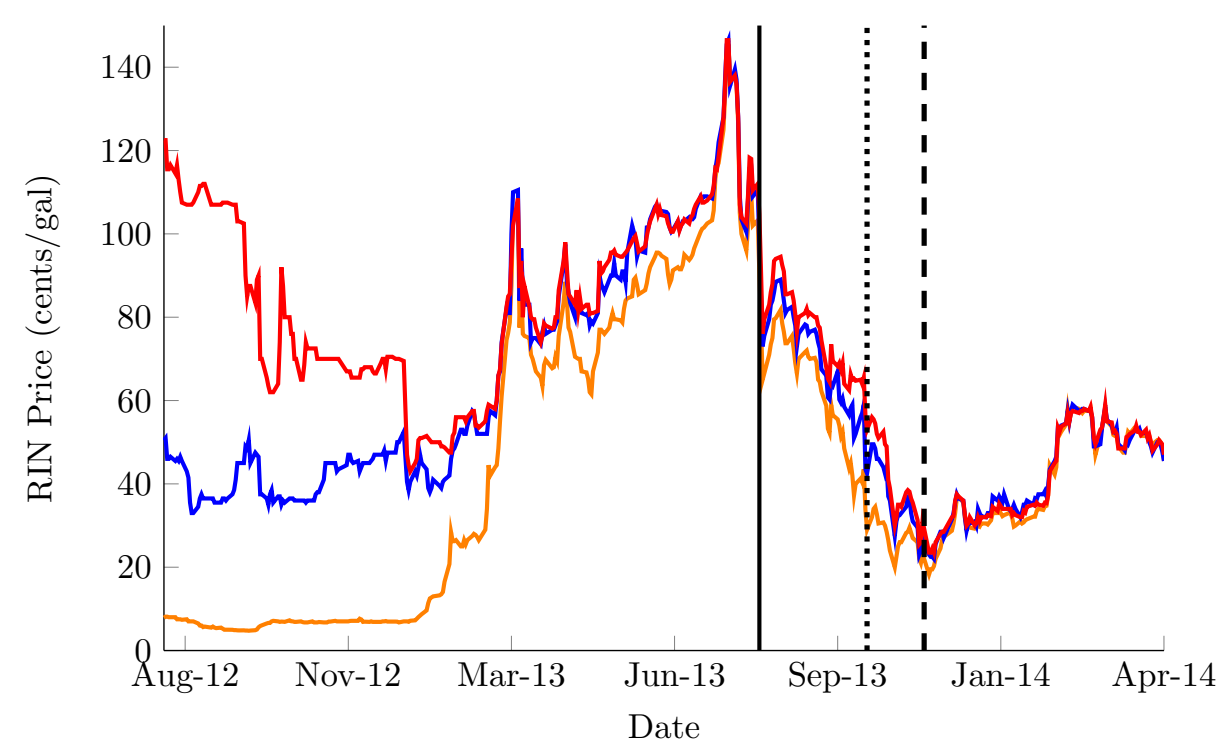

Note: The figure graphs 2013 conventional RIN prices (orange), advanced prices (blue), and biodiesel prices (red). The vertical solid line corresponds to the 2013 Final Rule release date, the dotted line is publication date of the Reuters article, and the dashed line is the 2014 Proposed Rule release date (Source: OPIS).

vintage RINs. For all price series we conduct Dickey-Fuller GLS unit root tests (Elliot et al., 1996). The results are presented in Table 3 . We cannot reject the presence of a unit root for any RIN series, suggesting that prices follow a random walk. ${ }^{18}$ The results are consistent with both our theoretical model and our findings from the Model Confidence Set exercise.

Figure 4 graphs the three series and the timing of the three policy shocks. As can be seen, all series traded prior to the large run-up in conventional RIN prices as well as during the subsequent decreases in prices in the latter half of 2013. On all three event dates, particularly the release of the 2013 Final Rule, all RIN prices appear to have experienced sharp decreases. Below, we explain our strategy to estimate and test whether these movements were attributable to the policy announcements.

\footnotetext{
${ }^{18}$ While price series may be non-stationary, or $\mathrm{I}(1)$, there may exist a stationary linear combination of the series. Cointegration tests using Johansen's trace statistic and the maximum eigenvalue statistic (Johansen, 1995) indicate that there are no cointegrating relationships among any of the RIN or energy price series. In addition, Engle-Granger test statistics (Engle and Granger, 1987) for regressions of each RIN prices series on the energy price series cannot reject the null hypothesis of no cointegration. Thus, we do not have strong evidence supporting cointegration between any of the series in our sample.

${ }^{19}$ Other authors have used similar methods to estimate the effect of policy announcements on stock and commodity markets

(Linn, 2010; Lemoine, 2013; Bushnell et al., 2013). Bielen et al. (2016) use calendar spreads in futures markets for commodities with exchange-traded futures markets to analyze the incidence of the termination of the U.S. ethanol subsidy on December 31 , 2011 on ethanol producers, farmers, oil refiners, blenders, and consumers.
} 
Table 3: Dickey-Fuller GLS Test Results

\begin{tabular}{cccc}
\hline \hline & \multicolumn{4}{c}{ Lags } \\
Price Series & 1 & 5 & 10 \\
\hline \multicolumn{4}{c}{ 2013 RIN Series } \\
Conventional RINs & -0.869 & -1.009 & -1.193 \\
Advanced RINs & -1.545 & -1.468 & -1.455 \\
Biodiesel RINs & -1.819 & -1.659 & -1.560 \\
\hline July 2014 Commodity Futures Series \\
Oil & $-3.048^{*}$ & -2.821 & -2.757 \\
Ethanol & -0.917 & -0.863 & -0.731 \\
Soybean Oil & -2.339 & -2.309 & -2.441 \\
S\&P-GS Commodity Index & $-3.161^{*}$ & $-3.076^{*}$ & $-3.322^{*}$ \\
\hline \hline
\end{tabular}

Note: The table presents DF-GLS test statistics allowing for a time trend (Elliot et al., 1996). 5\% critical values for lags 1, 5 and 10 are $-2.88,-2.87$ and -2.85 , respectively. ${ }^{*}$ denotes significance at $5 \%$.

\subsection{Estimation Strategy}

\subsubsection{RIN Prices}

To estimate the effect of fuel price changes and the three policy shocks on RIN prices, we adopt an event study framework. ${ }^{19}$ Our main specification is given by:

$$
\Delta \log \left(r_{t}\right)=\beta_{0}+\Delta \log \left(x_{t}\right) \beta+\sum_{m=1}^{3} \sum_{s \in S_{m}} \gamma_{m, s} \tau_{t, m, s}+\varepsilon_{t},
$$

where $\Delta \log \left(r_{t}\right)$ are differenced $\log$ RIN prices, $\Delta \log \left(x_{t}\right)$ is a vector of differenced log prices for all energy and commodity market data, $\tau_{t, m, s}$ is an indicator for day $t$ being trading day $s$ of event $m$, and $S_{m}$ is the event window. We estimate equation (8) separately for conventional, advanced, and biodiesel RINs for the period August 2012 to April 2014 to allow the events and energy and feedstock price shocks to have differential impacts on each RIN series. ${ }^{20}$ In traditional event studies of firm stock market prices, normal returns are specified as a mean daily return and a return due to the stock price's co-movement with a market index (MacKinlay, 1997). Motivated by our model in Section 3, we specify normal returns for RINs as a mean daily return $\beta_{0}$ plus returns to due changes in expected future fuel costs $\Delta \log \left(x_{t}\right)$. We construct $x_{t}$ using commodity futures prices for WTI crude oil, ethanol, and soybean oil. In Appendix C we explore specifications using other control variables. ${ }^{21}$

\footnotetext{
${ }^{20}$ We could alternatively estimate a panel regression that pools the $\Delta \log \left(r_{j, t}\right)$ for all RIN types $j$. Estimating equation (8) for each series is equivalent to estimating a panel model and allowing for $\beta_{j}$ and $\gamma_{m, s, j}$ to vary by RIN type. We prefer this more flexible form over more restrictive forms such as assuming $\beta=\beta_{j}$ for each RIN type $j$.

${ }^{21}$ We also estimated specification using spot market prices. Results are not sensitive to the contract used.
} 
Abnormal return estimates $\hat{\gamma}_{m, s}$ correspond to price changes for event $m$ on day $s$ that cannot be explained by changes in commodity and feedstock prices or the estimated average daily return. To see this, note that:

$$
\hat{\gamma}_{m, s}=\Delta \log \left(r_{t}\right)-\hat{\beta}_{0}-\Delta \log \left(x_{t}\right) \hat{\beta}
$$

for all $m$ and $s$. Abnormal returns are attributable to event $m$ so long as no other events outside of movements in $x_{t}$ affected RIN markets on the dates of interest. Because we observe daily RIN prices, the assumption is less restrictive than if we observed low frequency prices. To control for other potential confounding factors, we also estimate specifications that include day of week effects, month of year effects, and control for a flexible polynomial of time. ${ }^{22}$ The latter specification is analogous to a regression discontinuity design with time as the running variable and multiple breaks.

Traditional inference about the hypothesis $H_{0}: \gamma_{m, s}=0$ may be inappropriate in event study settings (Conley and Taber, 2011; Gelbach et al., 2013). Because abnormal returns are estimated based on a single observation, asymptotic arguments do not apply, and t- and F- statistics may exhibit poor size and power properties. As a result, we use the sample quantile (SQ) test proposed by Gelbach et al. (2013) for inference on all estimated abnormal returns. ${ }^{23}$ The test uses the distribution of $\hat{\varepsilon}_{t}$ for all non-event days to estimate empirical critical values from the density of the residuals. As long as the error process is stationary, the distribution of the residuals and empirical critical values will converge to the true null distribution of abnormal returns as $T \rightarrow \infty$.

Because RIN markets may not fully internalize the change in expected future compliance costs on the event day, we also construct cumulative abnormal returns (CARs) for each event by summing abnormal returns over two event window horizons: (i) a two-day event window accounting for abnormal returns for two trading days after each event; and (ii) a five-day event window. CARs for event $m$ over window $S_{m}$ are given by:

$$
\mathrm{CAR}_{m, S_{m}}=\sum_{s \in S_{m}} \hat{\gamma}_{m, s}
$$

Two important factors affect the interpretation of $\hat{\gamma}_{m, s}$ and the estimated CARs. First, if commodity markets were also affected by the events, then $\hat{\gamma}_{m, s}$ estimates returns in addition to adjustments in commodity prices due to the events. Second, $\hat{\gamma}_{m, s}$ estimates unanticipated information that was released from each event. If market participants had a positive prior probability that the events would occur, as they likely did, the estimated impacts of the events are attenuated. In other applications, researchers scale estimated effects using prior probabilities implied by predictive markets (Snowberg et al., 2011). We have no such prior information, so we interpret $\hat{\gamma}_{m, s}$ as the unanticipated information revealed by each event.

\footnotetext{
${ }^{22}$ We use a sixth order polynomial of time. More flexible functions do not change the results.

${ }^{23}$ Similar methods are used by Lemoine (2013) to study commodity market movements after negotiations for a comprehensive climate bill in the U.S. Senate ended unexpectedly.
} 


\subsubsection{Commodity Markets and Biofuel Firm Stock Prices}

The RFS2 is a major source of demand for biofuels and biofuel feedstocks. As such, changes in expected future demand for biofuels likely affect feedstock markets. We test this hypothesis by studying commodity futures markets using a similar estimation strategy as in equation (8) to test for abnormal returns in commodity markets following each event. For all commodity prices except WTI crude oil prices, we specify $\Delta \log \left(x_{t}\right)$ as the S\&P Goldman Sachs (S\&P-GS) Commodity Index, which is traded on the Chicago Mercantile Exchange. The index is composed of over twenty commodity futures, with heavy weights on energy futures contracts. Abnormal return estimates therefore correspond to those returns that cannot be explained by a commodity specific mean daily return as well as corresponding co-movements with the S\&P-GS Commodity Index. Given the importance of the RFS2 in driving demand for biofuel feedstocks, the events may have caused adjustments in multiple markets. To the extent that non-feedstock prices were also affected by the events, our estimates are attenuated. Because crude oil prices constitute a large share of the S\&P-GS commodity index, we specify normal returns for WTI contracts as those due to a mean daily return and co-movement with the Russell 3000 stock market index.

In addition, we test for abnormal stock market returns in the stock prices of publicly traded biofuel companies. We specify normal returns as a firm specific mean daily return and the covariance of the firm's returns with a broad market index, the Russell 3000. We estimate a joint model of average abnormal returns for biofuel firms and allow for differential effects for advanced, biodiesel, and cellulosic biofuel firms. The estimated equation is:

$$
\Delta \log \left(R_{i t}\right)=\beta_{0 i}+\Delta \log \left(x_{i t}\right) \beta+\mathbf{1}_{\kappa} \sum_{m=1}^{3} \sum_{s \in S_{m}} \gamma_{m, s} \tau_{i, t, m, s}+\varepsilon_{i t},
$$

where $i$ denotes the firm, $\Delta \log \left(R_{i t}\right)$ are differenced log stock prices, $\Delta \log \left(x_{i t}\right)$ are differenced $\log$ prices for the stock market index, $\tau_{i, t, m, s}$ are indicators for day $t$ being trading day $s$ of event $m$ for firm $i$, and $\mathbf{1}_{\kappa}$ is an indicator equal to one if firm $i$ produces or has large investments in biofuel category $\kappa$. In our regressions, $\kappa$ includes conventional, advanced, and biodiesel producers. For both commodity returns and stock returns, we include specifications using flexible time controls as in our RIN price regressions.

\subsection{Results: RIN Returns}

Table 4 presents the estimation results for 2013 conventional, advanced, and biodiesel RINs. All standard errors for normal returns are Newey-West standard errors allowing for arbitrary autocorrelation up to five lags. No normal returns are statistically significant, however, the sign of all point estimates are consistent with the theoretical model. The estimates suggest a one percent increase in WTI prices decrease RIN prices between $0.3 \%$ and $0.46 \%$, a one percent increase in ethanol prices increases RIN prices by $0.02 \%$ to $0.25 \%$, 
Table 4: Regression Results - Dependent Variable: Log 2013 RIN Price Changes

\begin{tabular}{|c|c|c|c|c|c|c|c|}
\hline & & \multicolumn{2}{|c|}{ Conventional RINs } & \multicolumn{2}{|c|}{ Advanced RINs } & \multicolumn{2}{|c|}{ Biodiesel RINs } \\
\hline & & (1) & $(2)$ & $(1)$ & $(2)$ & $(1)$ & $(2)$ \\
\hline \multicolumn{8}{|l|}{ Normal Returns } \\
\hline \multirow[t]{2}{*}{ Oil Futures } & & -0.460 & -0.455 & -0.361 & -0.340 & -0.313 & -0.294 \\
\hline & & $(0.369)$ & $(0.364)$ & $(0.345)$ & $(0.352)$ & $(0.342)$ & $(0.351)$ \\
\hline \multirow[t]{2}{*}{ Ethanol Futures } & & 0.259 & 0.202 & 0.084 & 0.025 & 0.226 & 0.153 \\
\hline & & $(0.219)$ & $(0.228)$ & $(0.276)$ & $(0.278)$ & $(0.248)$ & $(0.250)$ \\
\hline \multirow[t]{2}{*}{ Soybean Oil Futures } & & 0.569 & 0.602 & 0.218 & 0.280 & 0.664 & 0.677 \\
\hline & & $(0.336)$ & $(0.351)$ & $(0.399)$ & $(0.405)$ & $(0.390)$ & $(0.402)$ \\
\hline \multirow[t]{2}{*}{ Constant } & & 0.006 & 0.069 & 0.001 & -0.031 & -0.001 & -0.006 \\
\hline & & $(0.004)$ & $(0.043)$ & $(0.003)$ & $(0.037)$ & $(0.003)$ & $(0.037)$ \\
\hline Abnormal Returns & Day & & & & & & \\
\hline \multirow[t]{6}{*}{2013 Final Rule } & 0 & $-0.136^{* *}$ & $-0.113^{* *}$ & $-0.131^{*}$ & $-0.113^{*}$ & -0.061 & -0.053 \\
\hline & 1 & $-0.142^{* *}$ & $-0.125^{* *}$ & $-0.131^{*}$ & $-0.116^{*}$ & $-0.133^{* *}$ & $-0.127^{* *}$ \\
\hline & 2 & $-0.197^{* *}$ & $-0.173^{* *}$ & $-0.155^{* *}$ & $-0.131^{*}$ & $-0.181^{* *}$ & $-0.163^{* *}$ \\
\hline & 3 & 0.030 & 0.051 & 0.038 & 0.055 & 0.057 & 0.066 \\
\hline & 4 & 0.050 & 0.067 & 0.047 & 0.058 & 0.030 & 0.045 \\
\hline & 5 & 0.031 & 0.060 & 0.043 & 0.063 & 0.037 & 0.047 \\
\hline \multirow[t]{6}{*}{ Reuters Article } & 0 & $-0.144^{* *}$ & $-0.135^{* *}$ & -0.019 & 0.013 & -0.047 & -0.034 \\
\hline & 1 & 0.091 & 0.096 & 0.151 & 0.177 & 0.053 & 0.070 \\
\hline & 2 & 0.046 & 0.061 & -0.004 & 0.030 & -0.017 & -0.002 \\
\hline & 3 & 0.001 & 0.010 & -0.023 & 0.008 & -0.029 & -0.016 \\
\hline & 4 & -0.060 & -0.045 & -0.057 & -0.018 & -0.046 & -0.024 \\
\hline & 5 & $-0.083^{*}$ & -0.071 & -0.003 & 0.028 & -0.027 & -0.012 \\
\hline \multirow[t]{6}{*}{2014 Proposed Rule } & 0 & -0.042 & -0.020 & -0.035 & -0.025 & -0.047 & -0.045 \\
\hline & 1 & $-0.193^{* *}$ & $-0.177^{* *}$ & $-0.124^{*}$ & $-0.121^{*}$ & $-0.216^{* *}$ & $-0.211^{* *}$ \\
\hline & 2 & 0.061 & 0.088 & -0.022 & -0.011 & 0.002 & 0.004 \\
\hline & 3 & -0.015 & 0.004 & -0.003 & 0.005 & 0.032 & 0.033 \\
\hline & 4 & 0.019 & 0.046 & -0.027 & -0.011 & -0.059 & -0.047 \\
\hline & 5 & 0.083 & 0.104 & 0.149 & 0.155 & 0.108 & 0.110 \\
\hline Flexible Time Controls & & No & Yes & No & Yes & No & Yes \\
\hline $\mathrm{N}$ & & 422 & 422 & 422 & 422 & 422 & 422 \\
\hline SQ 5\% Critical Values & & -0.0786 & -0.0804 & -0.0997 & -0.0935 & -0.0682 & -0.0722 \\
\hline SQ 1\% Critical Values & & -0.1001 & -0.0999 & -0.1412 & -0.1374 & -0.1309 & -0.124 \\
\hline
\end{tabular}

Note: Standard errors in parentheses are Newey-West errors with 5 lags. Inference for abnormal returns are based on SQ critical values. The lower tail SQ critical values are given at the bottom of the table. Stars denote significance with ${ }^{*} \mathrm{p}<0.05$ and ${ }^{* *} \mathrm{p}<0.01$. 
Figure 5: RIN Cumulative Abnormal Returns

(a) 2013 Final Rule Release

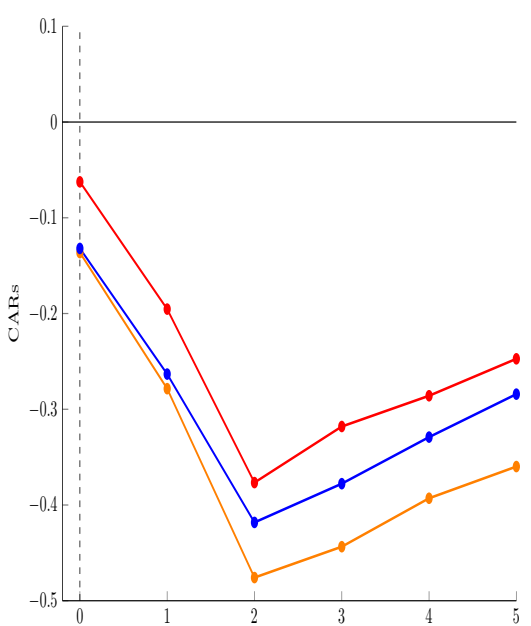

(b) Reuters Article

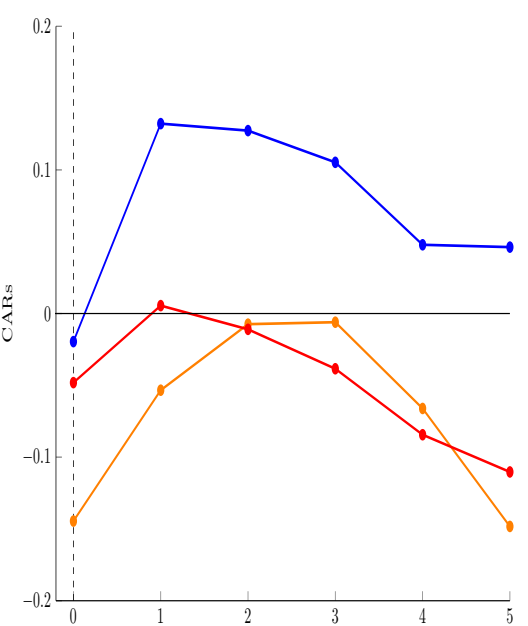

(c) 2014 Proposed Rule Release

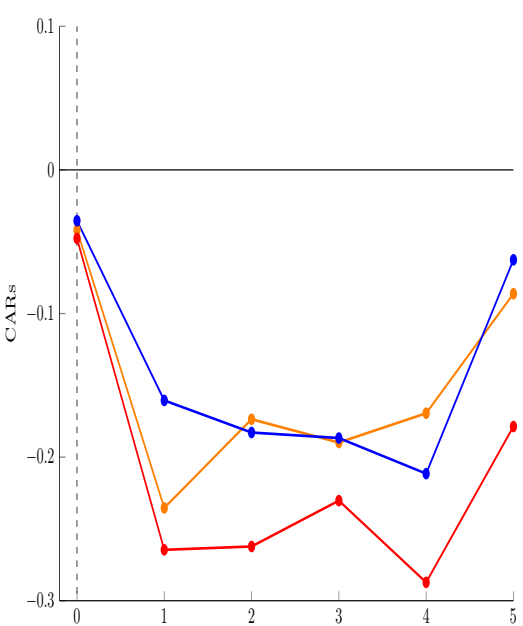

Note: The figure graphs cumulative abnormal returns (CARs) for conventional RINs in orange, advanced RINs in blue, and biodiesel RINs in red. The event day is normalized to day 0 .

and a one percent increase in soybean oil prices increases RINs between $0.22 \%$ and $0.66 \%$. The results suggest little variation in RIN prices over the sample period was due to movements in commodity markets, which were relatively stable in 2013 .

Abnormal return estimates are large and significant for all three series around the events, particularly following the release of the 2013 Final Rule. The day the 2013 Final Rule was released, conventional, advanced, and biodiesel RINs experienced around a 14\%, 13\%, and 6\% abnormal loss, respectively. Abnormal returns on the day the Rueters article was released were similar in magnitude as after the release of the Final Rule for conventional RINs; however, the returns are mostly positive and statistically insignificant on subsequent days. Advanced and biodiesel RINs did not experience significant abnormal returns following the release of the Reuters article. Abnormal returns around the 2014 Proposed Rule were small and statistically insignificant on the day the Rule was released; however, all series experienced large and significant abnormal losses on the second trading day after the Rule's release. The delay in the response to the 2014 Proposed Rule was likely because the Rule was released on a Friday afternoon.

Figure 5 graphs the cumulative abnormal returns (CARs) for each series following each event. Within two trading days after the release of the 2013 Final Rule, conventional RIN prices lost nearly $50 \%$ of their value, and advanced and biodiesel RIN prices fell between 35\% and 40\%. CARs recover slightly over a five-day window, with cumulative losses ranging from $18 \%$ to $36 \%$ across the series. CARs are more varied following the Reuters article and 2014 Proposed Rule. Following the Reuters article, conventional RIN prices decreased initially, recovered over a two-day horizon, and fell again over five days. Biodiesel RINs followed 
Table 5: Change in Value of the 2013 Renewable Volume Obligation

\begin{tabular}{lccc}
\hline \hline Event & Event Window & $\Delta$ in 2013 RVO Value $(\$$ bil $)$ & $95 \%$ Confidence Interval \\
\hline \multirow{2}{*}{2013 Final Rule } & Event Day & $-\$ 2.19^{* *}$ & {$[-\$ 2.40,-\$ 1.97]$} \\
& 2 Day & $-\$ 7.96^{* *}$ & {$[-\$ 8.49,-\$ 7.43]$} \\
\multirow{2}{*}{ Reuters Article } & 5 Day & $-\$ 5.99^{* *}$ & {$[-\$ 6.87,-\$ 5.12]$} \\
& Event Day & $-\$ 0.73^{* *}$ & {$[-\$ 0.83,-\$ 0.63]$} \\
2014 Proposed Rule & 2 Day & $\$ 0.001$ & {$[-\$ 0.14, \$ 0.15]$} \\
& 5 Day & $-\$ 0.80^{* *}$ & {$[-\$ 1.08,-\$ 0.52]$} \\
& Event Day & $-\$ 0.17^{* *}$ & {$[-\$ 0.22,-\$ 0.12]$} \\
& 2 Day & $-\$ 0.75^{* *}$ & {$[-\$ 0.86,-\$ 0.63]$} \\
\hline \hline
\end{tabular}

Note: The table presents the change in the value of the 2013 Renewable Volume Obligation (RVO) due to each event.

a similar trajectory. Advanced RIN prices do not appear to have been affected by the release of the Reuters article. Following the release of the Proposed Rule, all RIN categories followed a similar trajectory initially, losing approximately $30 \%$ over two trading days before slightly recovering over a five-day horizon.

One way to quantify the impact of the estimated abnormal returns is to calculate the implied change in the value of the subsidy (tax) provided by the program for the biofuel (fossil fuel) industry in 2013. This equals the value of the 2013 Renewable Volume Obligation (RVO). ${ }^{24}$ Applying Result 2 of our theory model to estimate the RVO value, we multiply the 2013 mandate volumes by the abnormal return estimates for each event. Results are presented in Table $5 .^{25}$

Given the high initial RIN prices in August 2013 and large abnormal returns, the largest losses occur after the 2013 Final Rule was released. On the day the 2013 Final Rule was released, the estimated abnormal return corresponds to a decrease in the value of the 2013 RVO between $\$ 1.97$ and $\$ 2.4$ billion. Within the two subsequent trading days, the losses increase to between $\$ 7.4$ and $\$ 8.5$ billion. Losses are smaller following the release of the Reuters article and 2014 Proposed Rule. Event day losses following the publication of the Reuters article are significant and on the order of $\$ 600$ to $\$ 830$ million. Cumulative losses recover over a two-day horizon, but fall over a longer event horizon. Following the release of the 2014 Final Rule, event day loss estimates range between $\$ 120$ and $\$ 215$ million, and increase over a two- and five-day horizon. To give a sense of magnitude of the losses, nameplate capacity construction costs for a typical Iowa ethanol

${ }^{24}$ The RVO is given by the right-hand side of equation (1) summed over all firms for each fuel type.

${ }^{25}$ To calculate the change in the value of the RVO and corresponding standard errors, we estimate a fully interacted panel analogue of equation (8) so that estimates correspond to those in specification (1) for each RIN type. We cluster standard errors at the month to allow for arbitrary serial correlation and correlation across RIN types. For each event and horizon, we convert the abnormal return estimates to $\$ /$ gal and multiply the value by the 2013 mandate volumes for each biofuel type. The mandated biofuel volumes for 2013 were 13.8 bgals, 0.83 bgals, and 1.92 bgals for conventional biofuel, advanced biofuel, and biodiesel, respectively. 
and biodiesel plant are around $\$ 2 /$ gal (Hofstrand, 2012). Thus, the cumulative five day losses following the release of the 2013 Final Rule could have been used to increase biofuel production capacity between $14 \%$ and 20\% (Nebraska Energy Office, 2014; Biodiesel Magazine, 2015).

\subsection{Results: Commodity and Biofuel Stock Returns}

Table 6 presents abnormal return estimates and SQ critical values for WTI crude oil, ethanol, soybean oil, corn, and sugar futures contracts. Overall, little movement is observed in commodity markets around the events. Few abnormal return estimates in each event window are statistically significant, and most significant returns occur several days after the events and are therefore unlikely to be attributable to our events.

The one exception occurs in soybean oil markets on the day the Reuters article was published, where we estimate a statistically significant abnormal loss of $-1.9 \%$. Appendix $\mathrm{C}$ demonstrates that the abnormal losses were observed across all soybean oil futures contracts trading at the time. The loss can be rationalized by recalling that the Reuters article revealed for the first time that the overall biofuel mandate would be set below 2013 levels, and therefore safely below the blend wall. Before the release of the 2013 Final Rule, the convergence in RIN prices across biofuel types indicated that biodiesel was the marginal compliance fuel for the overall biofuel mandate (Irwin, 2014a,b). As a result, reducing the 2014 mandates below the blend wall effectively served as a negative demand shock to biodiesel.

We also estimate abnormal and cumulative abnormal returns for the 12 publicly traded biofuel producers listed in Table $7 .{ }^{26}$ Each firm is classified as a producer or investor in conventional ethanol, advanced ethanol, or biodiesel based on publicly available firm profiles. We estimate equation (9) using indicators for each category. Abnormal return estimates therefore correspond to average abnormal returns for all companies within a given category. Table 8 summarizes the abnormal and cumulative abnormal return estimates, and presents p-values for a $\mathrm{F}$ test of $H_{0}: \sum_{s \in S} \gamma_{m, s}=0$ for each event $m$ and event window $S$. Separate event study estimates by firm are presented in Appendix C.

Conventional ethanol producers did not experience significant abnormal returns following any of the three events. Advanced biofuel producers, however, experienced large, statistically significant losses on the order of $3 \%$ to $12 \%$ following the release of the 2013 Final Rule, and small but insignificant losses following the release of the Reuters article. Biodiesel producers experienced small, insignificant abnormal losses following the release of the 2013 Final Rule that recover over two- and five-day horizons. Event day losses following the release of the Reuters article, however, are on the order of $1 \%$ to $1.2 \%$ and are statistically significant. The losses increase over longer horizons to approximately $2 \%$ on average, but are statistically insignificant. The results are consistent with our findings in soybean oil markets, suggesting that the revelation that the mandates would be below the blend wall caused an adverse demand shock to biodiesel markets.

\footnotetext{
${ }^{26}$ There are more biofuel producers in the U.S., however, many are privately owned.
} 
Table 6: Commodity Market Abnormal Return Estimates

\begin{tabular}{|c|c|c|c|c|c|c|c|c|c|c|c|}
\hline & \multirow{2}{*}{ Day } & \multicolumn{2}{|c|}{ WTI Crude } & \multicolumn{2}{|c|}{ Ethanol } & \multicolumn{2}{|c|}{ Soybean Oil } & \multicolumn{2}{|c|}{ Corn } & \multicolumn{2}{|c|}{ Sugar } \\
\hline & & (1) & (2) & (1) & (2) & (1) & (2) & (1) & (2) & (1) & (2) \\
\hline \multirow[t]{6}{*}{2013 Final Rule } & 0 & -0.006 & -0.009 & 0.006 & 0.003 & -0.008 & -0.011 & 0.000 & -0.004 & 0.001 & 0.001 \\
\hline & 1 & -0.002 & -0.004 & -0.008 & -0.009 & -0.007 & -0.010 & -0.000 & -0.003 & 0.016 & 0.017 \\
\hline & 2 & -0.008 & -0.012 & 0.002 & 0.002 & 0.001 & -0.001 & 0.007 & 0.006 & -0.001 & -0.001 \\
\hline & 3 & 0.012 & 0.009 & $-0.036^{* *}$ & $-0.040^{* *}$ & -0.007 & -0.008 & -0.015 & -0.017 & 0.006 & 0.005 \\
\hline & 4 & 0.006 & 0.002 & 0.000 & -0.003 & 0.017 & 0.016 & 0.019 & 0.015 & 0.004 & 0.004 \\
\hline & 5 & 0.005 & 0.003 & -0.019 & -0.021 & 0.005 & 0.002 & $-0.033^{*}$ & $-0.037^{*}$ & 0.002 & 0.003 \\
\hline \multirow[t]{6}{*}{ Reuters Article } & 0 & -0.006 & -0.006 & -0.008 & -0.010 & $-0.019^{*}$ & $-0.017^{*}$ & -0.009 & -0.007 & 0.011 & 0.011 \\
\hline & 1 & 0.000 & 0.000 & 0.001 & -0.001 & 0.003 & 0.004 & 0.007 & 0.006 & 0.005 & 0.006 \\
\hline & 2 & -0.002 & -0.001 & 0.012 & 0.011 & 0.009 & 0.008 & 0.016 & 0.015 & -0.015 & -0.013 \\
\hline & 3 & 0.003 & 0.005 & 0.007 & 0.007 & 0.015 & 0.014 & -0.004 & -0.003 & 0.012 & 0.015 \\
\hline & 4 & $-0.019^{*}$ & $-0.019^{*}$ & -0.007 & -0.006 & -0.001 & -0.001 & 0.003 & 0.007 & 0.002 & 0.003 \\
\hline & 5 & 0.002 & 0.003 & -0.002 & -0.004 & 0.012 & 0.013 & -0.004 & -0.001 & 0.014 & 0.014 \\
\hline \multirow[t]{6}{*}{2014 Proposed Rule } & 0 & -0.003 & -0.003 & -0.006 & -0.008 & -0.013 & -0.011 & -0.014 & -0.013 & -0.000 & 0.000 \\
\hline & 1 & -0.007 & -0.007 & 0.004 & 0.003 & -0.007 & -0.004 & -0.020 & -0.021 & 0.009 & 0.010 \\
\hline & 2 & -0.000 & 0.001 & -0.001 & -0.002 & -0.001 & -0.001 & 0.013 & 0.011 & -0.001 & 0.000 \\
\hline & 3 & 0.003 & 0.005 & $0.026^{*}$ & $0.026^{*}$ & 0.007 & 0.007 & -0.004 & -0.004 & 0.003 & 0.005 \\
\hline & 4 & 0.010 & 0.009 & 0.004 & 0.006 & $0.024^{*}$ & $0.025^{*}$ & 0.007 & 0.009 & -0.001 & 0.000 \\
\hline & 5 & -0.004 & -0.004 & -0.012 & -0.014 & -0.007 & -0.006 & -0.001 & 0.001 & -0.006 & -0.006 \\
\hline Flexible Time Controls & & No & Yes & No & Yes & No & Yes & No & Yes & No & Yes \\
\hline $\mathrm{N}$ & & 422 & 422 & 422 & 422 & 422 & 422 & 422 & 422 & 422 & 422 \\
\hline \multicolumn{12}{|c|}{ Sample Quantile Critical Values } \\
\hline \multirow[t]{2}{*}{$95 \%$} & Lower & -0.018 & -0.019 & -0.021 & -0.023 & -0.016 & -0.015 & -0.024 & -0.026 & -0.018 & -0.018 \\
\hline & Upper & 0.017 & 0.017 & 0.023 & 0.023 & 0.019 & 0.018 & 0.024 & 0.024 & 0.022 & 0.020 \\
\hline \multirow[t]{2}{*}{$99 \%$} & Lower & -0.030 & -0.028 & -0.030 & -0.029 & -0.021 & -0.021 & -0.041 & -0.038 & -0.027 & -0.027 \\
\hline & Upper & 0.024 & 0.025 & 0.033 & 0.032 & 0.030 & 0.027 & 0.049 & 0.047 & 0.027 & 0.026 \\
\hline
\end{tabular}

Note: SQ test critical values are estimated from the empirical residual distribution. Abnormal returns represent those that cannot be explained by corresponding movements in the S\&P-GS Commodity Index, or in the case of WTI crude, the Russell 3000 Index, and a daily mean return. * denotes the hypothesis is rejected at the $5 \%$ empirical critical value and ${ }^{* *}$ denotes the hypothesis is rejected at the $1 \%$ empirical critical value. 
Table 7: Biofuel Producers and Categories

\begin{tabular}{lll}
\hline \hline Firm & Ticker & Categories \\
\hline Archer Daniels Midland & ADM & Conventional, Biodiesel \\
Andersons Inc. & ANDE & Conventional \\
Cosan, Ltd. & CZZ & Advanced \\
FutureFuel Corp & FF & Biodiesel \\
Gevo, Inc. & GEVO & Advanced \\
Green Plains Renewable Energy & GPRE & Conventional \\
Methes Energies International & MEIL & Biodiesel \\
Neste Oil & NTOIY & Biodiesel \\
Pacific Ethanol & PEIX & Conventional, Advanced \\
Renewable Energy Group, Inc. & REGI & Biodiesel \\
Solazyme, Inc. & SZYM & Biodiesel \\
\hline \hline
\end{tabular}

Note: Categories reflect whether firms either produce or have significant investments in a particular advanced biofuel category. If a firm has no assigned category, the firm predominantly produces conventional corn-based ethanol.

The findings suggest that the incidence of the cuts to the RFS2 mandates by the EPA fell disproportionately on producers of advanced biofuels and firms that produce the marginal compliance fuel, biodiesel. The results suggest that the events undermined the policy, which in future years relies heavily on the development of a viable and large advanced biofuel industry (Figure 1a).

\section{Conclusions}

We provide a comprehensive study of compliance credit prices from a relatively new market-based policy. Our dynamic model of compliance with the RFS2 demonstrates the potential effects of changes in policy expectations on the price of compliance credits.

The three policy shocks in 2013 affected RIN markets in a number of ways. First, the events led to sudden and unexpectedly large decreases in the expected future stringency of the RFS2 mandates. In addition, the announcements increased uncertainty regarding future RFS2 compliance schedules. The findings here imply that the events caused large shifts in the value that the policy provides to the U.S. biofuel industry, and we estimate large impacts of the events on both the RIN market and related markets. In particular, we find evidence that the events adversely affected advanced biofuel firms and commodity markets of the marginal compliance fuel, namely biodiesel and soybean oil. 
Table 8: Cumulative Abnormal Returns: Biofuel Companies

\begin{tabular}{|c|c|c|c|c|c|c|c|}
\hline & & \multicolumn{2}{|c|}{ Conventional Producers } & \multicolumn{2}{|c|}{ Advanced Producers } & \multicolumn{2}{|c|}{ Biodiesel Producers } \\
\hline & & (1) & (2) & (1) & (2) & (1) & (2) \\
\hline \multirow{6}{*}{2013 Final Rule } & Event Day & -0.0032 & -0.0081 & $-0.0247^{*}$ & $-0.0317^{*}$ & -0.0038 & -0.0115 \\
\hline & & $(0.7059)$ & $(0.3848)$ & $(0.0185)$ & $(0.0116)$ & $(0.7572)$ & $(0.4319)$ \\
\hline & 2 Day & 0.0030 & -0.0075 & $-0.0706^{*}$ & $-0.0853^{* *}$ & 0.0157 & -0.0007 \\
\hline & & $(0.9047)$ & $(0.7414)$ & $(0.0109)$ & $(0.0055)$ & $(0.5939)$ & $(0.9836)$ \\
\hline & 5 Day & 0.0068 & -0.0135 & $-0.0941^{*}$ & $-0.1223^{* *}$ & 0.0332 & 0.0017 \\
\hline & & $(0.8696)$ & $(0.7155)$ & $(0.0117)$ & $(0.0065)$ & $(0.3308)$ & $(0.9692)$ \\
\hline \multirow{6}{*}{ Reuters Article } & Event Day & -0.0045 & -0.0024 & -0.0055 & -0.0026 & $-0.0122^{* *}$ & $-0.0090^{*}$ \\
\hline & & $(0.5610)$ & $(0.7585)$ & $(0.5143)$ & $(0.7390)$ & $(0.0084)$ & $(0.0184)$ \\
\hline & 2 Day & -0.0073 & -0.0023 & -0.0045 & 0.0025 & -0.0287 & -0.0208 \\
\hline & & $(0.5621)$ & $(0.8455)$ & $(0.7916)$ & $(0.8933)$ & $(0.1426)$ & $(0.3368)$ \\
\hline & 5 Day & -0.0253 & -0.0135 & -0.0311 & -0.0145 & -0.0213 & -0.0028 \\
\hline & & $(0.2445)$ & $(0.5087)$ & $(0.3047)$ & $(0.6292)$ & $(0.1373)$ & $(0.8154)$ \\
\hline \multirow{6}{*}{2014 Proposed Rule } & Event Day & -0.0225 & -0.0206 & 0.1211 & 0.1238 & -0.0057 & -0.0028 \\
\hline & & $(0.2543)$ & $(0.3138)$ & $(0.0952)$ & $(0.0910)$ & $(0.7021)$ & $(0.8570)$ \\
\hline & 2 Day & -0.0435 & -0.0393 & 0.0465 & 0.0523 & -0.0462 & -0.0398 \\
\hline & & $(0.2154)$ & $(0.2498)$ & $(0.1273)$ & $(0.1084)$ & $(0.2713)$ & $(0.3931)$ \\
\hline & 5 Day & 0.0425 & 0.0517 & 0.0963 & 0.1091 & -0.0682 & -0.0540 \\
\hline & & $(0.2629)$ & $(0.2260)$ & $(0.1144)$ & $(0.1132)$ & $(0.1240)$ & $(0.3107)$ \\
\hline Flexible Time Controls? & & No & Yes & No & Yes & No & Yes \\
\hline $\mathrm{N}$ & & 3685 & 3685 & 3685 & 3685 & 3685 & 3685 \\
\hline
\end{tabular}

Note: Stars denote significance with ${ }^{*} \mathrm{p}<0.05$ and ${ }^{* *} \mathrm{p}<0.01$. Abnormal return $\mathrm{p}$-values in parentheses are computed for the $\mathrm{F}$ test with 10 degrees of freedom of $H_{0}: \sum_{s \in S} \gamma_{m, s}=0$ for each event $m$ and event window $S$. Model (1) estimates normal returns as a mean constant return and those due to returns in the aggregate stock market index. Model (2) includes flexible time controls. 
The findings suggest that compliance with the RFS2 in 2013 was relatively inexpensive up to a $10 \%$ gasoline-ethanol blend, after which marginal costs increased sharply. Figure 6 graphs a hypothetical marginal compliance cost curve in this spirit. In the Figure, until the RFS2 standard reaches 10\%, marginal compliance costs are below $\$ 0.10 /$ gal, and the industry complies with the overall biofuel standard by increasing blending of conventional corn ethanol. As the standard moves beyond $10 \%$, the marginal fuel is biodiesel, which is costlier to produce due to both higher feedstock costs. Beyond a $12 \%$ standard, marginal compliance costs increase sharply and the industry complies by increasing sales of high-blend ethanol and biodiesel. In this setting, market expectations as to whether the mandates will exceed $10 \%$ have important impacts on RIN prices as well as the demand for advanced biofuels. The figure highlights that, for fuel markets, a rate standard is likely to be more efficient than a volumetric standard. The marginal compliance cost curve becomes steep not at a particular volume but at the blend rate of $10 \%$. A volume standard would potentially generate more volatile RIN prices as changes in fuel demand would cause movements along the steep part of the marginal compliance cost curve even without changes in mandated renewable fuel volumes.

As currently designed, the RFS2 left the EPA with few options with which it could respond to high RIN prices other than to reduce the statutory mandates. Our findings suggest that the RFS2 would benefit from alternative policy designs aimed specifically at addressing high compliance costs. For example, the regulation could institute a non-compliance penalty, or make 'paper' compliance credits available through an open credit window at a known price. Both mechanisms would allow the EPA to ensure compliance costs do not exceed levels deemed excessive by the regulator or policymakers. Roberts and Spence (1976) first proposed such a mechanism whereby a regulator supplements a tradable permit program with a fixed abatement subsidy and non-compliance penalty. Such hybrid policies ensure compliance costs remain in a given range, and the authors argue that the mechanism reduces the expected social cost of a policy when a regulator is uncertain about a policy's costs and benefits. Similar hybrid policies have since been studied by several authors who find that the mechanisms have desirable efficiency properties, particularly when quantity mechanisms are politically favored over price mechanisms (Pizer, 2002; Newell et al., 2005; Burtraw et al., 2010; Lade and Lin Lawell, 2015a).

The motivations for including price-stability mechanisms in fuel mandates differs from those typically used to justify such provisions under cap and trade programs. Programs such as the European Union Emissions Trading Scheme and the EPA's $\mathrm{SO}_{2}$ trading program have historically been most concerned with price variability as it relates to prices collapsing due to overallocation of permits (Hintermann, 2010; Fell, 2015). ${ }^{27}$ In contrast, we highlight that quantity-based mechanisms under fuel mandates leave policies susceptible to large increases in current compliance costs because of expected future technological and economic constraints that limit the feasibility of substantially increasing renewable energy production. A price stability mechanism

\footnotetext{
${ }^{27}$ One similarity is found in the market for sulfur dioxide allowances under the U.S. Acid Rain Program. Hitaj and Stocking (2016) show that regulatory announcements led to significant increases in volatility in the market for tradable allowances under the policy, and call for a more coherent communication policy for regulators enforcing such market-based mechanisms.
} 
Figure 6: Hypothetical Marginal Compliance Curve

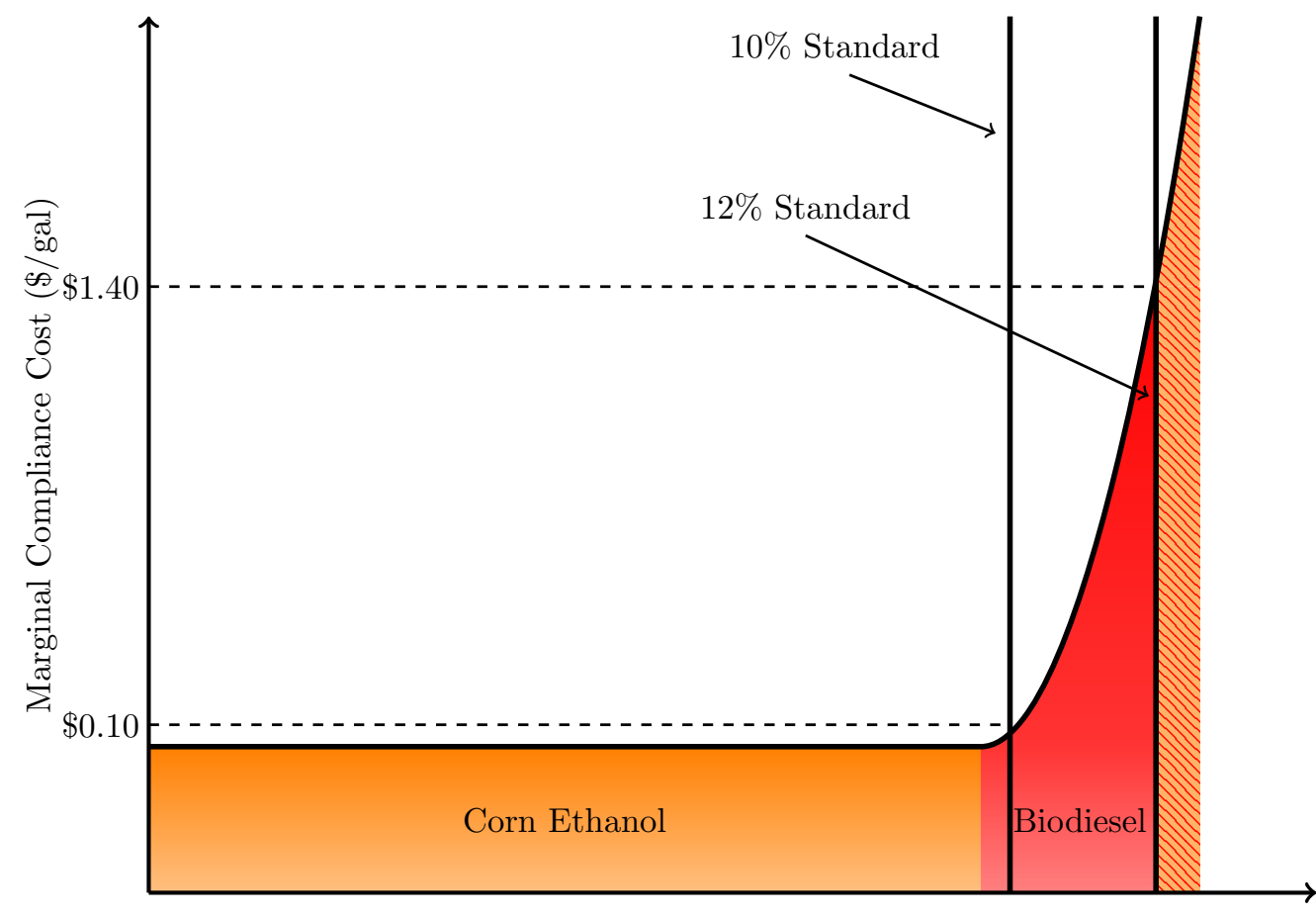

RFS Standard

Note: The figure graphs a hypothetical short-run marginal compliance cost curve for the RFS2 consistent with observed movements in the market in 2013. Above a $10 \%$ standard, the industry must move to more costly compliance options, increasing biodiesel production. Beyond a $12 \%$ standard, the industry must move to high-blend ethanol and biodiesel.

that acted like a price ceiling on compliance credits would retain the incentive for firms to invest in developing the new technologies required for future compliance.

The findings are important and have implications for policies beyond RFS2. Numerous policies currently in place and being proposed in the U.S. and abroad share many features with the RFS2. For example, several states have passed low carbon fuel standards and renewable portfolio standards that require large increases in the share of low carbon fuel and renewable electricity, respectively (National Low Carbon Fuel Standard Project, 2012; Department of Energy, 2015). In addition, the EPA's proposed Clean Power Plan requires states to institute either a mass-based or rate-based carbon emissions standard for fossil-fuel fired electric generation plants (Environmental Protection Agency, 2015a). Rate-based standards and low carbon fuel standards have similar market effects as fuel mandates (Holland et al., 2009). Given important capacity and production constraints that are inherent in energy markets, these policies will likely face similar challenges as those faced by the EPA in 2013. As such, anticipating these issues and designing the policies in a manner that allows the regulator to better address the issues highlighted in this work is imperative. 


\section{References}

Adler, K., R. Gantz, S. Kelly, M. Schneider, and R. Gough (2014). Cellulosic Biofuel Producers. November 2014. Accessed July 17, 2015. http://www.opisnet.com/Cellulosic2014.pdf.

Anderson, S. (2012). The Demand for Ethanol as a Gasoline Substitute. Journal of Environmental Economics and Management 63(2), 151-168.

Babcock, B. (2012). Outlook for Ethanol and Conventional Biofuel RINs in 2013 and 2014. CARD Policy Brief 12-PB 9.

Babcock, B. and S. Pouliot (2013). Price It and They Will Buy: How E85 Can Break the Blend Wall. CARD Policy Brief 13-PB 11.

Bento, A., R. Klotz, and J. Landry (2014). Are There Carbon Savings from US Biofuel Policies? The Critical Importance of Accounting for Leakage in Land and Fuel Markets. Energy Journal 36(3), 75-109.

Bielen, D. A., R. G. Newell, and W. A. Pizer (2016). Who Did the Ethanol Tax Credit Benefit? An Event Analysis of Subsidy Incidence. NBER Working Paper 13510.

Biodiesel Magazine (2015). Existing USA Biodiesel Plants. July 2, 2015. Accessed July 17, 2015. http: //www.biodieselmagazine.com/plants/listplants/USA/.

Burtraw, D., K. Palmer, and D. Kahn (2010). A Symmetric Safety Valve. Energy Policy 38(9), 4921-4932.

Bushnell, J., H. Chong, and E. Mansur (2013). Profiting from Regulation: An Event Study of the EU Carbon Market. American Economic Journal: Economic Policy 5(4), 78-106.

Carter, C., G. Rausser, and A. Smith (2016). Commodity storage and the market effects of biofuel policies. American Journal of Agricultural Economics, Forthcoming.

Clancy, M. and G. Moschini (2015). Mandates and the Incentive for Environmental Innovation. CARD Working Paper 15-WP 557.

Coase, R. (1960). The Problem of Social Cost. Journal of Law and Economics, 3, 1-44.

Conley, T. and C. Taber (2011). Inference with "Difference-in-Diifferences" with a Small Number of Policy Changes. Review of Economics and Statistics 93(1), 113-125.

Corts, K. (2010). Building out alternative fuel retail infrastructure: Government fleet spillovers in E85. Journal of Environmental Economics and Management 59, 219-34.

Crocker, T. (1966). The Structuring of Atmospheric Pollution Control Systems. The Economics of Air Pollution. W.W. Norton. 
Dales, J. H. (1968). Pollution, Property and Prices. Toronto University Press.

de Gorter, H. and D. Just (2009). The Economics of a Blend Mandate for Biofuels. American Journal of Agricultural Economics 91(3), 738-750.

Department of Energy (2015). Database of State Incentives for Renewable and Efficiency: Detailed Summary Maps. Accessed August 18, 2015. http://www.dsireusa.org/resources/detailed-summary-maps/.

Diebold, F. and R. Mariano (1995). Comparing Predictive Accuracy. Journal of Business and Economic Statistics 13(3), 253-263.

Dixit, A. and R. Pindyck (1994). Investment Under Uncertainty. Princeton University Press.

Du, X. and M. Carriquiry (2013). Flex-Fuel Vehicle Adoption and Dynamics of Ethanol Prices: Lessons from Brazil. Energy Policy 59(1), 507-512.

Du, X. and D. Hayes (2009). The Impact of Ethanol Production on U.S. and Regional Gasoline Markets. Energy Policy 37(8), 3227-3234.

Elliot, G., T. J. Rothenberg, and J. H. Stock (1996). Efficient Tests for an Autoregressive Unit Root. Econometrica 64(4), 813-836.

Energy Information Agency (2013a). Short-Term Energy Outlook. January 2013. Accessed August 21, 2015. http://www.eia.gov/forecasts/steo/archives/jan13.pdf.

Energy Information Agency (2013b). What Caused the Run-Up in Ethanol RIN Prices During Early 2013? Energy Information Agency: Today in Energy, June 13, 2013. Accessed August 21, 2015. http://www. eia.gov/todayinenergy/detail.cfm?id=11671.

Engle, R. and C. Granger (1987). Cointegration Error Correction: Representation, Estimation, and Testing. Econometrica 55(2), 251-276.

Environmental Protection Agency (2007). Final Rule: Renewable Fuel Standard. Federal Register 72(83), 23900-24014.

Environmental Protection Agency (2013a). EPA Finalizes 2013 Renewable Fuel Standards. EPA-420F-13-042. August 2013. Accessed July 17, 2015. http://www.epa.gov/otaq/fuels/renewablefuels/ documents/420f13042.pdf.

Environmental Protection Agency (2015a). Fact Sheet: Clean Power Plan Framework . May 11, 2015. Accessed August 17, 2015. <http://www2.epa.gov/carbon-pollution-standards/ fact-sheet-clean-power-plan-framework>.

Environmental Protection Agency (2015b). Final Renewable Fuel Standards for 2014, 
2015 and 2016, and the Biomass-Based Diesel Volume for 2017. November 2015. Accessed December 2015. http://www.epa.gov/renewable-fuel-standard-program/ final-renewable-fuel-standards-2014-2015-and-2016-and-biomass-based.

Environmental Protection Agency (January 2013b). EPA Proposes 2013 Renewable Fuel Standards. EPA-420-F-13-007. January 2013. Accessed July 17, 2015. http://www.epa.gov/otaq/fuels/ renewablefuels/documents/420f13007.pdf.

Fama, E. (1965). The Behavior of Stock Market Prices. Journal of Business 38(1), 34-105.

Fell, H. (2015). Comparing Policies to Confront Permit Over-Allocation. Resources for the Future Discussion Paper DP 15-17.

Gelbach, J., E. Helland, and J. Klick (2013). Valid Inference in Single-Firm, Single-Event Studies. American Law and Economics Review 15(2), 495-541.

Hansen, P. R., A. Lunde, and J. M. Nason (2011). The Model Confidence Set. Econometrica 79(2), 453-97.

Hausman, C., M. Auffhammer, and P. Berk (2012). Farm Acreage Shocks and Food Prices: An SVAR Approach to Understanding the Impacts of Biofuels . Environmental and Resource Economics 52(1), $117-136$.

Hintermann, B. (2010). Allowance Price Drivers in the First Phase of the EU ETS. Journal of Environmental Economics and Management 59(1), 43-56.

Hitaj, C. and A. Stocking (2016). Market Efficiency and the U.S. Market for Sulfur Dioxide Allowances. Energy Economics 55, 134-147.

Hofstrand, D. (2012). Tracking Ethanol Profitability. Iowa State University Extension and Outreach. July 2012. Accessed July 17, 2015. http://www.extension.iastate.edu/agdm/energy/html/d1-10.html.

Holland, S., C. Knittel, and J. Hughes (2009). Greenhouse Gas Reductions Under Low Carbon Fuel Standards? American Economic Journal: Economic Policy 1(1), 106-146.

Holland, S., C. Knittel, J. Hughes, and N. Parker (2014). Some Inconvenient Truths About Climate Change Policies: The Distributional Impacts of Transportation Policies. Review of Economics and Statistics 97(5), 1052-1069.

Holland, S., C. Knittel, J. Hughes, and N. Parker (2015). Unintended Consequences of Transportation Policies: Land-use, Emissions, and Innovation. The Energy Journal 36(3), 35-74.

Holland, S. and M. Moore (2012). When to Pollute, When to Abate? Intertemporal Permit Use in the Los Angeles $\mathrm{NO}_{x}$ Market . Land Economics 88(2), 275-299. 
Holland, S. and M. Moore (2013). Market Design in Cap and Trade Programs: Permit Validity and Compliance Timing. Journal of Environmental Economics and Management 66(3), 671-687.

Irwin, S. (2013a). Biodiesel Supply, Demand, and RINs Pricing? farmdoc daily, Department of Agricultural and Consumer Economics, University of Illinois, October 24, 2013.

Irwin, S. (2013b). What's Behind the Plunge in RINs Prices? farmdoc daily, Department of Agricultural and Consumer Economics, University of Illinois, October 10, 2013.

Irwin, S. (2014a). Rolling Back the Write Down of the Renewable Mandate for 2014: The RINs Market Rings the Bell Again. farmdoc daily 4(148), Department of Agricultural and Consumer Economics, University of Illinois.

Irwin, S. (2014b). Understanding the Behavior of Biodiesel RINs Prices. farmdoc daily 4(196), Department of Agricultural and Consumer Economics, University of Illinois.

Johansen, S. (1995). Likelihood-Based Inference in Cointegrated Vector Autoregressive Models. Oxford University Press.

Khanna, M., A. Ando, and F. Taheripour (2008). Welfare Effects and Unintended Consequences of Ethanol Subsidies. Applied Economic Perspectives and Policy 30(3), 411-421.

Kling, C. and J. Rubin (1997). Bankable permits for the control of environmental pollution. Journal of Public Economics 64, 101-115.

Knittel, C., B. Meiselman, and J. Stock (2015). The Pass-Through of RIN Prices to Wholesale and Retail Fuels under the Renewable Fuel Standard. Working Paper.

Knittel, C. and A. Smith (2015). Ethanol Production and Gasoline Prices: A Spurious Correlation. Energy Journal 36(1), 73-113.

Lade, G. E. and C.-Y. C. Lin Lawell (2015a). Mandating Green: On the Design of Renewable Fuel Policies and Cost Containment Mechanisms. Working Paper.

Lade, G. E. and C.-Y. C. Lin Lawell (2015b). The Design and Economics of Low Carbon Fuel Standards. Research in Transportation Economics 52, 91-99.

Lapan, H. and G. Moschini (2012). Second-Best Biofuels Policies and the Welfare Effects of Quantity Mandates and Subsidies. Journal of Environmental Economics and Management 63(2), 224-241.

Lemoine, D. (2013). Green Expectation: Current Effects of Anticipated Carbon Pricing. University of Arizona Working Paper 13-09.

Lemoine, D. (2016). Escape from Third-Best: Rating Emissions for Intensity Standards. Environmental and Resource Economics, Forthcoming. 
Linn, J. (2010). The Effect of Cap and Trade Programs on Firm Profits: Evidence from the Nitrogen Oxide Budget Trading Program. Journal of Environmental Economics and Management 59(1), 1-14.

Lo, A. and A. C. MacKinlay (1988). Stock Market Prices Do Not Follow Random Walks: Evidence from a Simple Specification Test. The Review of Financial Studies 1(1), 41-66.

Lo, A. and A. C. MacKinlay (1999). A Non-Random Walk Down Wall Street. Princeton University Press.

MacKinlay, A. C. (1997). Event Studies in Economics and Finance. Journal of Economic Literature 35(1), $13-39$.

Malkiel, B. (2005). Reflections on the Efficient Market Hypothesis: 30 Years Later. The Financial Review 40(1), 1-9.

McPhail, L., P. Westcott, and H. Lutman (2011). The Renewable Identification Number System and US Biofuel Mandates. USDA Economic Research Service Outlook BIO-03.

Miao, R., D. Hennessy, and B. Babcock (2012). Investment in Cellulosic Biofuel Refineries: Do Waivable Biofuel Mandates Matter? American Journal of Agricultural Economics 94(3), 750-762.

Montgomery, W. D. (1972). Markets in Licenses and Efficient Pollution Control Programs. Journal of Economic Theory 5(3), 395-418.

Morgenson, G. and R. Gebeloff (2013). Wall St. Exploits Ethanol Credits, and Prices Spike. The New York Times September 14, 2013. Accessed July 17, 2015. http://www.nytimes.com/2013/09/15/business/ wall-st-exploits-ethanol-credits-and-prices-spike.html?_r=0.

National Low Carbon Fuel Standard Project (2012). World Map of Regional Policies. July 16, 2012. Accessed August 17, 2015. <http://nationallcfsproject.ucdavis.edu/map/>.

Nebraska Energy Office (2014). Ethanol Facilities Capacity by State and Plant. April 2014. Accessed July 17, 2015. http://www.neo.ne.gov/statshtml/122.htm.

Newell, R., W. Pizer, and J. Zhang (2005). Managing Permit Markets to Stabilize Prices. Environmental and Resource Economics 31(2), 133-157.

Oil Price Information Service (2015). OPIS Methodology. Accessed July 17, 2015. http://www.opisnet. com/about/methodology. aspx.

Pizer, W. (2002). Combining Price and Quantity Controls to Mitigate Global Climate Change. Journal of Public Economics 85(3), 409-434.

Podkul, C. (2013). Analysis: Lawsuits Likely as EPA Declares US Ethanol Blend Wall a 'Reality'. Reuters, October 11, 2013. Accessed July 17, 2015. http://www.reuters.com/article/2013/10/11/ us-ethanol-blendwall-analysis-idUSBRE99A09420131011. 
Pouliot, S. and B. Babcock (2014a). Impact of Ethanol Mandates on Fuel Prices when Ethanol and Gasoline are Imperfect Substitutes. CARD Working Paper 14-WP 549.

Pouliot, S. and B. Babcock (2014b). Impact of Increased Ethanol Mandates on Prices at the Pump. CARD Policy Brief 14-PB 18.

Pouliot, S. and B. Babcock (2014c). The Demand for E85: Geographic Location and Retail Capacity Constraints. Energy Economics 45(1), 134-143.

Rajagopal, D., G. Hochman, and D. Zilberman (2011). Multi-criteria Comparison of Fuel Policies: Renewable Fuel Standards, Clean Fuel Standards, and Fuel GHG Tax. Journal of Regulatory Economics 18(3), 217233.

Rajagopal, D. and R. Plevin (2013). Implications of Market-Mediated Emissions and Uncertainty for Biofuel Policies. Energy Policy 56(1), 75-82.

Roberts, M. and W. Schlenker (2013). Identifying Supply and Demand Elasticities of Agricultural Commodities: Implications for the US Ethanol Mandate. American Economic Review 103(6), 2265-2295.

Roberts, M. and M. Spence (1976). Effluent Charges and Licenses Under Uncertainty. Journal of Public Economics 5(3), 193-208.

Rubin, J. (1996). A Model of Intertemporal Emission Trading, Banking, and Borrowing. Journal of Environmental Economics and Management 31(3), 269-286.

Sadaka, S. (2012). Biodiesel. University of Arkansas Cooperative Extension Service: FSA1050.

Salvo, A. and C. Huse (2013). Build It, But Will They Come? Evidence from Consumer Choice Between Gasoline and Sugarcane Ethanol. Journal of Environmental Economics and Management 66(2), 251-279.

Schennach, S. (2000). The Economics of Pollution Permit Banking in the Context of Title IV of the 1990 Clean Air Act Amendments. Journal of Environmental Economics and Management 40(3), 189-210.

Smith, A. (2005). Partially Overlapping Time Series: A New Model for Volatility Dynamics in Commodity Futures. Journal of Applied Econometrics 20(3), 405-422.

Snowberg, E., J. Wolfers, and E. Zitzewitz (2011). How Prediction Markets Can Save Event Studies. NBER Working Paper 16949.

Thompson, W., S. Meyer, and P. Westhoff (2010). The new market for Renewable Identification Numbers. Applied Economic Perspectives and Policy 32(4), 588-603.

Thompson, W., S. Meyer, and P. Westhoff (2012). A Question Worth Billions: Why Isn't the Conventional RIN Price Higher? FAPRI-MU Report 12-12. 
USDA Economic Research Service (2013). US Drought 2012: Farm and Food Impacts. July 26, 2013. Accessed July 17, 2015. http://www.ers.usda.gov/topics/in-the-news/ us-drought-2012-farm-and-food-impacts . aspx.

Verleger, P. (2013). Renewable Identification Numbers. Presentation to Agricultural Advisory Committee: Commodity Futures Trading Commission. Accessed August 17, 2015. http://www.pkverlegerllc.com/ assets/documents/130725CFTCRINS1.pdf.

Weitzman, M. L. (1974). Prices vs. Quantities. Review of Economic Studies 41(4), 477-491.

Whistance, J., D. Ripplinger, and W. Thompson (2016). Biofuel-related price transmission using renewable identification number prices to signal mandate regime. Energy Economics 55, 19-29.

White, H. (2000). A Reality Test for Data Snooping. Econometrica 68(5), 1097-1126.

Wright, B. (2014). Global Biofuels: Key to the Puzzle of Grain Market Behavior. Journal of Economic Perspectives 28(1), 73-98. 


\section{A Dynamic Model of Compliance: Derivations}

Result 1: The Karush-Kuhn-Tucker (KKT) conditions for a firm facing problem (3) are given by: ${ }^{28}$

$$
\begin{gathered}
q_{i, t}^{c} \geq 0 \quad \perp \quad P_{t}-C_{i, t}^{c^{\prime}}\left(q_{i, t}^{c}\right)+\beta \mathbb{E}_{t} \frac{\partial V_{i, t+1}}{\partial B_{i, t+1}} \frac{\partial B_{i, t+1}}{\partial q_{i, t}^{c}} \leq 0 \\
q_{i, t}^{r} \geq 0 \quad \perp \quad P_{t}-C_{i, t}^{r^{\prime}}\left(q_{i, t}^{r}\right)+\beta \mathbb{E}_{t} \frac{\partial V_{i, t+1}}{\partial B_{i, t+1}} \frac{\partial B_{i, t+1}}{\partial q_{i, t}^{r}} \leq 0 \\
-r_{t}+\beta \mathbb{E}_{t} \frac{\partial V_{i, t+1}}{\partial B_{i, t+1}} \frac{\partial B_{i, t+1}}{\partial w_{i, t}}=0 \\
B_{i, T+1} \lambda_{i}=0,
\end{gathered}
$$

where ' $\perp$ ' denotes 'is complementary to' for all optimality conditions, implying that at least one equation binds with equality; and where $\lambda_{i}$ denotes the firm's Lagrange multiplier on the policy constraint. The last term in each of the first three conditions reflects the effect of the choice variables on the firm's value function. Substituting forward in the conventional fuel optimality condition, the term can be rewritten as:

$$
\beta \mathbb{E}_{t} \frac{\partial V_{i, t+1}}{\partial B_{i, t+1}} \frac{\partial B_{i, t+1}}{\partial q_{i, t}^{c}}=-\alpha \beta \mathbb{E}_{t} \frac{\partial V_{i, t+1}}{\partial B_{i, t+1}}=-\beta^{(T-t)} \alpha \mathbb{E}_{t}\left[\lambda_{i}\right]
$$

Similar arguments follow for the renewable fuel and compliance credit optimality conditions. After making the above substitution, we obtain:

$$
\begin{array}{cc}
q_{i, t}^{c} \geq 0 \quad \perp \quad P_{t}-C_{i, t}^{c^{\prime}}\left(q_{i, t}^{c}\right)-\beta^{(T-t)} \alpha \mathbb{E}_{t}\left[\lambda_{i}\right] \leq 0 \\
q_{i, t}^{r} \geq 0 \quad \perp \quad P_{t}-C_{i, t}^{r^{\prime}}\left(q_{i, t}^{r}\right)+\beta^{(T-t)} \mathbb{E}_{t}\left[\lambda_{i}\right] \leq 0 \\
r_{t}=\beta^{(T-t)} \mathbb{E}_{t}\left[\lambda_{i}\right] \\
B_{i, T+1} \lambda_{i}=0 .
\end{array}
$$

Equation (12) implies that firms equalize their discounted expected marginal compliance costs, $\beta^{(T-t)} \mathbb{E}_{t}\left[\lambda_{i}\right]$, to the tradable credit price. Thus, so long as the policy constraint binds for some firm(s) on the final date, $r_{T}>0$ and the credit price incentivizes the marginal firm to produce enough renewable fuel to meet the mandate. Substituting backwards, credit prices in a rational expectations equilibrium must satisfy:

$$
r_{t}=\beta^{(T-t)} \mathbb{E}_{t}\left[r_{T}\right] \quad \forall t
$$

To solve for equilibrium credit prices, consider a representative, aggregate producer's problem. Given competitive markets, the solution to the representative firm's problem will replicate the competitive market outcome. Consider the representative firm's problem on the final day $T$ when compliance costs are determined, given by:

$$
\max _{q_{T}^{c}, q_{T}^{r}} P_{T}\left(Q_{T}\right) Q_{T}-C_{T}^{c}\left(q_{T}^{c}\right)-C_{T}^{r}\left(q_{T}^{r}\right) \text { subject to } B_{T+1} \geq 0,
$$

\footnotetext{
${ }^{28}$ The vector $\Theta_{t}$ of shocks is suppressed for notational simplicity.
} 
where $q_{T}^{c}=\sum_{i} q_{i, T}, q_{T}^{r}=\sum_{i} q_{i, T}^{r}, B_{T+1}=\sum_{i} B_{i, T+1}$, and $C_{T}^{j}\left(q_{T}^{j}\right)$ are aggregate cost functions for fuel $j$, given by minimizing costs across all firms' cost functions. Under a binding mandate, $\sum_{i} w_{i, T}=0$ and therefore credits do not enter the aggregate producer problem. The optimality conditions are given by:

$$
\begin{gathered}
q_{T}^{c} \geq 0 \quad \perp \quad P_{T}-C_{T}^{c^{\prime}}\left(q_{T}^{c}\right)-\alpha \lambda_{T} \leq 0 \\
q_{T}^{r} \geq 0 \quad \perp \quad P_{T}-C_{T}^{r^{\prime}}\left(q_{T}^{r}\right)+\lambda_{T} \leq 0 \\
\lambda_{T} \geq 0 \quad \perp \quad B_{T+1} \geq 0 .
\end{gathered}
$$

With tradable credits, it follows from equation (12) that $r_{T}=\lambda_{T}$. The optimality condition on the policy constraint states that credit prices will be positive if the mandate binds on the industry and zero otherwise. From the optimality condition for renewable fuel, it follows that:

$$
r_{T}=\max \left[C_{T}^{r^{\prime}}\left(q_{T}^{r}\right)-P_{T}, 0\right]=\max \left[\frac{C_{T}^{r^{\prime}}\left(q_{T}^{r}\right)-C_{T}^{c^{\prime}}\left(q_{T}^{c}\right)}{1+\alpha}, 0\right] .
$$

Result 2: If the mandate is expected to bind, then $\mathbb{E}_{t}\left[r_{T}\right]>0$ and equations (10) and (11) imply that the policy taxes the conventional fuel and subsidizes the renewable fuel. The implicit tax on conventional fuel is given by $\alpha r_{t}$, and the implicit subsidy for renewable fuel is given by $r_{t}$. From the policy constraint, we have:

$$
\sum_{i} q_{i, t}^{r}=\sum_{i} \alpha q_{i, t}^{c}
$$

where $w_{i, t}$ fall out as $\sum_{i} w_{i, t}=0$ under a binding mandate. Multiplying by the credit price yields:

$$
r_{t} \sum_{i} q_{i, t}^{r}=\alpha r_{t} \sum_{i} q_{i, t}^{c}
$$

The condition states that in equilibrium, the value of the subsidy to the biofuel industry equals the value of the tax on the conventional fuel industry.

Results 3 \& 4: Each firm's Bellman equation is given by:

$$
\begin{gathered}
V_{i, t}\left(B_{i, t} ; \Theta_{t}\right)=\max _{\substack{q_{i, t}^{c}, r_{i, t}^{r} \geq 0, w_{i, 1, t}, w_{i, 2, t}}} P_{t}\left(Q_{t} ; \Theta_{t}\right) Q_{i, t}-C_{i, t}^{c}\left(q_{i, t}^{c} ; \Theta_{t}\right)-C_{i, t}^{r}\left(q_{i, t}^{r} ; \Theta_{t}\right)-r_{1, t} w_{i, 1, t}-r_{2, t} w_{i, 2, t} \\
+\beta \mathbb{E}_{t}\left[V_{i, t+1}\left(B_{i, t+1} ; \Theta_{t+1}\right)\right]
\end{gathered}
$$

subject to

$$
\begin{aligned}
B_{i, 1, t+1} & =B_{i, 1, t}+\left(q_{i, t}^{r}-\alpha_{1} q_{i, t}^{c}\right) \mathbf{1}\left(t \leq T_{1}\right)+w_{i, 1, t} \\
B_{i, 2, t+1} & =B_{i, 2, t}+\left(q_{i, t}^{r}-\alpha_{2} q_{i, t}^{c}\right) \mathbf{1}\left(t>T_{1}\right)+w_{i, 2, t} \\
B_{i, 1, T_{1}+1} & \geq-\gamma_{1} \sum_{t=1}^{T_{1}} \alpha_{1} q_{i, t}^{c} \\
B_{i, 2, T_{2}+1} & \geq-\gamma_{2} \sum_{t=T_{1}+1}^{T_{2}} \alpha_{2} q_{i, t}^{c} \\
B_{i, 1, T_{2}+1}+B_{i, 2, T_{2}+1} & \geq 0 \\
B_{i, 1,0}=B_{i, 2,0} & =0 .
\end{aligned}
$$


The third and fourth constraints are the borrowing and banking restrictions, respectively. The fifth constraint is the policy constraint. The relevant firm-level optimality conditions necessary to derive RIN prices relate to $w_{i, 1, t}$ and $w_{i, 2, t}$, and are given by:

$$
\begin{aligned}
& r_{1, t}= \begin{cases}\beta^{\left(T_{2}-t\right)} \mathbb{E}_{t}\left[\lambda_{i}\right]+\beta^{\left(T_{1}-t\right)} \mathbb{E}_{t}\left[\Phi_{i, 1}\right] & \text { if } t \leq T_{1} \\
\beta^{\left(T_{2}-t\right)} \mathbb{E}_{t}\left[\lambda_{i}\right] & \text { if } t>T_{1}\end{cases} \\
& r_{2, t}=\beta^{\left(T_{2}-t\right)} \mathbb{E}_{t}\left[\lambda_{i}+\Phi_{i, 2}\right],
\end{aligned}
$$

where $\lambda_{i}$ is the firm's Lagrange multiplier on the policy constraint, and $\Phi_{i, 1}$ and $\Phi_{i, 2}$ are the Lagrange multipliers on the borrowing and banking constraints, respectively. Equations (14) and (15) state that firms buy and sell compliance credits until their marginal compliance costs net of the banking and borrowing constraints are equalized.

To solve for market clearing RIN prices, as before consider a representative, aggregate firm's problem. On each day, the aggregate firm's Bellman equation is given by:

$$
\begin{aligned}
V_{t}\left(B_{t} ; \Theta_{t}\right)=\max _{q_{t}^{c}, q_{t}^{r} \geq 0} P_{t}\left(Q_{t} ; \Theta_{t}\right) Q_{t}-C_{t}^{c}\left(q_{t}^{c} ; \Theta_{t}\right) & -C_{t}^{r}\left(q_{t}^{r} ; \Theta_{t}\right)+\beta \mathbb{E}_{t}\left[V_{t+1}\left(B_{t+1} ; \Theta_{t+1}\right)\right] \\
\text { subject to } & \geq-\gamma_{1} \sum_{t=1}^{T_{1}} \alpha_{1} q_{t}^{c} \\
B_{1, T_{1}+1} & \geq-\gamma_{2} \sum_{t=T_{1}+1}^{T_{2}} \alpha_{2} q_{t}^{c} \\
B_{2, T_{2}+1} & \geq 0 \\
B_{1, T_{2}+1}+B_{2, T_{2}+1} & \geq 0 \\
B_{1,0}=B_{2,0} & =0 .
\end{aligned}
$$

Interior optimality conditions for $q_{t}^{c}$ and $q_{t}^{r}$ for $t \in\left\{t, \ldots, T_{1}\right\}$ are, respectively:

$$
\begin{gathered}
P_{t}=C_{t}^{c^{\prime}}\left(q_{t}^{c}\right)+\alpha_{1} \beta^{\left(T_{2}-t\right)} \mathbb{E}_{t}[\lambda]+\alpha_{1}\left(1-\gamma_{1}\right) \beta^{\left(T_{1}-t\right)} \mathbb{E}_{t}\left[\Phi_{1}\right] \\
P_{t}=C_{t}^{r^{\prime}}\left(q_{t}^{r}\right)-\beta^{\left(T_{2}-t\right)} \mathbb{E}_{t}[\lambda]-\beta^{\left(T_{1}-t\right)} \mathbb{E}_{t}\left[\Phi_{1}\right]
\end{gathered}
$$

where $\lambda$ denotes the Lagrange multiplier on the aggregate policy constraint and $\Phi_{1}$ denotes the Lagrange multiplier on the aggregate borrowing restriction. Interior optimality conditions for $t \in\left\{T_{1}+1, \ldots, T_{2}\right\}$ for each fuel are given by:

$$
\begin{gathered}
P_{t}=C_{t}^{c^{\prime}}\left(q_{t}^{c}\right)+\alpha_{2} \beta^{\left(T_{2}-t\right)} \mathbb{E}_{t}\left[\lambda+\left(1-\gamma_{2}\right) \Phi_{2}\right] \\
P_{t}=C_{t}^{r^{\prime}}\left(q_{t}^{r}\right)-\beta^{\left(T_{2}-t\right)} \mathbb{E}_{t}\left[\lambda+\Phi_{2}\right],
\end{gathered}
$$

where $\Phi_{2}$ denotes the Lagrange multiplier on the aggregate banking restriction.

Consider the solution on the terminal date $t=T_{2}$. From equations (14) and (15), RIN prices are:

$$
\begin{aligned}
& r_{1, T_{2}}=\lambda \\
& r_{2, T_{2}}=\lambda+\Phi_{2} .
\end{aligned}
$$


Thus, any difference between RIN prices on day $T_{2}$ is driven solely by a binding banking constraint.

We have three scenarios to consider on day $T_{2}$. First, if none of the policy constraints bind, both credit prices are zero. Second, if the total mandate binds but the banking constraint does not bind $\left(\Phi_{2}=0\right.$ and $\lambda>0$ ), then equations (18) and (19) implies that the RIN prices are equal and given by:

$$
r_{1, T_{2}}=r_{2, T_{2}}=\lambda=C_{T_{2}}^{r^{\prime}}\left(q_{T_{2}}^{r}\right)-P_{T_{2}}=\frac{C_{T_{2}}^{r^{\prime}}\left(q_{T_{2}}^{r}\right)-C_{T_{2}}^{c^{\prime}}\left(q_{T_{2}}^{c}\right)}{1+\alpha_{2}}>0 .
$$

Third, if the banking constraint binds $\left(\Phi_{2}>0\right)$, then there are surplus period 1 credits that the firm would like to use towards its period 2 compliance obligation, but the banking restriction prevents it from fully doing so. These surplus period 1 credits therefore have no value on the margin, i.e., $r_{1, T_{2}}=0$. From (14), this implies that $\lambda=0$, i.e., the total mandate is not binding. Solving for the period 2 RIN price using equations (18) and (19) yields:

$$
\begin{aligned}
& r_{1, T_{2}}=0 \\
& r_{2, T_{2}}=\Phi_{2}=C_{T_{2}}^{r^{\prime}}\left(q_{T_{2}}^{r}\right)-P_{T_{2}}=\frac{C_{T_{2}}^{r^{\prime}}\left(q_{T_{2}}^{r}\right)-C_{T_{2}}^{c^{\prime}}\left(q_{T_{2}}^{c}\right)}{1+\alpha_{2}\left(1-\gamma_{2}\right)}>0 .
\end{aligned}
$$

Now, consider the borrowing constraint. A binding borrowing constraint means there are no period 1 RINs available for trade in period 2. On date $T_{1}$, the market resolves whether the borrowing constraint binds, so if the constraint is binding, then this is the last day a market exists for both RINs. From equations (14), (16) and (17), the period 1 RIN price on day $T_{1}$ is given by:

$$
r_{1, T_{1}}=\beta^{\left(T_{2}-T_{1}\right)} \mathbb{E}_{T_{1}}[\lambda]+\Phi_{1}=C_{T_{1}}^{r^{\prime}}\left(q_{T_{1}}^{r}\right)-P_{T_{1}}=\frac{C_{T_{1}}^{r^{\prime}}\left(q_{T_{1}}^{r}\right)-C_{T_{1}}^{c^{\prime}}\left(q_{T_{1}}^{c}\right)}{1+\alpha_{1}}+\frac{\alpha_{1} \gamma_{1}}{1+\alpha_{1}} \Phi_{1}>0 .
$$

Using (14) and (15), and the fact that a binding borrowing constraint means that the banking constraint will not bind $\left(\Phi_{2}=0\right)$, the difference between RIN prices on day $T_{1}$ is therefore:

$$
\begin{aligned}
\Phi_{1} & =r_{1, T_{1}}-r_{2, T_{1}} \\
& =\left(C_{T_{1}}^{r^{\prime}}\left(q_{T_{1}}^{r}\right)-P_{T_{1}}\right)-\beta^{\left(T_{2}-T_{1}\right)} E_{T_{1}}\left[\max \left[C_{T_{2}}^{r^{\prime}}\left(q_{T_{2}}^{r}\right)-P_{T_{2}}, 0\right]\right] .
\end{aligned}
$$

Thus, the Lagrange multiplier on the borrowing constraint reflects the discounted difference in marginal compliance costs between the costlier first compliance period $T_{1}$ and the second compliance period $T_{2}$. Using equations (16)-(19), we can solve further to obtain:

$$
\begin{aligned}
\Phi_{1} & =\frac{C_{T_{1}}^{r^{\prime}}\left(q_{T_{1}}^{r}\right)-C_{T_{1}}^{c^{\prime}}\left(q_{T_{1}}^{c}\right)}{1+\alpha_{1}}+\frac{\alpha_{1} \gamma_{1}}{1+\alpha_{1}} \Phi_{1}-r_{2, T_{1}} \\
& =\frac{C_{T_{1}}^{r^{\prime}}\left(q_{T_{1}}^{r}\right)-C_{T_{1}}^{c^{\prime}}\left(q_{T_{1}}^{c}\right)}{1+\alpha_{1}\left(1-\gamma_{1}\right)}-\frac{1+\alpha_{1}}{1+\alpha_{1}\left(1-\gamma_{1}\right)} r_{2, T_{1}} .
\end{aligned}
$$

Substituting into the expression for the period 1 RIN price and simplifying yields:

$$
r_{1, T_{1}}=\frac{C_{T_{1}}^{r^{\prime}}\left(q_{T_{1}}^{r}\right)-C_{T_{1}}^{c^{\prime}}\left(q_{T_{1}}^{c}\right)}{1+\alpha_{1}\left(1-\gamma_{1}\right)}-\frac{\alpha_{1} \gamma_{1}}{1+\alpha_{1}\left(1-\gamma_{1}\right)} r_{2, T_{1}} .
$$


In sum, on any day $t$, we have:

$$
\begin{aligned}
& r_{1, t}= \begin{cases}\beta^{\left(T_{2}-t\right)} \mathbb{E}_{t}\left[r_{2, T}-\Phi_{2}+\beta^{\left(T_{1}-T_{2}\right)} \Phi_{1}\right] & \text { if } t \leq T_{1} \\
\beta^{\left(T_{2}-t\right)} \mathbb{E}_{t}\left[\lambda_{i}\right] & \text { if } t>T_{1}\end{cases} \\
& r_{2, t}=\beta^{\left(T_{2}-t\right)} \mathbb{E}_{t}\left[r_{2, T}\right]=\beta^{\left(T_{2}-t\right)} \mathbb{E}_{t}\left[\max \left[C_{T_{2}}^{r^{\prime}}\left(q_{T_{2}}^{r}\right)-P_{T_{2}}, 0\right]\right] .
\end{aligned}
$$

Result 5: Each firm's maximization problem in period $t$ is:

$$
\begin{gathered}
V_{i, t}\left(B_{i, 1, t}^{r}, B_{i, 2, t}^{r} ; \Theta_{t}\right)=\max _{\substack{q_{i, t}^{c}, q_{i, 1, t}^{r}, q_{i, 2, t}^{r} \geq 0, w_{i, 1, t}, w_{i, 2, t}}} P_{t}\left(Q_{t} ; \Theta_{t}\right) Q_{i, t}-C_{t}^{c}\left(q_{i, t}^{c} ; \Theta_{t}\right)-\sum_{j} C_{i, j, t}^{r}\left(q_{i, j, t}^{r} ; \Theta_{t}\right)-\sum_{j} r_{j, t} w_{i, j, t} \\
+\beta \mathbb{E}_{t} V_{i, t+1}\left(B_{i, 1, t+1}^{r}, B_{i, 2, t+1}^{r} ; \Theta_{t+1}\right)
\end{gathered}
$$

subject to $\quad B_{i, 1, t+1}^{r}=B_{i, 1, t}^{r}+q_{i, 1, t}^{r}+w_{i, 1, t}+q_{i, 2, t}^{r}+w_{i, 2, t}-\alpha_{1}^{r} q_{i, t}^{c}$

$$
\begin{gathered}
B_{i, 2, t+1}^{r}=B_{i, 2, t}^{r}+q_{i, 2, t}^{r}+w_{i, 2, t}-\alpha_{2}^{r} q_{i, t}^{c} \\
B_{i, 1, T+1}^{r} \geq 0, B_{i, 2, T+1}^{r} \geq 0, \\
B_{i, 1,1}^{r}=0, B_{i, 2,1}^{r}=0 .
\end{gathered}
$$

Let $\lambda_{i, j}$ denote the Lagrange Multipliers for each policy constraint $j=\{1,2\}$. The firm's optimality conditions are:

$$
\begin{array}{ccc}
q_{i, t}^{c} \geq 0 & \perp & P_{t}-C_{i, t}^{c^{\prime}}\left(q_{i, t}^{c}\right)-\beta^{(T-t)}\left(\alpha_{1} \mathbb{E}_{t}\left[\lambda_{i, 1}\right]+\alpha_{2} \mathbb{E}_{t}\left[\lambda_{i, 2}\right]\right) \leq 0 \\
q_{i, 1, t}^{r} \geq 0 & \perp & P_{t}-C_{i, 1, t}^{r^{\prime}}\left(q_{i, 1, t}^{r}\right)+\beta^{(T-t)} \mathbb{E}_{t}\left[\lambda_{i, 1}\right] \leq 0 \\
q_{i, 2, t}^{r} \geq 0 & \perp & P_{t}-C_{i, 2, t}^{r^{\prime}}\left(q_{i, 2, t}^{r}\right)+\beta^{(T-t)}\left(\mathbb{E}_{t}\left[\lambda_{i, 1}\right]+\mathbb{E}_{t}\left[\lambda_{i, 2}\right]\right) \leq 0 \\
r_{1, t}=\beta^{(T-t)} \mathbb{E}_{t}\left[\lambda_{i, 1}\right] \\
r_{2, t}=\beta^{(T-t)}\left(\mathbb{E}_{t}\left[\lambda_{i, 1}\right]+\mathbb{E}_{t}\left[\lambda_{i, 2}\right]\right) \\
B_{i, 1, T+1}^{r} \lambda_{i, 1}=0, \quad B_{i, 2, T+1}^{r} \lambda_{i, 2}=0 .
\end{array}
$$

Equations (20) and (21) state the firms produce where their individual compliance costs equal the market clearing RIN price. With tradable credits, it therefore follows that:

$$
\begin{aligned}
& r_{1, T}=\lambda_{1} \\
& r_{2, T}=\lambda_{1}+\lambda_{2}=r_{1, T}+\lambda_{2},
\end{aligned}
$$

where $\lambda_{j}$ is the Lagrange multiplier for policy constraint $j$ in the aggregate firm's problem. Using similar arguments as in Result 1 and writing the problem in the final period using an aggregate producer, it can be shown that:

$$
\begin{aligned}
r_{1, T} & =\max \left[C_{1, T}^{r^{\prime}}\left(q_{1, T}^{r}\right)-P_{T}, 0\right] \\
r_{2, T} & =\max \left[C_{2, T}^{r^{\prime}}\left(q_{2, T}^{r}\right)-P_{T}, 0\right] \\
\lambda_{2} & =\max \left[C_{2, T}^{r^{\prime}}\left(q_{2, T}^{r}\right)-\max \left[C_{1, T}^{r^{\prime}}\left(q_{1, T}^{r}\right), P_{T}\right], 0\right] .
\end{aligned}
$$


From this and the firm optimality conditions, it follows that:

$$
\begin{aligned}
& r_{1, t}=\beta^{(T-t)} \mathbb{E}_{t}\left[\lambda_{1}\right]=\beta^{(T-t)} \mathbb{E}_{t}\left[r_{1, T}\right], \\
& r_{2, t}=\beta^{(T-t)} \mathbb{E}_{t}\left[\lambda_{1}+\lambda_{2}\right]=\beta^{(T-t)} \mathbb{E}_{t}\left[r_{1, T}+\lambda_{2}\right] .
\end{aligned}
$$




\section{B The Model Confidence Set Details}

A key prediction from Result 1 of our theoretical model is that each RIN type and vintage should satisfy:

$$
r_{t}=\beta \mathbb{E}_{t}\left[r_{t+1}\right] .
$$

Equation (22) states that RINs should follow Hotelling's rule and rise at the rate of interest in expectation. Because daily RIN prices are reported and there is presumably no cost to storing credits, it is reasonable to assume $\beta \approx 1$. Thus, equation (22) can be written as:

$$
\mathbb{E}_{t}\left[r_{t+1}\right]-r_{t}=0
$$

Equation (23) states RIN prices should satisfy a rational expectations equilibrium, and current period periods should incorporate all expectations regarding future prices.

This sections presents a test of whether equation (23) holds for all observed RIN types and vintages. An important implication of equation (23) is that observed price changes in period $t+1$ should be uncorrelated with variables $\mathbf{x}$ observed in period $t$, i.e., future RIN price movements should be unpredictable. This is equivalent to the hypothesis:

$$
H_{0}: \mathbb{E}_{t}\left[\mathbf{x}_{t}\left(r_{t+1}-r_{t}\right)\right]=0
$$

for any set of potential predictor variables $\mathbf{x}_{t}$.

Unpredictability represents a necessary, though not sufficient, condition for market efficiency. Thus, the test does not necessarily address all concerns. To the extent that significant predictability in RIN markets is found, however, there would be reasonable cause for concern regarding whether RIN markets exhibit proper price discovery, and would invalidate our identification strategy in Section 5.

A number of methods are available to test $H_{0}$. For example, through introspection and drawing knowledge of RIN markets, a vector $\mathbf{x}_{t}$ could be specified and testing $H_{0}$ would amount to a joint hypothesis test of $H_{0}: \beta=0$ from the model $\Delta r_{t+1}=\mathbf{x}_{t} \beta+\varepsilon_{t+1}$. In the absence of an obvious superior model, selecting the 'best' model using an information or testing criterion could be employed.

Given well-established problems with controlling the family-wise error rate when selecting among competing models using multiple testing criterion (White, 2000), $H_{0}$ is tested here using a forecast exercise. ${ }^{29}$ Given a vector of potential predictors, $\mathbf{x}_{t}$, a large set of competing RIN forecasts is constructed and compared to the random walk model implied by equation (23) using the Model Confidence Set (MCS) procedure developed by Hansen et al. (2011). Given a set of competing forecasts, the MCS estimates the best model(s), as well as all models whose performance cannot be statistically significantly distinguished from the top competing model(s).

\footnotetext{
${ }^{29}$ Family-wise error rate is defined as the probability of rejecting at least one null hypothesis when the hypothesis is in fact true, i.e., the family-wise error rate is the probability of making at least one Type I error.
} 
Given a vector $\mathbf{x}_{t}^{\prime}$, define the set $M_{0}$ as the set containing all models constructed from combinations of $\mathbf{x}_{t}^{\prime}$, with models indexed by $i=1, \cdots, m_{0}$. Each model is evaluated by its predictive ability according to a specified loss function $L_{i, t}$ for each evaluation period $t=1, \cdots, T$. For this exercise, a mean squared forecast error loss function is used with:

$$
L_{i, t}=L\left(\Delta r_{t}-\Delta \hat{r}_{i, t}\right)=\left(\Delta r_{t}-\Delta \hat{r}_{i t}\right)^{2}
$$

where $\Delta r_{t}$ is the realized change in RIN prices and $\Delta \hat{r}_{i t}$ is the forecast change in RIN prices by model $i$ in evaluation period $t$. Define $\mu_{i, j}=\mathbb{E}\left(d_{i j, t}\right)$ as the expected loss differential between models $i$ and $j$, where $d_{i j, t}=L_{i, t}-L_{j, t}$. Given $\mu_{i, j}$, the MCS estimates $M^{*}$, defined as the set of all models that are indistinguishable from the best performing model:

$$
M^{*}=\left\{i \in M_{0}: \mu_{i, j} \leq 0 \text { for all } j \in M_{0}\right\} .
$$

Hansen et al. (2011) develop methods to estimate $\hat{M}_{1-\alpha}$, which converges in probability to $M^{*}$ with Type I error $\alpha$. To implement the procedure, the method uses an equivalence test, $\delta_{M}$, to evaluate each model in $M$ according to their relative losses and identify the worst performing forecast model. Given $\delta_{M}$, an elimination rule $e_{M}$ eliminates the model from the set if a specified testing criterion is satisfied.

The procedure begins by setting $M=M_{0}$ and comparing all models based on their expected loss differentials. The equivalence test sequentially compares the 'worst' performing model, identified by $\delta_{M}$, in the set and eliminates the model from the set if the elimination rule $e_{M}$ is satisfied. When a model is eliminated, a new set $M=M_{1}$ is constructed and the procedure is repeated until the equivalence test $e_{M}$ is not rejected. The output, $\hat{M}$, is thus defined as the set of all 'surviving' models from the procedure.

Hansen et al. (2011) constructs MCS p-values with the property that if $\hat{p}_{i} \leq \alpha$, the model is excluded from the confidence set $\hat{M}_{1-\alpha}$. This guarantees that:

$$
\lim _{t \rightarrow \infty} \operatorname{Pr}\left(M^{*} \subset \hat{M}_{1-\alpha}\right) \geq 1-\alpha .
$$

Thus, the procedure guarantees that the family-wise error rate is controlled. In addition, the MCS has the advantage that the p-values can be interpreted in a similar fashion as traditional p-values for parameter inference. In this sense, a high p-value implies a low probability that the model is not contained in $M^{*}$.

Hansen et al. (2011) suggest a number of methods to construct the MCS. For this exercise, each RIN MCS is constructed using t-statistics comparing the relative sample loss between models $i$ and $j$ as $\bar{d}_{i j}=$ $T^{-1} \sum_{t=1}^{T} d_{i j, t}$. The t-test statistics are constructed as:

$$
t_{i j}=\frac{\bar{d}_{i j}}{\sqrt{\operatorname{vâr}\left(\bar{d}_{i j}\right)}} .
$$

The test statistic is a DM test (Diebold and Mariano, 1995) comparing the competing forecasts. Because the test statistic depends on nuisance parameters, the asymptotic distribution of $\bar{d}_{i j}$ is non-standard. Thus, the bootstrap procedure developed by White $(2000)$ is used to estimate $\operatorname{var}\left(\bar{d}_{i j}\right)$. 
Given the t-statistics for each mode, the hypothesis $H_{0}: \mu_{i j}=0 \forall i, j \in M$ is constructed. Testing $H_{0}$ requires a test statistic and elimination rule consistent with the properties of the MCS discussed in Hansen et al. (2011). For this exercise, the test statistic $T_{M} \equiv \max _{i, j \in M}\left|t_{i j}\right|$ is used. The elimination rule used to identify the model that is to be eliminated from the MCS is chosen as $e_{M}=\operatorname{argmax}_{i \in M} \sup _{j \in M} t_{i j}$. Thus, the model $e_{M}$ is removed from the MCS whenever the absolute value of the p-value for the t-test is below the threshold $\alpha$.

Given the setup above, our algorithm for constructing the MCS is:

1. Define the set of all models $M_{0}$.

2. For each model, forecast RIN price changes using a moving block estimation window. Calculate $L_{i, t}$ and $\bar{L}_{i}$ for each model.

3. Form t-statistics $t_{i j}$ based on the relative average loss of each model. Calculate the variance based on the bootstrapped values of the loss functions.

4. Test $H_{0}: \mu_{i j}=0$ for all $i, j \in M$ using test statistic $T_{M}$. Let $P_{H_{0}, M}=B^{-1} \sum_{b} 1_{T_{\max }>T_{b, \max }^{*}}$ be the bootstrap p-value for the test statistic $T_{M}$. If $P_{H_{0}, M}<\alpha$ then $H_{0, M}$ is rejected and the model identified by $e_{M}$ is eliminated from the set.

5. Repeat 4 until $H_{0, M}$ is not rejected and stop the procedure.

The resulting set of models is denoted $\hat{M}_{1-\alpha}^{*}$ and is the $(1-\alpha)$ model confidence set. P-values for each model $e_{M_{j}}$ are defined as $\hat{p}_{e_{M_{j}}} \equiv \max _{i \leq j} P_{H_{0}, M_{j}}$. Thus, p-values for each model equals either to maximum of the bootstrap value computed in step 4 or the p-value calculated in any prior step. By construction, the $\mathrm{p}$-value of the last surviving model or models is $1 .^{30}$

An MCS is constructed for each observed RIN type and vintage. To increase the power of the test, a combined forecast for each RIN type is constructed using the front-year RIN prices for each RIN type. In addition, to guard against the possibility that daily data may be reported with a lag by OPIS, Wednesdayto-Wednesday forecasts are constructed using the combined forecast series. Table B.1 lists the variables used to construct $M_{0}$ for each RIN series. Forecasts data includes lag RIN price levels and differences, relevant commodity futures price series, and three macroeconomic variables. The initial model set $M_{0}$ is constructed using every combination of the variables in Table B.1 with up to three variables in each model, for a total of 378 competing forecasts.

The results from the MCS exercise are summarized in Table B.2. The p-value and rank of the random walk model for each RIN series and vintage are reported. In addition, the size of the $90 \%$ and $75 \%$ MCS

\footnotetext{
${ }^{30}$ Code to implement the procedure was written written by Kevin Shephard through the Oxford MFE Toolbox, and is available online at http://www.kevinsheppard.com/ (accessed February, 2014).
} 
Table B.1: Model Confidence Set: Description of Variables

\begin{tabular}{lcc}
\hline \hline Variable & Description & Source \\
\hline Outcome Variables & $2007-2014$ Conventional RINs \\
$\Delta r_{t}=r_{t}-r_{t-1}$ & $2011-2014$ Advanced RINs \\
& $20010-2014$ Biodiesel RINs & OPIS \\
\hline Lag RIN Prices & Lag RIN Price Level & OPIS \\
$r_{t-1}$ & Lag Differenced RIN Price & OPIS \\
$\Delta r_{t-1}$ & OPIS \\
\hline Future Data Prices* & WTI Oil Futures Continuous Contract & \\
$X_{1, t-1}$ & Corn No. 2 Futures Continuous Contract & NYMEX \\
$X_{2, t-1}$ & Soybean Oil Futures Continuous Contract & CME \\
$X_{3, t-1}$ & CME No.11 Futures Futures Continuous Contract \\
$X_{4, t-1}$ & ICE \\
$X_{5, t-1}$ & Henry Hub Natural Gas Futures Continuous Contract & CME \\
$X_{6, t-1}$ & CME \\
\hline Macroeconomic Indicators & \\
$W_{1, t-1}$ & Month U.S. Treasury Constant Maturity Rate & FRED \\
$W_{2, t-1}$ & Russell 3000 Index & NYSE \\
$W_{3, t-1}$ & S\&P Goldman Sachs Commodity Index & CME \\
\hline Notes: For all futures price data, multiple contracts trade in any given period. We use the front \\
month series, defined as the price for the contract with an expiration date closest to the trading day.
\end{tabular}

are presented. For example, for the 2007 conventional series, the random walk forecast ranked 5 th out of the 378 models, with a p-value of 0.866 , well above conventional rejection levels. While the random walk was not the top performing model in the set $M_{0}$, it does not perform statistically significantly worse than all other models in the set for even a 20\% MCS. The large size of the MCS suggests that no single model or group of models significantly and consistently outperforms others.

Overall, the results from the MCS exercise are encouraging. The random walk forecast generally ranks among the top performing models, and is never rejected from the $75 \%$ or $90 \%$ MCS for any series. The random walk model for some RIN series such as for 2011-2013 advanced and 2011 biodiesel RINs perform relatively poorly; however, Wednesday to Wednesday random walk forecasts for all series are among the top competing models. This suggests that the results for these series may be driven by report timing issues or day-to-day illiquidity in the markets that are resolved over a week. For all forecast models, the size of the $75 \%$ and $90 \%$ MCS is large, and in many instances includes all competing forecasts. This suggests that no one model or group of models outperforms the others in a statistically significantly manner.

Table B.3 lists the top competing model for each RIN series and vintage. No one variable or group of variables is common across the top models for conventional RINs, though for advanced RINs, Henry Hub Futures and the lag difference of RINs appear in many of the top forecast models. The presence of the lag difference RIN price in the top performing model suggests that there may be some memory in RIN prices, and that prior shocks may in part inform future shocks, particularly for advanced and biodiesel RINs. This finding is likely driven by lagged reporting of transactions. Sugar futures, soybean oil futures, and the S\&PGS Commodity Index appear in many of the top competing variables with biodiesel RINs. Only soybean 
Table B.2: Model Confidence Set Summary

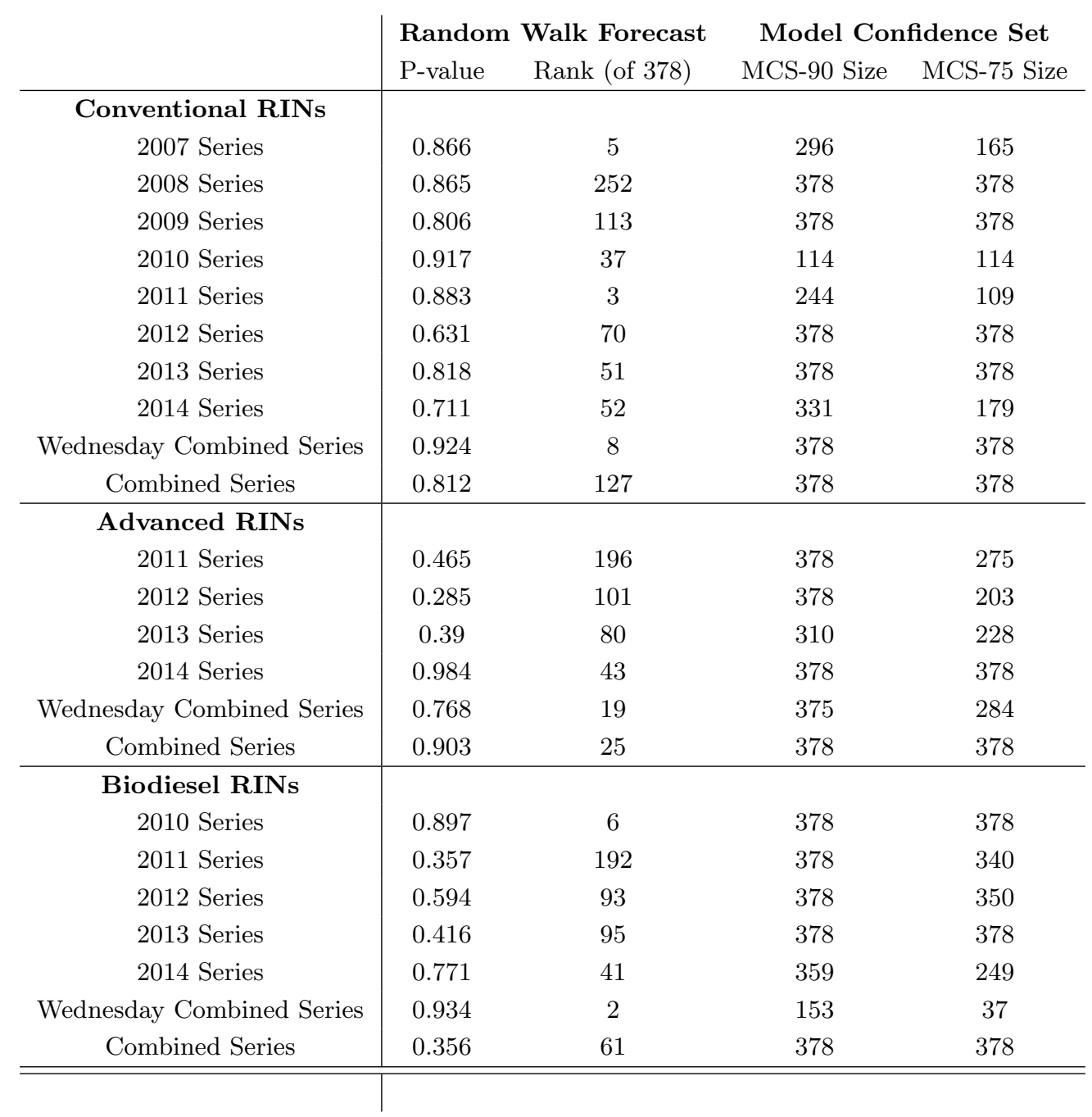

oil futures remain in the Wednesday to Wednesday MCS, suggesting the results may be driven by either reporting timing issues or illiquidity in the biodiesel RIN market.

Given the findings that policy announcements were the main drivers of RIN prices, alternative MCS's were constructed using indicators for lagged policy announcements, where the policy announcement indicator is equal to one if a specific policy announcement occurred on the previous day and zero otherwise. The policy announcements include the release of the 2013 Proposed and Final Rules, the release of the Reuters article, and the release of the 2014 Proposed Rule. Including policy indicators generally diminishes the performance of the random walk forecast, and in several instances the top performing forecast models include policy indicators. The result is consistent with the findings in Section 5 that RIN prices continued to fall for a number of days following each announcement. The overall improvements from including the policy announcements, however, are modest. For all estimated Model Confidence Sets with policy announcement indicators, the random walk forecast is never excluded from the $90 \%$ MCS. 
Table B.3: MCS: Top Competing Models

\begin{tabular}{|c|c|}
\hline Series & Variables \\
\hline \multicolumn{2}{|l|}{ Conventional RINs } \\
\hline 2007 Series & Sugar \\
\hline 2008 Series & Russell 3000, Treasury Bill \\
\hline 2009 Series & WTI Futures, Corn Futures \\
\hline 2010 Series & Sugar Futures, Russell 3000, S\&P-GS Commodity Index \\
\hline 2011 Series & Corn Futures \\
\hline 2012 Series & Russell 3000, S\&P-GS Commodity Index, Treasury Bill \\
\hline 2013 Series & WTI Futures, Russell 3000, S\&P-GS Commodity Index \\
\hline 2014 Series & Russell 3000, S\&P-GS Commodity Index \\
\hline Wednesday Combined Series & Sugar Futures, Russell 3000 \\
\hline Combined Series & Lag Difference RIN, Henry Hub Futures, Treasury Bill \\
\hline \multicolumn{2}{|l|}{ Advanced RINs } \\
\hline 2011 Series & Lag Difference RIN, Soybean Oil Futures, Henry Hub Futures \\
\hline 2012 Series & Corn Futures, Henry Hub Futures, S\&P-GS Commodity Index \\
\hline 2013 Series & Henry Hub Futures, S\&P-GS Commodity Index \\
\hline \multirow{3}{*}{$\begin{array}{c}2014 \text { Series } \\
\text { Wednesday Combined Series } \\
\text { Combined Series }\end{array}$} & Corn Futures, Soybean Oil Futures, S\&P-GS Commodity Index \\
\hline & Lag Difference RIN, Soybean Oil Futures \\
\hline & Corn Futures, Henry Hub Futures \\
\hline \multicolumn{2}{|l|}{ Biodiesel RINs } \\
\hline 2010 Series & Lag RIN, Sugar Futures \\
\hline 2011 Series & Lag RIN, Sugar Futures, Henry Hub Futures \\
\hline 2012 Series & Soybean Oil Futures, Russell 3000, S\&P-GS Commodity Index \\
\hline 2013 Series & Soybean Oil Futures, Sugar Futures, S\&P-GS Commodity Index \\
\hline 2014 Series & Sugar Futures, Russell 3000, S\&P-GS Commodity Index \\
\hline Wednesday Combined Series & Soybean Oil Futures \\
\hline Combined Series & Sugar Futures, Russell 3000, S\&P-GS Commodity Index \\
\hline
\end{tabular}

\section{Robustness Checks}

\section{C.1 RIN Abnormal Returns}

Section 5 specifies normal returns for RINs as a function of log price changes of WTI, ethanol and soybean oil futures contracts. Here, we consider alternative specifications using commodity prices that more directly reflect ethanol and biodiesel production costs. For conventional and advanced RINs, we specify normal returns as a function of reformulated gasoline (RBOB), yellow number 2 corn, number 11 sugar, soybean oil, and Henry Hub natural gas futures prices. For biodiesel RINs we use New York Harbor ultra low sulfur diesel (ULSD) futures prices instead of gasoline futures prices. All futures prices are for July 2014 contracts, and are collected from the CME Group. We estimate equation (8) separately for each RIN series using the alternative normal returns specifications, as well as estimate specifications using flexible time controls.

Results are presented in Table C.1. As in Table 4, all normal return estimates are insignificant, but have the expected signs. RBOB and ULSD futures decrease conventional and biodiesel RIN prices, respectively, and their magnitudes are similar to those observed for WTI futures prices. Increases in corn, sugar, soybean oil and natural gas prices all increase RIN prices modestly. Importantly, abnormal return estimates are nearly 
identical to those in Table 4. As previously, the largest abnormal returns occur for all RIN series around the release of the 2013 Final Rule. Abnormal return estimates are more heterogeneous across RIN types following the release of the Reuters article and 2014 Proposed Rule. Prices for conventional RINs decreases most on the day the Reuters article was released, but recover over the subsequent two days. Advanced RINs did not experience abnormal returns on the publication date of the Reuters article, but experienced abnormal positive returns on the day following the release, while biodiesel RINs did not experience any statistically significant abnormal returns around the event dates. All series experienced small, negative abnormal returns on the date the 2014 Proposed Rule was published, and much larger abnormal returns on the following day.

\section{C.2 Commodity Market Abnormal Returns}

To ensure the commodities market results from Section 5.3 are not driven by our selection of July 2014 future contracts, we run similar regressions as in Section 5.3 for March, May, July, September, and December futures contracts for all commodity prices for 2014 and 2015. ${ }^{31}$ Tables C.2 and C.3 present the abnormal return estimates for the event day and subsequent trading day. Significant abnormal returns are determined by estimating SQ critical values for each series. Consistent with our main findings, no significant abnormal returns are observed for any event for WTI crude oil, ethanol, No. 11 sugar, or No. 2 yellow corn futures contracts. The only significant abnormal returns are observed for soybean oil futures contracts on the day the Reuters article was released. Abnormal return point estimates range from $-1.48 \%$ to $-2.05 \%$ across the contracts, and all but three contracts experience statistically significant negative returns.

\section{C.3 Biofuel Firm Abnormal Returns}

Figure C.1 graphs the cumulative abnormal returns (CARs) over a five day horizon for each biofuel firm. The graphs are meant to provide further insight into which firms drive the results presented in Table 8. Cumulative abnormal returns are estimated by regressing the log daily stock price change on an aggregate market index, a mean daily return, and flexible time controls for each individual stock. All estimates use a 90 day estimation window, though using a longer window size does not affect the findings. The left column graphs CARs for large biofuel producers with investments in advanced and biodiesel production. The right column graphs CARs for smaller biofuel producers, each of which is either a biodiesel producer or advanced ethanol producer. The first, second and third rows correspond to cumulative abnormal returns following the 2013 Final Rule, Reuters article, and 2014 Proposed Rule release dates. Note the different scale for each axis.

Following the release of the 2013 Final Rule, the largest abnormal returns are observed among smaller advanced and biodiesel firms (e.g., Gevo and Methes Energies International). In addition, larger biofuel

\footnotetext{
${ }^{31}$ Futures contracts are only observed for March, May, July and October for No. 11 sugar futures contracts.
} 
producers with investments in advanced biofuels (e.g., Pacific Ethanol and Cosan) experience small negative returns. Interestingly, Valero appears to have experienced a sustained positive abnormal return. Given that Valero is both a major oil refiner and a large biofuel producer, the result is consistent with a costly biofuel policy binding on the firm.

Little movement is observed among large biofuel producers following the Reuters article; however, large losses were observed for a few small biodiesel producers, consistent with our findings in commodity markets. Large losses and gains are observed for larger biofuel producers following the release of the 2014 Proposed rule; however, estimates are noisy, consistent with the findings that losses were not statistically significant in Table 8. 
Table C.1: Regression Results - Dependent Variable: Log 2013 RIN Price Changes*

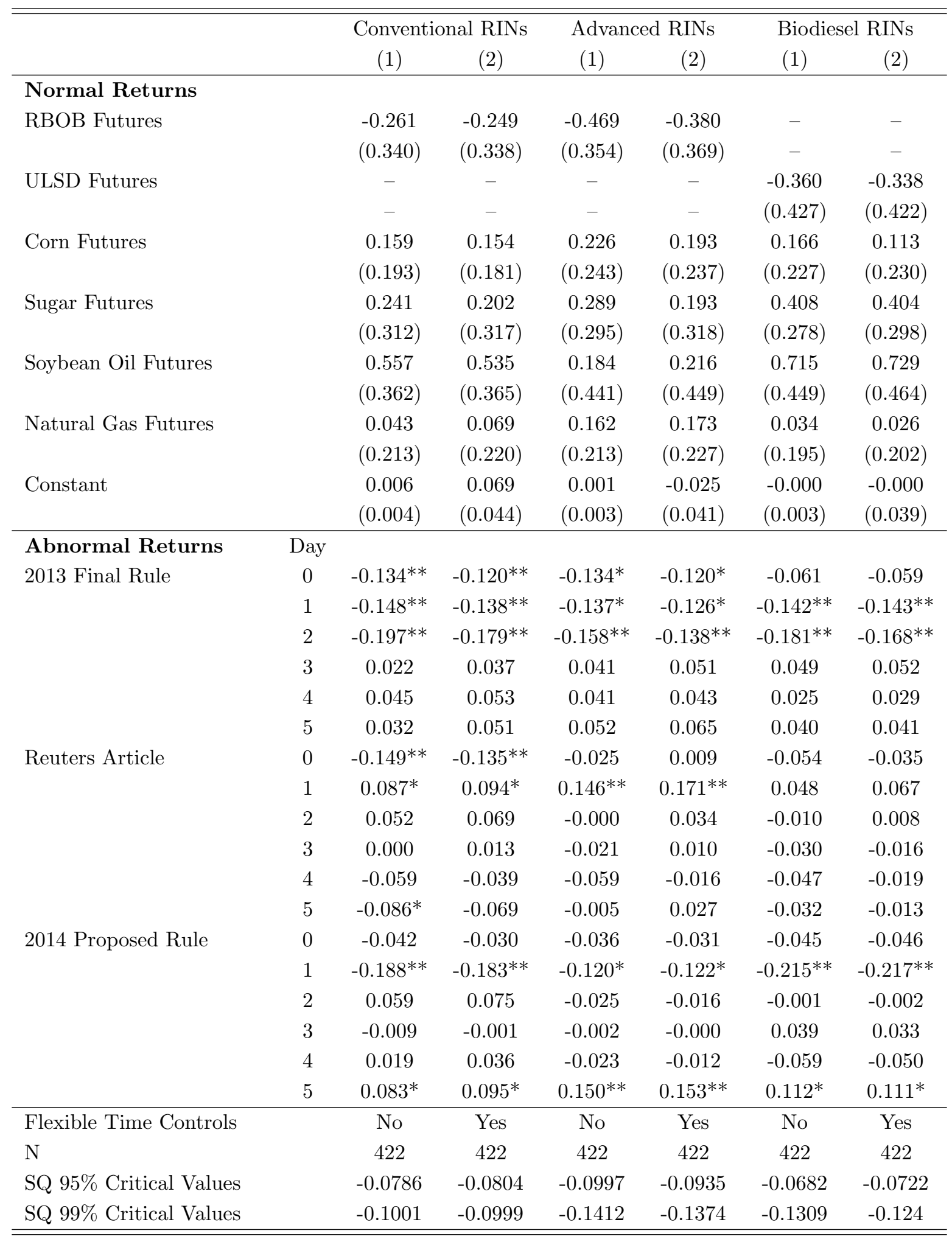

*Note: Standard errors in parentheses are Newey-West errors with 5 lags. Inference for abnormal returns are based on SQ critical values. The lower tail SQ critical values are given at the bottom of the table. Stars denote significance with $* \mathrm{p}<0.05$ and ${ }^{* *} \mathrm{p}<0.01$. 
Table C.2: Fuel Market Abnormal Returns by Contract

\begin{tabular}{cccccccc}
\hline \hline & \multicolumn{2}{c}{ 2013 Final Rule } & \multicolumn{2}{c}{ Reuters Article } & \multicolumn{2}{c}{ 2014 Proposed Rule } \\
& Contract & Day 0 & Day 1 & Day 0 & Day 1 & Day 0 & Day 1 \\
\hline \multirow{6}{*}{ Ethanol } & December-13 & 0.0104 & -0.0077 & -0.0093 & 0.007 & -0.0009 & 0.016 \\
& March-14 & 0.0057 & -0.0079 & -0.0083 & 0.0061 & -0.0067 & -0.0121 \\
& May-14 & 0.0052 & -0.008 & -0.0084 & 0.0006 & -0.0066 & -0.0122 \\
& July-14 & 0.0057 & -0.0075 & -0.0078 & 0.0008 & -0.0063 & 0.004 \\
& September-14 & 0.0058 & -0.0074 & -0.0077 & 0.0009 & -0.0062 & 0.0041 \\
& December-14 & 0.006 & -0.0073 & -0.0076 & 0.0012 & -0.006 & 0.0043 \\
& March-15 & 0.0061 & -0.0072 & -0.0075 & 0.0013 & -0.0059 & 0.0044 \\
& May-15 & 0.0061 & -0.0072 & -0.0075 & 0.0013 & -0.0059 & 0.0044 \\
& July-15 & 0.0061 & -0.0072 & -0.0075 & 0.0013 & -0.0059 & 0.0044 \\
& September-15 & 0.0061 & -0.0071 & -0.0074 & 0.0013 & -0.0058 & 0.0044 \\
& December-15 & 0.0059 & -0.0074 & -0.0076 & 0.0013 & -0.0059 & 0.0043 \\
\hline December-13 & -0.0045 & -0.0028 & -0.0124 & 0.0018 & -0.0017 & -0.0048 \\
& March-14 & -0.0045 & -0.0015 & -0.0079 & 0.0003 & -0.0024 & -0.0053 \\
& May-14 & -0.0057 & -0.0019 & -0.0073 & 0.0004 & -0.003 & -0.0064 \\
& July-14 & -0.0061 & -0.0021 & -0.0065 & 0.0003 & -0.0034 & -0.0069 \\
& September-14 & -0.0058 & -0.0013 & -0.0052 & 0.0004 & -0.0035 & -0.0066 \\
WTI Crude & December-14 & -0.0055 & -0.0005 & -0.0035 & 0.0005 & -0.0031 & -0.0062 \\
& March-15 & -0.0055 & 0 & -0.0024 & 0.0003 & -0.0022 & -0.0057 \\
& May-15 & -0.0055 & 0.0005 & -0.0022 & -0.0003 & -0.0017 & -0.0053 \\
& July-15 & -0.0052 & 0.001 & -0.002 & -0.0005 & -0.0013 & -0.0049 \\
& September-15 & -0.0046 & 0.0015 & -0.0016 & -0.0004 & -0.0007 & -0.0046 \\
& December-15 & -0.0041 & 0.0018 & -0.0011 & -0.0007 & -0.0003 & -0.0044 \\
\hline \hline
\end{tabular}

Note: SQ test critical values for each contract is given in Table 6. Abnormal returns represent those returns that cannot be explained bo corresponding movements in the S\&P-GS Commodity Index, or in the case of WTI crude, the Russell 3000 Index, and a daily mean return. Specification (2) includes flexible time controls. * denotes the hypothesis is rejected at the $5 \%$ empirical critical value and $* *$ denotes the hypothesis is rejected at the $1 \%$ empirical critical value. 
Table C.3: Fuel Market Abnormal Returns by Contract

\begin{tabular}{|c|c|c|c|c|c|c|c|}
\hline & \multirow[b]{2}{*}{ Contract } & \multicolumn{2}{|c|}{2013 Final Rule } & \multicolumn{2}{|c|}{ Reuters Article } & \multicolumn{2}{|c|}{2014 Proposed Rule } \\
\hline & & Day 0 & Day 1 & Day 0 & Day 1 & Day 0 & Day 1 \\
\hline \multirow{11}{*}{ Soybean Oil } & December-13 & -0.0111 & -0.0086 & $-0.0205^{*}$ & 0.0025 & -0.0118 & -0.0077 \\
\hline & March-14 & -0.01 & -0.008 & $-0.0196^{*}$ & 0.0017 & -0.0122 & -0.0076 \\
\hline & May-14 & -0.0092 & -0.0067 & $-0.0191^{*}$ & 0.0026 & -0.0128 & -0.007 \\
\hline & July-14 & -0.008 & -0.0066 & $-0.0187^{*}$ & 0.003 & -0.0131 & -0.0067 \\
\hline & September-14 & -0.0077 & -0.0061 & $-0.0177^{*}$ & 0.0035 & -0.0135 & -0.0064 \\
\hline & December-14 & -0.008 & -0.0068 & -0.0152 & 0.0053 & -0.0153 & -0.0052 \\
\hline & March-15 & -0.0076 & -0.0036 & -0.0148 & 0.0055 & -0.0151 & -0.0048 \\
\hline & May-15 & -0.0078 & -0.0007 & -0.0148 & 0.0053 & -0.015 & -0.0034 \\
\hline & July-15 & -0.008 & -0.0002 & $-0.0162^{*}$ & 0.0078 & -0.015 & -0.0037 \\
\hline & September-15 & -0.0078 & 0.0043 & $-0.0161^{*}$ & 0.0051 & -0.0159 & -0.0015 \\
\hline & December-15 & -0.0079 & 0.0042 & $-0.0162^{*}$ & 0.0003 & -0.009 & -0.0076 \\
\hline \multirow{8}{*}{ No. 11 Sugar } & March-14 & 0.003 & 0.0189 & 0.0133 & 0.0058 & -0.0042 & 0.0124 \\
\hline & May-14 & 0.0012 & 0.0172 & 0.0129 & 0.0061 & -0.0018 & 0.0111 \\
\hline & July-14 & 0.0007 & 0.0167 & 0.0114 & 0.0055 & 0.0003 & 0.01 \\
\hline & October-14 & 0.0005 & 0.0154 & 0.0105 & 0.0051 & 0.0032 & 0.0096 \\
\hline & March-15 & 0.0003 & 0.0141 & 0.0097 & 0.0046 & 0.0042 & 0.0089 \\
\hline & May-15 & 0.0009 & 0.0141 & 0.0086 & 0.0041 & 0.004 & 0.0082 \\
\hline & July-15 & 0.001 & 0.0148 & 0.0064 & 0.0041 & 0.0045 & 0.0069 \\
\hline & October-15 & 0.0029 & 0.0162 & 0.0049 & 0.0037 & 0.0052 & 0.007 \\
\hline \multirow{11}{*}{ No. 2 Yellow Corn } & December-13 & 0.0003 & 0.0005 & -0.0091 & 0.0089 & -0.0098 & -0.0226 \\
\hline & March-14 & 0.0004 & 0.0001 & -0.0087 & 0.0077 & -0.0134 & -0.0214 \\
\hline & May-14 & 0.001 & 0.0007 & -0.009 & 0.0079 & -0.0145 & -0.0205 \\
\hline & July-14 & -0.0001 & -0.0004 & -0.0089 & 0.0067 & -0.0143 & -0.0196 \\
\hline & September-14 & 0.0007 & -0.0011 & -0.0084 & 0.0059 & -0.0142 & -0.0189 \\
\hline & December-14 & 0.0023 & -0.0005 & -0.0086 & 0.0064 & -0.0146 & -0.0182 \\
\hline & March-15 & 0.0029 & 0.0016 & -0.0079 & 0.0052 & -0.0147 & -0.017 \\
\hline & May-15 & 0.003 & 0.0017 & -0.0067 & 0.0041 & -0.015 & -0.0157 \\
\hline & July-15 & 0.0021 & 0.0009 & -0.0064 & 0.0041 & -0.0156 & -0.016 \\
\hline & September-15 & 0.0028 & 0.0025 & -0.0029 & 0.0021 & -0.0141 & -0.0159 \\
\hline & December-15 & 0.0075 & 0.0006 & -0.0042 & 0.0086 & -0.0146 & -0.0143 \\
\hline
\end{tabular}

Note: SQ test critical values for each contract is given in Table 6. Abnormal returns represent those returns that cannot be explained bo corresponding movements in the S\&P-GS Commodity Index, or in the case of WTI crude, the Russell 3000 Index, and a daily mean return. Specification (2) includes flexible time controls. * denotes the hypothesis is rejected at the $5 \%$ empirical critical value and $* *$ denotes the hypothesis is rejected at the $1 \%$ empirical critical value. 
Figure C.1: Biofuel Firm Cumulative Abnormal Returns*

(a) Large Biofuel Producers
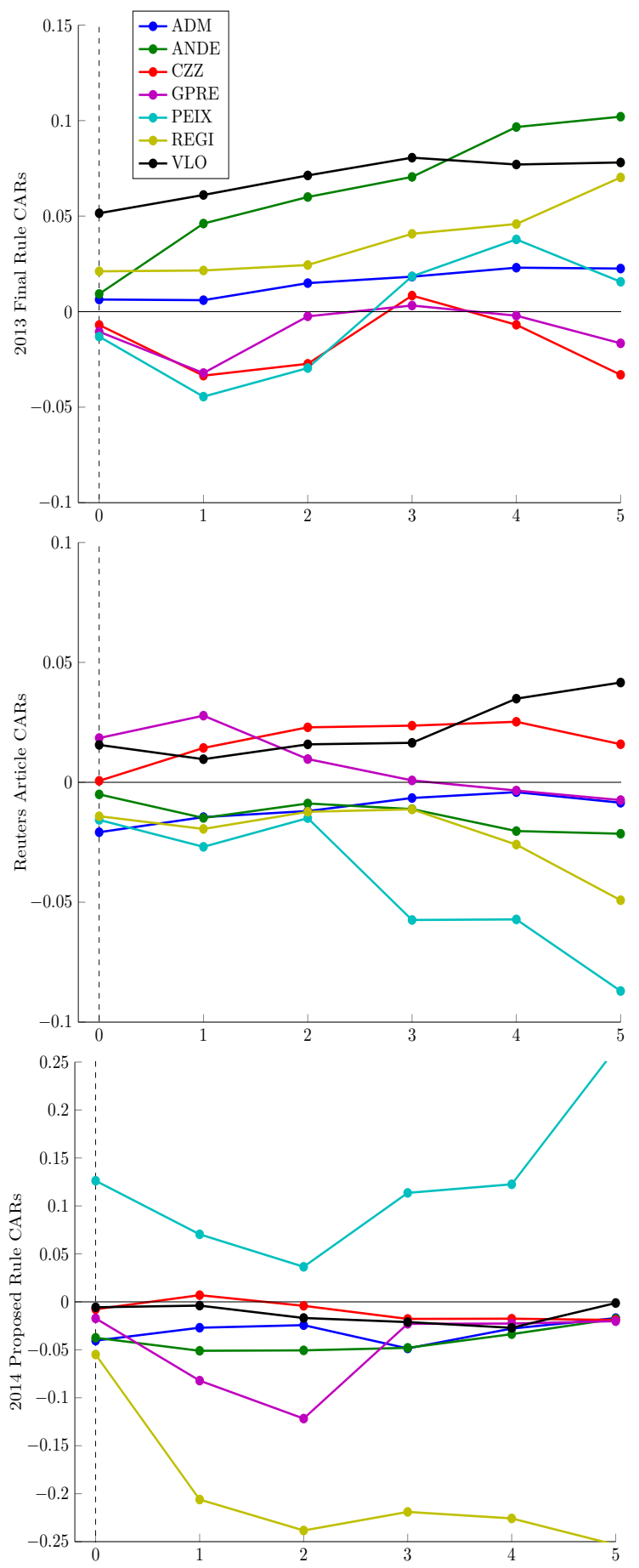

(b) Small Biofuel Producers
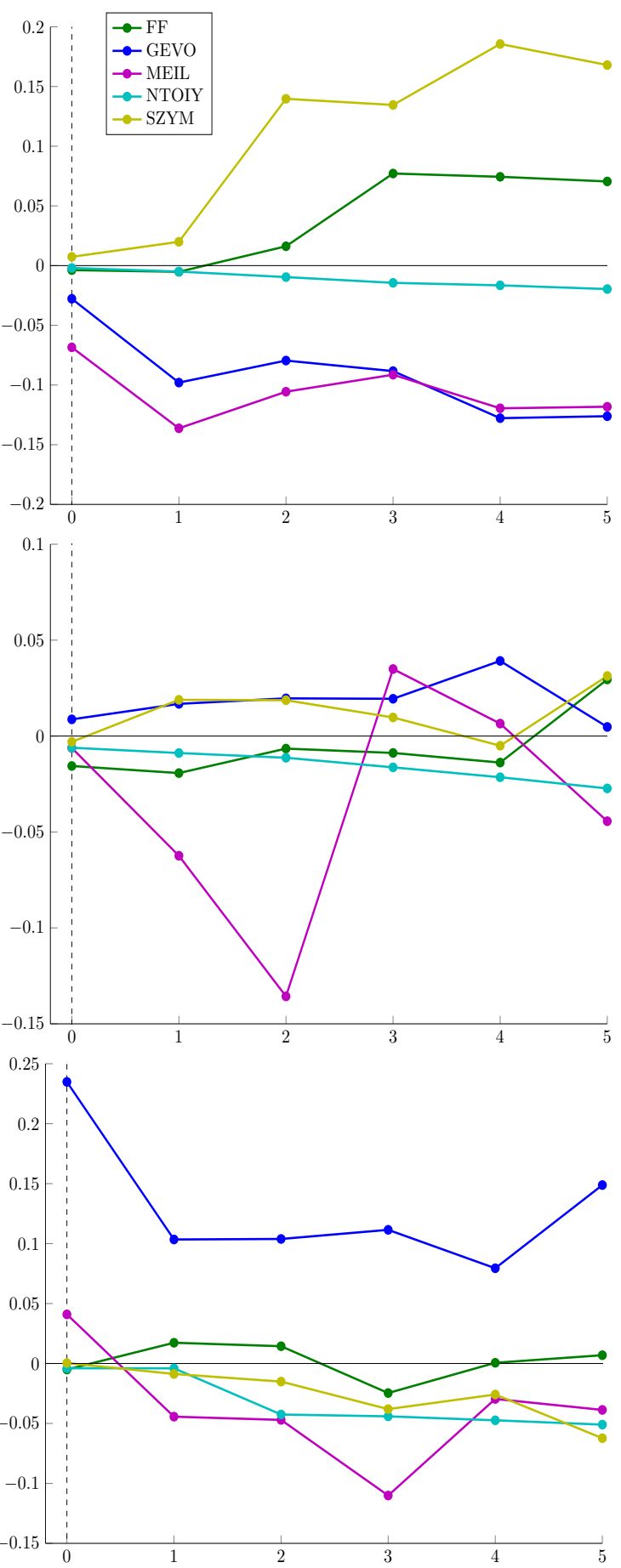

*Note: The figure graphs cumulative abnormal returns (CARs) by firm for each policy event of interest. The left column graphs CARs for large biofuel producers, and the right column graphs CARs for biofuel producers with smaller production capacities. 